\title{
THE VROMAN EFFECT: A MOLECULAR LEVEL DESCRIPTION OF FIBRINOGEN DISPLACEMENT
}

\author{
A Dissertation \\ by \\ SEUNG-YONG JUNG
}

\begin{abstract}
Submitted to the Office of Graduate Studies of
Texas A\&M University

in partial fulfillment of the requirements for the degree of

DOCTOR OF PHILOSOPHY
\end{abstract}

December 2003

Major Subject: Chemistry 


\title{
THE VROMAN EFFECT: A MOLECULAR LEVEL DESCRIPTION OF FIBRINOGEN DISPLACEMENT
}

\author{
A Dissertation \\ by \\ SEUNG-YONG JUNG \\ Submitted to Texas A\&M University \\ in partial fulfillment of the requirements for the degree of \\ DOCTOR OF PHILOSOPHY
}

Approved as to style and content by:

\begin{tabular}{c}
\hline Paul S. Cremer \\
(Chair of Committee) \\
\hline $\begin{array}{c}\text { D. Wayne Goodman } \\
\text { (Member) }\end{array}$
\end{tabular}

\begin{tabular}{c}
\hline $\begin{array}{c}\text { Hagan Bayley } \\
\text { (Member) }\end{array}$ \\
\hline $\begin{array}{c}\text { Gregory D. Reinhart } \\
\text { (Member) }\end{array}$ \\
\hline Emile A. Schweikert \\
(Head of Department)
\end{tabular}

December 2003

Major Subject: Chemistry 


\begin{abstract}
The Vroman Effect: A Molecular Level Description of Fibrinogen Displacement.

(December 2003)

Seung-Yong Jung,

B.S., Korea University; M.S., Korea University

Chair of Advisory Committee: Dr. Paul S. Cremer
\end{abstract}

Investigations of specific and nonspecific interactions of biomolecules at liquid/solid interfaces are presented. To investigate specific multivalent ligand-receptor interactions, bivalent antibodies and haptens bound to solid supported membrane were used as models for ligand-receptor coupling. Novel microfabrication strategies, which included spatially addressed bilayer arrays and heterogeneous microfluidic assays, in conjunction with total internal reflection microscopy, was employed to achieve this goal. These high throughput techniques allow thermodynamic data of binding interactions to be acquired with only a few microliters of analyte and superior signal to noise. The results yield both the first and second dissociation constant for bivalent IgG antibodies with membrane bound hapten molecules. Studies were conducted both as a function of hapten density and cholesterol content in the membrane.

Another research area of this dissertation is the molecular level description of nonspecific adsorption and displacement of the model protein, fibrinogen, onto hydrophilic surfaces. Techniques such as atomic force microscopy, immunochemical 
assays, fluorescence microscopy, and vibrational sum frequency spectroscopy were employed to probe this system. The results demonstrate that the protein's $\alpha \mathrm{C}$ domains play the critical role. When fibrinogen is adsorbed to a hydrophilic surface via these moieties, its displacement rate in the presence of human plasma is approximately 170 times faster than when these domains are not in direct surface contact. Even more significantly, spectroscopic studies show evidence for highly aligned Arg and Lys residues interacting with the negatively charged substrate only when the $\alpha \mathrm{C}$ domains make direct surface contact. The interfacial ordering of these residues appears to be the hallmark of a weak and labile electrostatic attraction between the substrate and the adsorbed macromolecule. 


\section{ACKNOWLEDGMENTS}

First of all, I would like to thank my advisor, Dr. Paul S. Cremer, for his support and guidance during my graduate years. I also would like to offer special thanks to Dr. Hagan Bayley who gave me helpful advice and thoughtful discussions.

Many thanks go to all of the Cremer group members. Especially deep appreciation goes to a passionate scientist and my best friend, Mr. Matthew A. Holden, who always cheers me up.

My utmost thanks goes to my wife, Misun Kang, who has helped and done whatever it takes to make this possible. I express my love and gratitude to my six month old boy, Alex K. Jung, who makes me happy and smile all the time. 
TABLE OF CONTENTS

Page

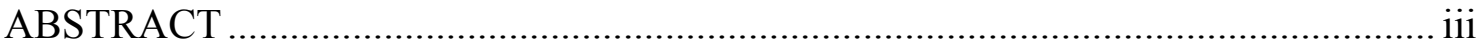

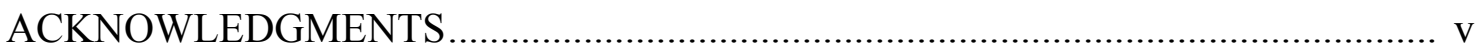

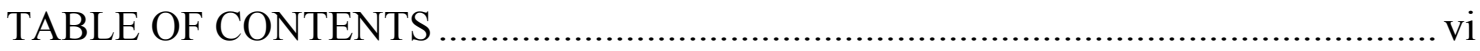

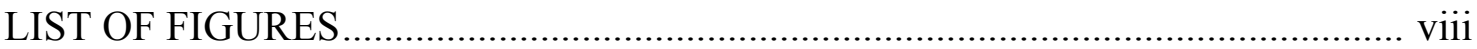

CHAPTER

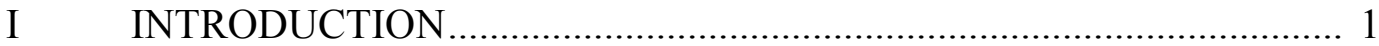

II EXPERIMENTAL AND INSTRUMENTAL

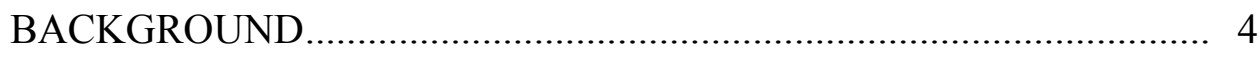

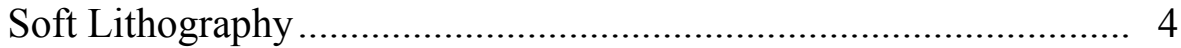

Atomic Force Microscopy .............................................................. 7

Introduction ................................................................... 7

Interaction between tip and sample .......................................... 12

Tip and tip effect .................................................................... 15

Vibrational Sum Frequency Spectrosocpy ......................................... 17

III MULTIVALENT LIGAND-RECEPTOR INTERACTIONS

ON PLANAR SUPPORTED MEMBRANES ……………………….... 25

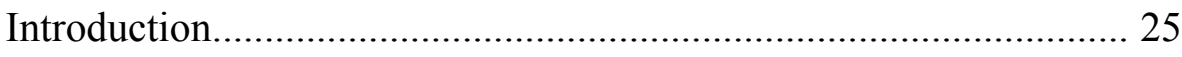

Creation of Spatially Addressed Arrays ............................................ 29

Supported Bilayer Microfluidics ...................................................... 32

Creation of Immunoassays .............................................................. 35

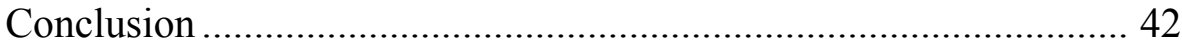

IV THE VROMAN EFFECT: A MOLECULAR LEVEL DESCRIPTION OF FIBRINOGEN DISPLACEMENT ................................................... 43

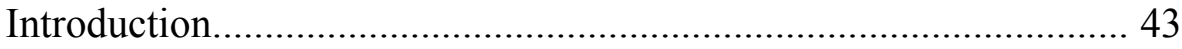

Materials and Methods ………………………………………......... 46 
CHAPTER Page

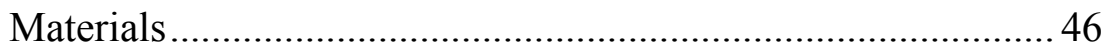

Atomic force microscopy .................................................. 47

Vibrational sum frequency spectroscopy .............................. 47

Total internal reflection fluorescence microscopy ..................... 48

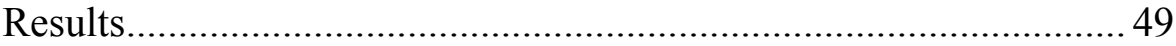

Protein displacement kinetics............................................... 49

Atomic force microscopy and immunochemistry .................... 52

Vibrational sum frequency spectroscopy ............................. 59

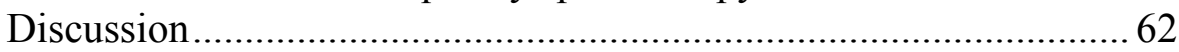

V SPECTROSCOPIC EVIDENCE FOR THE NH STRETCHING: A FIBRINOGEN ADSORPTION ONTO FUSED SILICA....................... 64

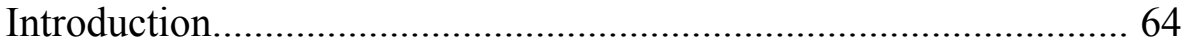

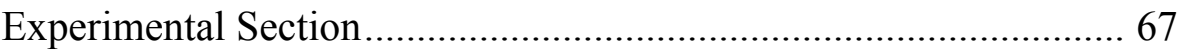

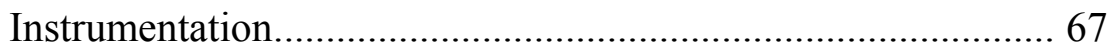

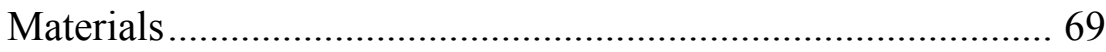

Data acquisition.......................................................... 70

Results and Discussion .............................................................. 70

Time dependence of fibrinogen adsorption............................ 70

Fibrinogen adsorption ....................................................... 72

$\mathrm{H}_{2} \mathrm{O}^{16}$ and $\mathrm{H}_{2} \mathrm{O}^{18}$ spectra ................................................. 76

Fragment $\mathrm{X}$ and $\alpha \mathrm{C}$ domain adsorbed at $\mathrm{pH} 8.0$ in $\mathrm{H}_{2} \mathrm{O}$.......... 79

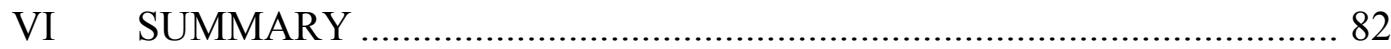

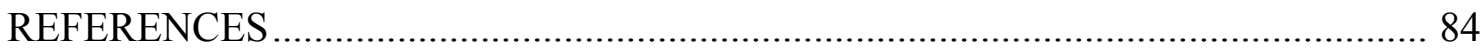

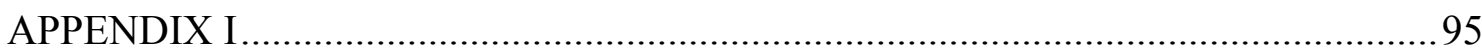

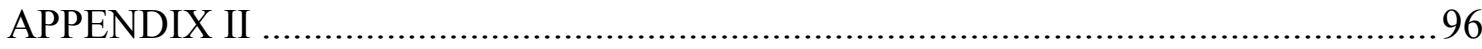

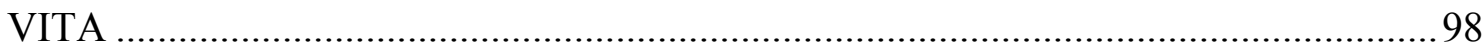




\section{LIST OF FIGURES}

FIGURE

Page

1 The structures of siloxane oligomer, curing agent and poly(dimethylsiloxane) (PDMS) .................................................. 5

2 Schematic procedure for creating the PDMS stamp ...........................6 6

$3 \quad$ Forces involved in atomic force microscopy ................................ 8

4 Schematic diagram of components of AFM ...................................... 10

5 Schematic diagram of operation of contact mode AFM .......................... 11

$6 \quad$ Typical force-distance diagram during approaching

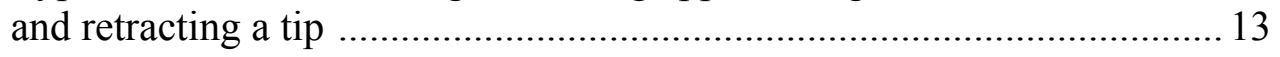

$7 \quad$ Schematic diagram of tip convolution ................................................ 16

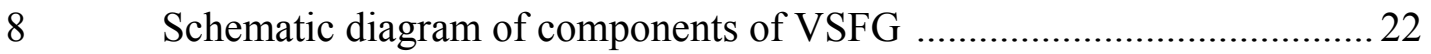

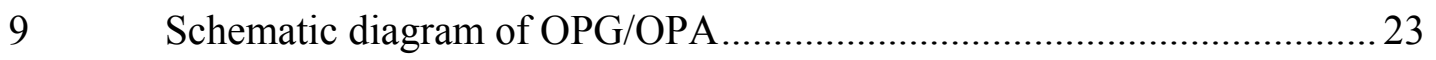

10 Schematic diagram of a supported phospholipid bilayer membrane containing a covalently attached ligand molecule (in green).................. 26

11 (a) An IgG antibody (in red) approaches a phospholipid membrane containing fluid ligands (in green). (b) The species first binds to one ligand and (c) then diffuses laterally to bind to a second ligand.......

12 (a) A schematic representation of a $2 \times 2$ array of addressed supported fluid biomembranes with various components in each box. (b) An epifluorescence image of a $3 \times 3$ array of fluid biomembranes that have been addressed using the spatial addressing techniques described above

13 (a) An epifluorescence image of a $4 \times 4$ membrane array. (b) A quantitative plot of fluorescence intensity vs. cholesterol content at each DNP ligand concentration.... 
14 (a) Schematic diagram of bilayer coated PDMS microchannels on a planar glass substrate. The bilayer coats both the glass and polymer surfaces. Protein solutions can then be injected into the channels as indicated by the arrows. (b) Epifluorescence image of a spatially addressed array of eight egg PC bilayer coated microchannels. The channels are alternately coated with bilayers containing $1 \mathrm{~mol} \%$ Texas Red and $3 \mathrm{~mol} \%$ fluorescein labeled lipids.

15 TIRFM setup for imaging antibody-antigen interactions on bilayer coated chips.

16 (a) Bulk phase epifluorescence image of Alexa 594 dye-labeled anti-DNP inside bilayer coated microchannels. Starting from the left-hand-side, the antibody concentrations are $13.2 \mu \mathrm{M}, 8.80 \mu \mathrm{M}$, $5.87 \mu \mathrm{M}, 3.91 \mu \mathrm{M}, 2.61 \mu \mathrm{M}, 1.74 \mu \mathrm{M}, 1.16 \mu \mathrm{M}, 0.77 \mu \mathrm{M}, 0.52 \mu \mathrm{M}$, $0.34 \mu \mathrm{M}, 0.23 \mu \mathrm{M}$ and $0.15 \mu \mathrm{M}$, respectively. A line scan of fluorescence intensity (dotted line) across the microchannels is plotted in (b).

17 (a) A total internal reflection fluorescence image of the same conditions as shown in Figure 10a. (b) Line scan of fluorescence intensity (white line) across the microchannels

18 Binding curve for the DNP/anti-DNP system on a fluid phospholipid membrane

19 Molecular structure of human plasma fibrinogen (HPF). The D and $\mathrm{E}$ domains are formed from two sets of three polypeptide chains (A $\alpha, B \beta$ and $\lambda$ ) connected by 29-disulfide bonds. The N-termini of these chains form the $\mathrm{E}$ domain while the $\mathrm{C}$-termini of the $\mathrm{B} \beta$ and $\lambda$ chains make up the two D domains. HPF is $90 \AA$ x $475 \AA$ x $60 \AA$ with a molecular weight of $340 \mathrm{kD}$..

20 Displacement of Alexa 594-labeled fibrinogen from a silica surface by a $5 \%$ human plasma solution. The closed circles $(\bullet)$ indicate experiment with $5 \%$ human plasma after only exposing the sample to PBS at $\mathrm{pH}$ 8.0. The open circles (o) show displacement kinetics with 5\% human plasma after $\mathrm{pH}$ cycling through 3.2 and back to 8.0. The inverted triangles $(\boldsymbol{\nabla})$ represent a control experiment where only buffer was introduced over the HPF coated surface. 
21 AFM images of HPF on silica surface at $5 \mu \mathrm{g} / \mathrm{ml}$ (a), $1.5 \mu \mathrm{g} / \mathrm{ml}$ (b), and $0.5 \mu \mathrm{g} / \mathrm{ml}$ (c). Images were obtained after washing out the protein solution with pure PBS. Each image is $500 \mathrm{~nm} \times 500 \mathrm{~nm}$ on a side 53

22 AFM images of a single HPF molecule adsorbed at the silica/buffer interface (a) at $\mathrm{pH} 8.0$ and (b) at $\mathrm{pH} 8.0$ after cycling to $\mathrm{pH} 3.2$. The line profiles for height vs. position (from the white lines) are shown below each image

23 Fluorescence images of Alexa 594-labeled anti-fibrinogen (anti- $\alpha \mathrm{C}$ domain) antibody applied to (a) an HPF coated surface after $\mathrm{pH}$ cycling, (b) an HPF coated surface at $\mathrm{pH} 8.0$ without $\mathrm{pH}$ cycling and (c) a silica surface without HPF ..... 56

24 The proposed mechanism for interfacial HPF rearrangement upon $\mathrm{pH}$ cycling 58

25 Sum frequency spectra of (a) a bare silica/water interface at $\mathrm{pH}$ 8.0, (b) an HPF coated surface at $\mathrm{pH} 8.0$, (c) an HPF coated surface at $\mathrm{pH} 5.5$, (d) an HPF coated surface at $\mathrm{pH} 3.2$, (e) an HPF coated surface at $\mathrm{pH} 5.5$ after cycling to $\mathrm{pH} 3.2$, and (f) an HPF coated surface at $\mathrm{pH} 8.0$ after cycling to $\mathrm{pH} 3.2$.

26 Structure of fibrinogen (a) and fragment products cleaved by plasmin (b)

27 Diagram of a flow cell used for adsorption studies of fibrinogen at the silica/water interface. The laser beams used in the VSFS experiments are shown with their approximate geometry....

28 Sum frequency intensity at $3270 \mathrm{~cm}^{-1}$ monitored during the adsorption of fibrinogen at $\mathrm{pH} 8.0$ from a $0.01 \mathrm{mg} / \mathrm{ml}$ protein solution.

The fibrinogen solution was introduced at $\mathrm{t}=5 \mathrm{~min}$.

29 Sum frequency spectra of a bare silica/water interface at (a) $\mathrm{pH}$ 8.0, (c) $\mathrm{pH} 5.5$, and (e) $\mathrm{pH}$ 3.2. Sum frequency spectra of HPF coated silica surface at (b) $\mathrm{pH} 8.0$, (d) $\mathrm{pH} 5.5$ and (f) $\mathrm{pH} 3.2$ 74

30 Sum frequency spectra of (a) a bare silica/water interface at $\mathrm{pH} 8.0$, (b) an HPF coated surface at $\mathrm{pH} 8.0$, (c) an HPF coated surface 
FIGURE $\quad$ Page

at $\mathrm{pH}$ 5.5. In these spectra $\mathrm{H}_{2} \mathrm{O}^{16}$ data are plotted with blue dots and $\mathrm{H}_{2} \mathrm{O}^{18}$ with red dots ............................................................. 77

31 Sum frequency spectra of the silica/water interface at $\mathrm{pH} 8.0$ after the adsorption of (a) fragment $\mathrm{X}$ from fibrinogen and (b) the $\alpha \mathrm{C}$ domains. 


\section{CHAPTER I}

\section{INTRODUCTION}

Interactions at biological interfaces includes non-specific adsorption, specific ligand and receptor binding, enzymatic reactions, cell adhesion and cell-cell communication. ${ }^{1}$ For example, the adhesion of viruses or bacteria to the surface of a cell, which is the very early stage of infection, as well as an antibody binding to its antigen are mediated by specific ligand-receptor interactions. ${ }^{2}$ Therefore, discouraging or encouraging these kinds of engagement and developing inhibitors of these reactions are very important issues in medical science. Another interesting issue is the non-specific adsorption of proteins on man made surface because it is believed that this process is important to pharmaceutical, medical, and biomaterials science. ${ }^{3-6}$ Specifically, biofouling is initiated by the non-specific adsorption of proteins onto artificial surfaces such as hip implants and other material. ${ }^{3}$ Competitive adsorption and displacement of proteins on artificial surfaces is known as Vroman effect. Leo Vroman and his colleagues found in late 1960's that the complicated adsorption and subsequent displacement of proteins in blood happened when a hydrophilic surface was exposed to blood plasma. Since then abundant experimental data has been reported about the adsorption of proteins at liquid/solid interfaces. ${ }^{7,8}$

To pursue the investigation of specific and nonspecific binding, total internal

This dissertation follows the style of the Journal of the American Chemical Society. 
reflection fluorescence microscopy, surface plasmon resonance, ellipsometry, neutron reflectivity measurements, quartz crystal microbalance detection, circular dichroism spectroscopy, and attenuated total internal reflection (ATR)- FTIR served as techniques of choice for decades. ${ }^{9-25}$ However, a theoretical and molecular level understanding of these interactions is still missing because of the lack of proper tools. Fortunately, from late 1980's, two important techniques for the study of biomolecules at the interface have been developed. ${ }^{26}$ In 1982, a powerful laser system made second order nonlinear optical procedures available for investigating various boundaries such as the solid/air, liquid/air, liquid/liquid, and solid/liquid interfaces. ${ }^{27-36}$ Information about the interfacial alignment of molecules such as water or proteins was made possible by sum frequency generation. Another tool is atomic force microscopy (AFM) which branched out from probe microscopies by adopting an optical lever technique. ${ }^{37}$ Because AFM uses only force between its probe and sample to scan the surface, non-conducting biosamples could be imaged with atomic resolution. ${ }^{38,39}$ Also, the ability of AFM to image in solution made observing biological reactions in an environment very close to physiological conditions possible.

In the studies presented herein, these relatively new techniques were combined to obtain thermodynamic, spectroscopic and conformational information about the interactions between proteins and surfaces both specifically and non-specifically.

This thesis is ordered as follows: the experimental procedures, instrumental background, microfabrication, AFM, and SFG are explained in Chapter II. 
Chapter III contains an investigation of thermodynamic properties of specific binding interactions between antibodies and antigens on artificial supported bilayers. Various micropatterning methods, such as spatially addressed microarrays, microcontact displacement and microchannels, were developed to study the nature of multivalent interactions between anti-dinitrophenyl (DNP) IgG and DNP-DPHE on fluid membranes with total internal reflection fluorescence microscopy (TIRFM) and epi-fluorescence microcopy.

Chapter IV discusses the mechanism of nonspecific adsorption of a model protein, fibrinogen, on a negatively charged hydrophilic surface and the effect of $\mathrm{pH}$ on protein displacement. AFM, fluorescence microscopy, and SFG were employed to reveal the structural changes of proteins induced by $\mathrm{pH}$.

Chapter V discusses the origin of a characteristic peak generated by fibrinogen at the silica/water interface using SFG, isotopically labeled water $\left(\mathrm{H}_{2} \mathrm{O}^{18}\right)$, and fragments of fibrinogen. From these experiments, the role of a specific domain plays in nonspecific adsorptions was more clearly understood. 


\section{CHAPTER II}

\section{EXPERIMENTAL AND INSTRUMENTAL BACKGROUND}

\section{SOFT LITHOGRAPHY}

The microfabrication technique of soft lithography was used to create microfluidic devices to probe interactions at the biointerface. The main advantage of this technique is that it enables us to employ less sample per experiment and collect more information in less time via combinatorial methods. ${ }^{40}$ All of the microfabricated devices used in these investigations were made from poly(dimethylsiloxane) (PDMS, Sylgard 184, Dow Corning Co. Midland, MI) elastomers. ${ }^{41}$ PDMS monomer turns into solid polymer via a curing agent which cross links as shown in Figure 1. ${ }^{42}$ Therefore, PDMS molds or stamps of various shapes could be produced with the proper casts. Once it is cured at $75^{\circ} \mathrm{C}$ for 5 hours, the PDMS polymer shows very good optical and physical properties. This polymer is optically transparent down to $300 \mathrm{~nm}$, which is critical in our application of fluorescence microscopy, and it is chemically inert because of its low surface free energy. Also, by simple plasma treatment, a permanent bond with glass can be forged. In our laboratory, the various shapes of microfluidic channels were designed using Corel Draw software. Once printed from a 2400 dpi printer, these designs were imaged on black and white film via photographic reduction, and film negative served as the photomask. Through these films, UV was irradiated onto glass slides covered with photoresist (Microposit S 1813, Shipley, Marlborough, MA) and the 
Siloxane monomer<smiles>C=C[Si](C)(C)O[Si](C)(C)[Si](C)(C)CC</smiles>

$$
n=\sim 60
$$

Cross linker<smiles></smiles>

$n=\sim 10$

$\mathrm{R}=\mathrm{CH}_{3}$ or $\mathrm{H}$<smiles>[CH]O[Si](C)(CC[Si](C)(C)OC)O[Si](C)(C)O[Si](C)(C)O[Si](C)(CC[Si](C)(C)OCC)OCC</smiles>

PDMS

Figure 1. The structures of siloxane oligomer, curing agent and poly(dimethylsiloxane) (PDMS). ${ }^{42}$ 


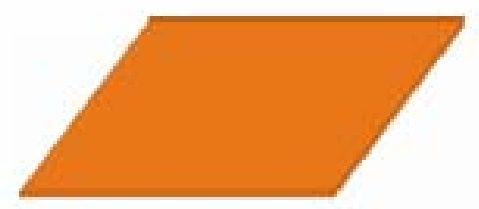

1) Photoresist coated glass

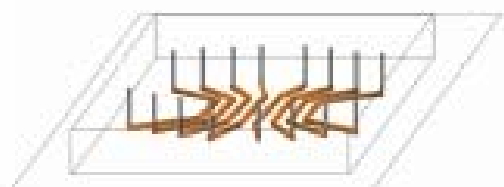

3) Curing PDMS

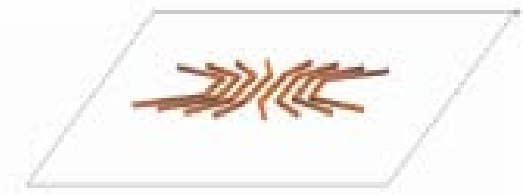

2) Pattern by photolithography

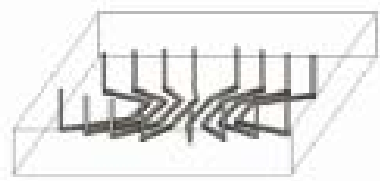

4) Plasma cleaning

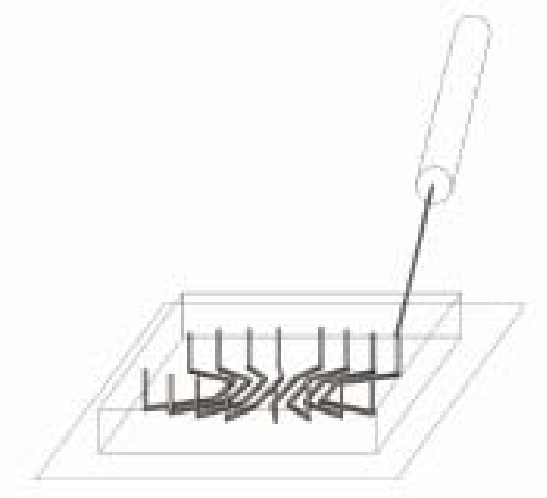

5) Attaching onto the glass

Figure 2. Schematic procedure for creating the PDMS stamp. 
UV exposed region was removed by developing solution as shown in Figure 2. Patterns on the glass slides were created by UV protected areas and the PDMS was cured on these master plates to form a mold. After careful peeling off and rinsing with acetone, the patterned PDMS mold was attached to a clean glass substrate after oxygen plasma treatment. $^{43}$

\section{ATOMIC FORCE MICROSCOPY}

\section{Introduction}

Since the atomic force microscope (AFM), or scanning force microscope (SFM) was invented in 1986 by Binnig, Quate and Gerber, ${ }^{37}$ it has become one of the most common scanning microscopes because of its numerous advantages. Even though only limited chemical information about surfaces and adsorbates can be obtained by AFM, this technique does not need an electrically conductive sample or high vacuum. AFM can even get images with molecular level resolution in solution which is essential for investigating biological procedures in situ. AFM uses a sharp probe placed over the surface of a sample. A cantilever which has a tip on the end bends in response to the force applied on a tip by contacting the sample. The main forces contributing to the bending of the cantilever are Coulombic forces and attractive van der Waals interactions between the atoms within a tip and atoms of the sample surface. That is the reason why it is called atomic force microscopy. However, in practice, fluid film damping, electrostatic force, fluid surface tension (capillary forces) may also play important roles 


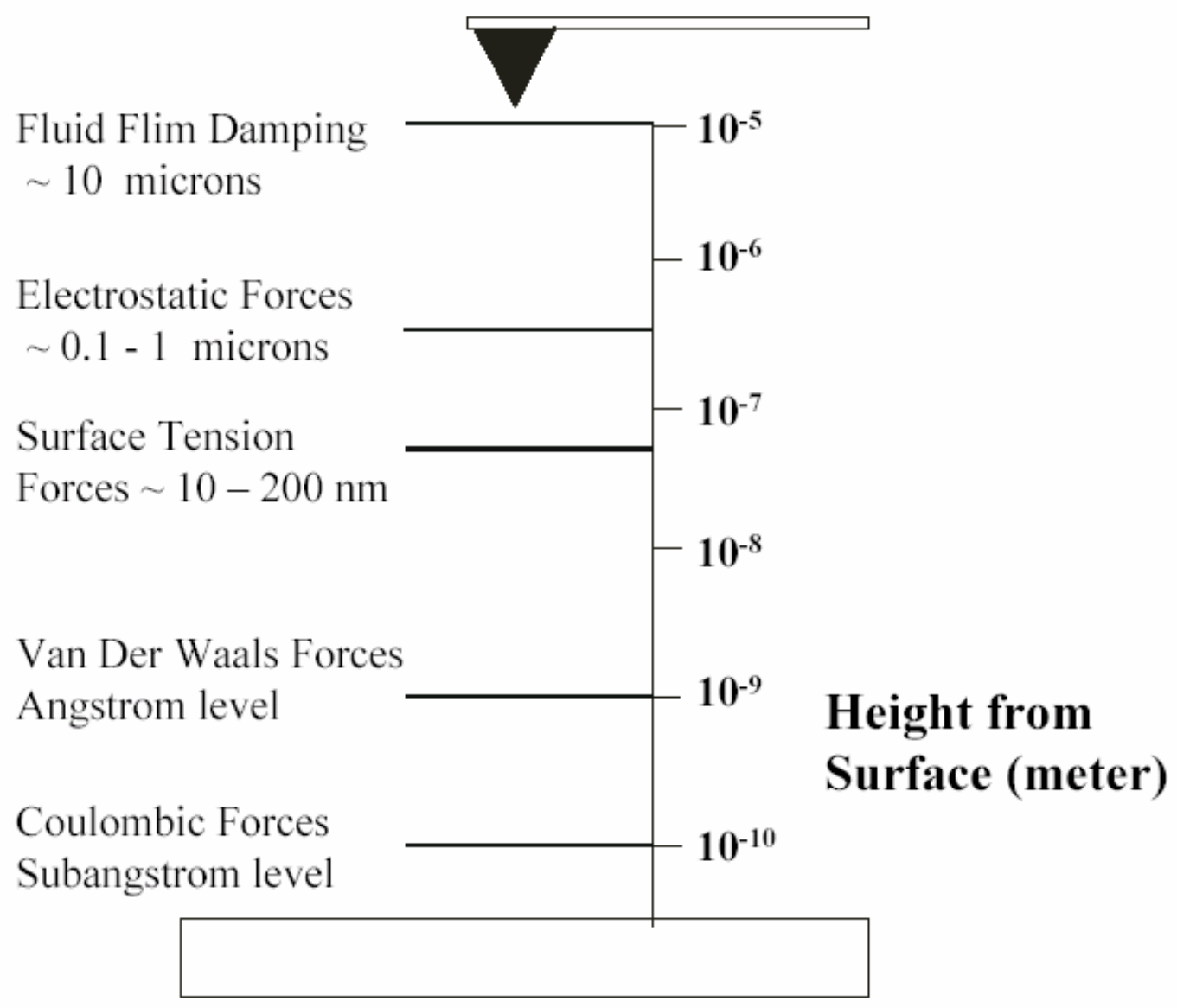

Figure 3. Forces involved in atomic force microscopy. 
as shown in Figure 3. ${ }^{44,45}$ These interactions could give false information about the height of a sample. Normally, optimum conditions are found by measuring the height of standard biofilms such as a solid supported bilayer at various $\mathrm{pH}$ values and ionic strengths. The very early days of AFM used a scanning tunneling microscope at the end of a cantilever as a detector for the bending of the lever, but now an optical lever technique is the most common detection technique for AFM. Figure 4 shows three basic parts of the AFM (head, scanner, and controller). The head has components of an optical lever such as laser, mirror, photodiode and cantilever. The controller is connected to a computer and it collects signal from a photodiode and regulates the motion of the scanner. The scanner uses lead zirconate titanate piezoelectric ceramics (PZT) to make movements along the $\mathrm{X}, \mathrm{Y}$, and $\mathrm{Z}$ axes. Both $\mathrm{J}$ and $\mathrm{E}$ scanners were utilized in this work. The $\mathrm{J}$ scanner scans $125 \mu \mathrm{m} \times 125 \mu \mathrm{m}(\mathrm{X}$ and $\mathrm{Y}$ axis) and $5 \mu \mathrm{m}$ heights. The E scanner can offer less scan area $(10 \mu \mathrm{m} \times 10 \mu \mathrm{m}$ and $2.5 \mu \mathrm{m}$ heights $)$, but gives much less noise because of its compact size and rigidity. Figure 5 illustrates how an optical lever works in contact mode. The laser beam is originally focused on a cantilever and reflected onto split photodiode arrays. The position of the beam is originally aligned to hit a center of the photodiode. The photodiode is divided into 4 sections, which give signal from each section $(\mathrm{A}, \mathrm{B}, \mathrm{C}, \mathrm{D})$ as well as the total signal ( $\mathrm{S}=$ $\mathrm{A}+\mathrm{B}+\mathrm{C}+\mathrm{D}$ ). When a cantilever is pushed up by high feature on the substrate (Figure 5), the laser beam is also deflected to hit the lower part of the photodiode array. The voltage from the lower part of the photodiode $(C+D)$ increases, when the upper part of 


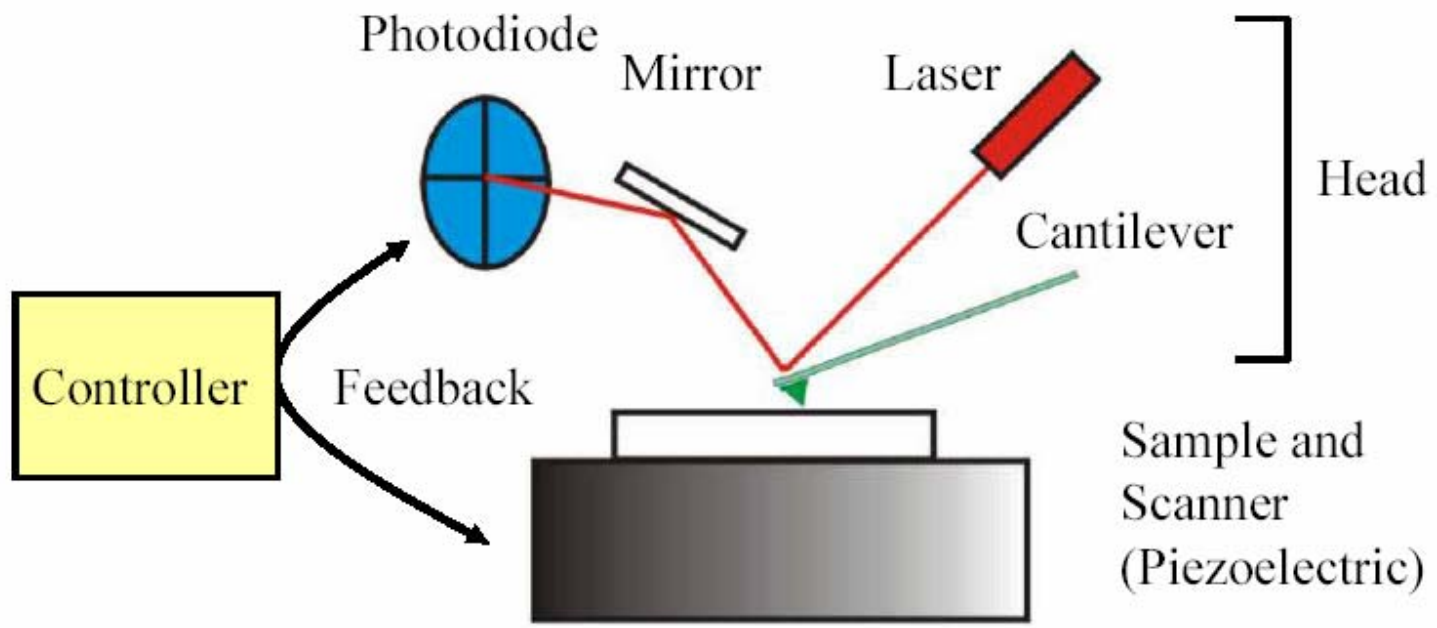

Figure 4. Schematic diagram of components of AFM. 

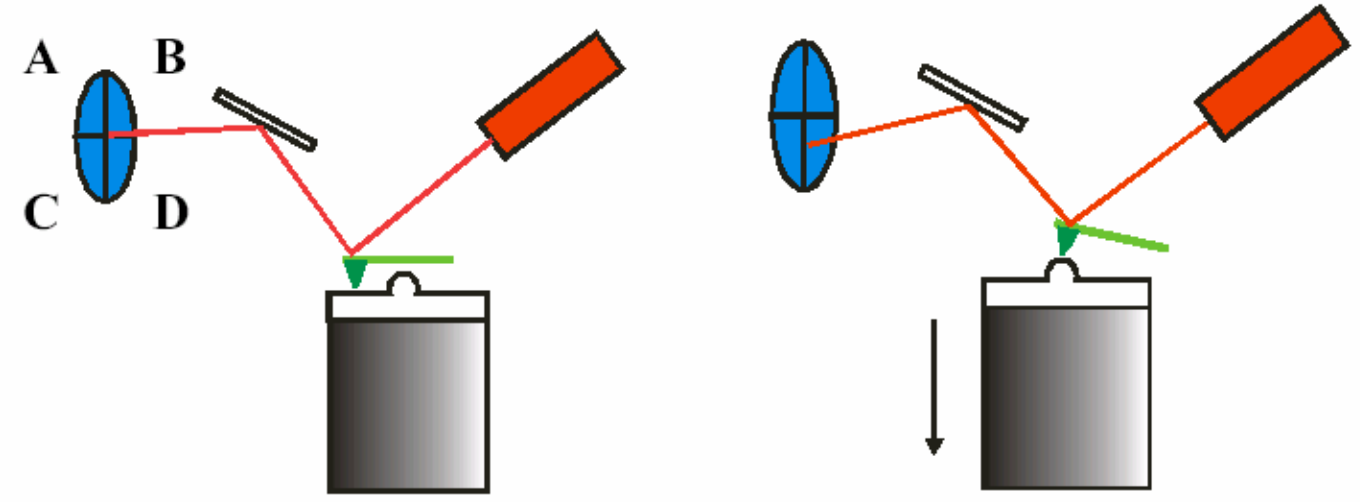

$$
\begin{array}{ll}
(\mathrm{A}+\mathrm{B})+(\mathrm{C}+\mathrm{D})=\text { Constant } & (\mathrm{A}+\mathrm{B})+(\mathrm{C}+\mathrm{D})=\text { Constant } \\
(\mathrm{A}+\mathrm{B})-(\mathrm{C}+\mathrm{D}) \approx 0 & (\mathrm{~A}+\mathrm{B})-(\mathrm{C}+\mathrm{D})=\text { Negative }
\end{array}
$$

Figure 5. Schematic diagrams of the operation of contact mode AFM. 
the photodiode $(\mathrm{A}+\mathrm{B})$ receives a smaller fraction of laser beam. The Vertical Deflection $((A+B)-(C+D))$ voltage will be negative, and this differential is sensed by feedback electronics. This causes a drop in the voltage of the $\mathrm{Z}$ piezo crystal by the controller. It, therefore, retracts the piezo crystal. As the $\mathrm{Z}$ piezo retracts, the laser will be recentered onto photodiode arrays $((A+B)=(C+D))$. In the case of frictional/lateral force microscopy $(\mathrm{FFM} / \mathrm{LFM})$, signals from $(\mathrm{A}+\mathrm{C})$ and $(\mathrm{B}+\mathrm{D})$ are measured instead of $(\mathrm{A}+\mathrm{B})$ and $(\mathrm{C}+\mathrm{D})$ to monitor frictional properties of samples.

\section{Interaction between tip and sample}

AFM images could be obtained by three main modes, such as contact mode, tapping mode, and non-contact mode. Contact mode is the most basic method of AFM operation. A tip and sample remain in close contact as scanning proceeds. This contact is achieved by keeping constant force between the tip and the sample surface. This force (F) is proportional to the cantilever deflection in the $\mathrm{z}$ direction perpendicular to sample surface $(\mathrm{z})$ by the followed equation:

$F=k z$

where $\mathrm{k}$ is the spring constant of the cantilever.

Ideally, the force changes as a function of distance from the sample surface as shown in a force- distance diagram (Figure 6). ${ }^{46}$ When an AFM tip approaches the sample surface, the cantilever experiences various forces. Figure 6 (a) shows there is no tip- surface interaction when the distance between the tip and surface are sufficiently large. If a tip is approached close enough to the surface, a tip jumps onto sample surface 


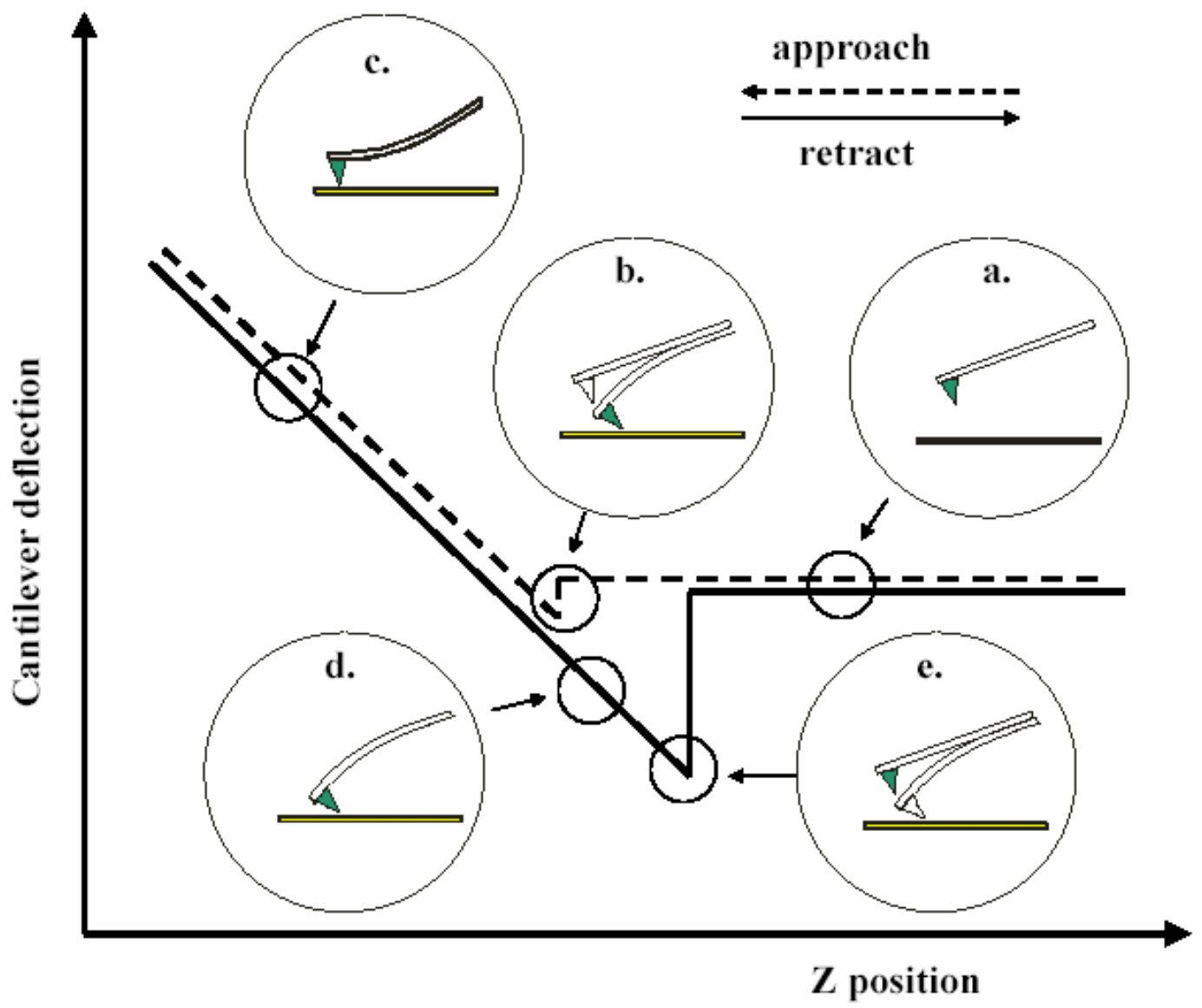

Figure 6. Typical force-distance diagram during approaching and retracting a tip. 
and tip-sample contact is accomplished due to van der Waals force. (Figure 6 (b)). With increases in force, a cantilever deflects further and this deflection is linearly proportional to the spring constant of the cantilever.(jump-to contact, Figure 6 (c)). Permanent or elastic deformation may occur to a tip or sample in this region. If a tip is retracted, deflection of the cantilever is reversed with respect to the initial direction of the jump-to contact. Further contact of a tip to the surface occurs and leads to negative deflection of the cantilever because of capillary forces (Figure 6 (d)). It is usually observed in ambient air, but not in aqueous solution or in high vacuum. Once a breaking force is large enough to overcome capillary forces, abrupt pull-out happens (Figure 6 (e)) and a cantilever returns to its original deflection (Figure 6 (a)). Contact mode is used to image hard and stable samples which are not affected by lateral forces applied by the tip. Even though force applied to biomaterials is minimized and kept just enough to maintain contact with the sample (typically order of $\mathrm{nN}$ ), damage and/or the translocation of the soft and weakly adsorbed biomolecules could occur due to lateral friction forces. To reduce frictional interactions and deformation of soft samples, other modes have been developed. Tapping mode is one of these imaging modes. In tapping mode, a tip is oscillated at its resonant frequency (in air 50-500 kHz, in fluids $\sim 10 \mathrm{kHz}$ ) at an amplitude of several tens of $\mathrm{nm}$ if a tip does not touch the surface. When this oscillating tip moves toward surface, it only taps the surface and dissipates energy for a very small fraction of its oscillation period. This energy loss leads to significant reduction of tip amplitude which is used to measure surface topographic features. Similar to contact mode, the average cantilever deflections are input to a feedback loop to maintain a 
constant average applied force. Tapping mode is preferred for the imaging of biomaterials because of the relatively small energy transactions. Another frequently used mode is phase imaging mode because it can be taken with tapping mode at the same time. The variations in the material properties such as hardness, elasticity and adhesion lead to a phase differences in cantilever oscillation. These phase differences are also monitored by the controller with the topological information. Another imaging method is non-contact mode. In non-contact mode, a cantilever oscillates in the attractive van der Waals force region and force gradients are measured by shifts in the resonance frequency of the cantilever. The advantage of this mode is to minimize or eliminate energy dissipated from the tip of a soft sample.

\section{Tip and tip effect}

Because an AFM image is obtained by interactions between the tip and sample surface, the resolution and quality of images largely depend on geometrical and physical properties of the tips. Microfabricated $\mathrm{Si}$ (silicon) and $\mathrm{Si}_{3} \mathrm{~N}_{4}$ (silicon nitride) are the most common AFM tips. An etched silicon probe is used for tapping mode in air and has a $20 \mathrm{~nm}$ tip diameter while silicon nitride tips with $20-60 \mathrm{~nm}$ diameters are employed for contact mode in air and tapping mode in solution. A $125 \mu \mathrm{m}$ long silicon probe with a $40 \mathrm{~N} / \mathrm{m}$ spring constant was used in our group. In the case of the silicon 


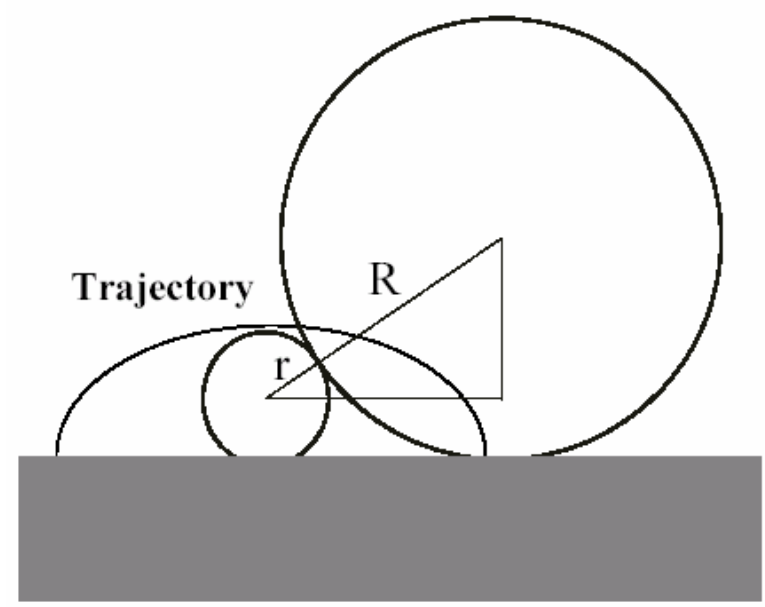

$\mathrm{R}=$ radius of tip

$\mathrm{r}=$ radius of sample

\section{Actual AFM image}

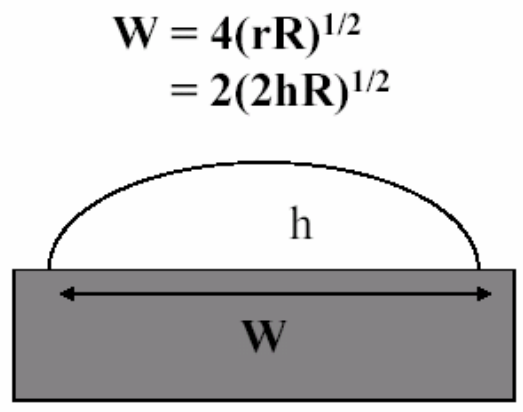

$\mathrm{W}=$ measured width

$\mathrm{h}=$ measured height

Figure 7. Schematic diagram of tip convolution. 
nitride probe, 4 different cantilevers with $0.06-0.58 \mathrm{~N} / \mathrm{m}$ spring constants were used. The slope of the pyramidal silicon and silicon nitride tips were $55^{\circ}$. The main influences of a tip on images are compression, broadening, and side wall profile effects. ${ }^{39,47,48}$ Compression effects occur when a tip is over soft material. This compression results in deformation of a sample. It is important to apply minimum force on a sample in order to avoid this compression. In our experiment, force applied to the sample was carefully monitored not to exceed more than $100 \mathrm{pN}$. Tip broadening happens when the radius of curvature of a tip is greater than the size of the feature being imaged. In this case, the side of the tip makes direct contact with the sample before the end of the tip reaches it and microscope responds to the feature prematurely. As a result, the size of the feature is exaggerated compared to its actual size. This effect is also referred to as tip convolution. To minimize this problem, sharp ended tips should be used. Also, tip calibration should be done with a standard material using the equation in Figure 7 . The side wall profile effect is crucial when steep sloped features are imaged. This effect can be prevented by using high aspect ratio tips instead of standard pyramidal tips.

\section{VIBRATIONAL SUM FREQUENCY SPECTROSCOPY}

Vibrational sum frequency spectroscopy (VSFS) was adopted to observe molecular vibrational spectrum at surfaces. Sum frequency generation (SFG) is a second order nonlinear optical procedure in which a tunable IR beam with a frequency $\omega_{\text {IR }}$ and a visible laser beam with frequency $\omega_{\text {vis }}$ overlap in the medium to produce an output oscillating nonlinear polarization at the frequency of the sum of the incident IR and 
visible beams $\left(\omega_{\text {sum }}=\omega_{\text {IR }}+\omega_{\text {vis }}\right)$. As a second order nonlinear technique, VSFS is obtained only when inversion symmetry (in the dipole approximation) is broken. It gives rise to unique and characteristic properties of the surface because the interface necessarily lacks inversion symmetry and the majority of signal is obtained at interfacial boundaries. Both the experimental and theoretical details of VSFS have been described elsewhere. $^{36,49,50}$

The Polarization, $\mathrm{P}$, in a medium induced by an incident electric field can be expressed by the following equation:

$$
P=\alpha^{(1)} E_{1}+\chi^{(2)} E_{1} E_{2}+\ldots
$$

where $\alpha^{(1)}$ and $\chi^{(2)}$ are the first and second order polarizabilities. When incident laser beams with high intensity are focused spatially and temporally, a coherent nonlinear polarization in the molecules at the interface is induced and this nonlinear polarization is at the sum of the two frequencies. An infrared laser beam is tuned through the spectral region of interest (usually $2600-3800 \mathrm{~cm}^{-1}$ ) and the frequency of the visible beam is fixed. When the energy of the tunable IR source matches the energy of a molecular vibrational mode of a surface species during the scanning, a strong resonance enhancement in the sum frequency response is induced. Therefore, vibrational spectra are obtained in VSFS experiments through these resonance enhancements. As shown in equation (1), the sum frequency signal, $I_{S F S}$, is proportional to the square of the second order nonlinear susceptibility, $\chi^{(2)}$. $\chi^{(2)}$ can be broken into two parts, a frequency dependent resonant term, $\chi_{R}^{(2)}$, and a nonresonant term, $\chi_{N R}^{(2)}$ : 


$$
I_{S F S} \propto\left|\chi^{(2)}\right|^{2} I_{v i s} I_{I R}=\left|\chi_{R}^{(2)}+\chi_{N R}^{(2)}\right|^{2} I_{v i s} I_{I R}
$$

where, $I_{v i s}$ and $I_{I R}$ denote the visible and IR beam intensities, respectively. The nonresonant term, $\chi_{N R}^{(2)}$, is dependent on polarizabilities of the molecules at interfaces and can be expressed as

$\chi_{N R}^{(2)}=k e^{i \phi}$

where $\mathrm{k}$ is the nonresonant vibrational contribution and $\phi$ is the phase difference between the resonant vibrational mode and nonresonant vibrational mode. This nonresonant term is included in the full spectral analysis. The resonant term comes from the resonance frequency between a photon and a vibrational mode of the interfacial molecules. It can be expressed as follows:

$$
\chi_{R_{n}}^{(2)}=\sum_{n} \frac{A_{q}}{\omega_{I R}-\omega_{n}+i \Gamma_{n}}
$$

where $A_{q}, \omega_{n}, \omega_{I R}$, and $\Gamma_{n}$ are the oscillator strength, resonant frequency, frequency of the IR beam, and the damping constant of the $n^{\text {th }}$ vibrational resonant mode, respectively. The $A_{q}$ term is proportional to the product of the infrared and Raman transition dipole moments and can expressed as:

$$
A_{q} \propto \frac{\partial \mu_{n}}{\partial Q} \frac{\partial \alpha_{l m}}{\partial Q}
$$

where $\mu_{n}$ and $\alpha_{l m}$ are dipole moment and polarizability and Q is the normal coordinate. From the above relation, only molecules that obey both the Raman and IR selection rules can contribute to sum frequency signal. This is essentially the heart of the sum 
frequency selection rules giving rise to interfacial sensitivity. Namely, the vast majority of signal is derived from an ordering of dipoles, which occurs readily at interfaces. When $\chi^{(2)}$ is converted to Cartesian coordinates, four independent non-zero elements of $\chi^{(2)}$ are left when the xy plane is isotropic:

$\chi_{z z z} ; \chi_{x x z}=\chi_{y y z} ; \chi_{x z x}=\chi_{y z y} ; \chi_{z x x}=\chi_{z y y}$

where $\mathrm{z}$ refers to the direction normal to the surface. These four elements contribute to the signal under four different combinations of polarizations, which are SSP, SPS, PSS and PPP, where $\mathrm{P}$ refers to a polarization perpendicular to the surface and $\mathrm{S}$ refers to a polarization parallel to the surface. SSP polarization means the polarization of sum frequency signal is $\mathrm{S}$, the polarization of the visible beam is $\mathrm{S}$ and the polarization of infrared beam is $\mathrm{P}$. Because SSP polarization gives information about vibrational modes with transition moments which have components perpendicular to the surface plane, this combination of polarizations was used to take SFG spectra in my experiments.

Our SFG system has four main parts: a Nd:YAG laser generating a $1064 \mathrm{~nm}$ source beam, an optical parametric generation/ optical parametric amplification (OPG/OPA; LaserVision, Bellevue, WA) stage, a sample stage, and a detector. The schematic diagrams for the whole SFG system are shown in Figure 8.

In my experiments, a $1064 \mathrm{~nm}$ beam was generated by an active-passive mode locked Nd:YAG laser (PY61c, Continuum, Santa Clara) with a pulse duration of $\sim 21$ ps and a repetition rate of $20 \mathrm{~Hz}$. This $1064 \mathrm{~nm}$ beam was sent into the OPG/OPA to produce a frequency doubled beam at $532 \mathrm{~nm}$ and tunable IR light from $2000 \mathrm{~cm}^{-1}$ to $4000 \mathrm{~cm}^{-1}$. As shown in Figure 9, the $1064 \mathrm{~nm}$ beam was split into two portions of 
about $70 \%$ and $30 \%$ at the first beam splitter at the beginning of the OPG/OPA processes. The $70 \%$ portion was used to generate a $532 \mathrm{~nm}$ beam through the first potassium titanyl phosphate (KTP) crystal by a beam doubling procedure. This $532 \mathrm{~nm}$ beam was spit again and one fraction of the radiation was sent to the sample stage as a visible light source. The other portion of $532 \mathrm{~nm}$ was transmitted to a second KTP crystal set and converted to a tunable near IR beam (wavelength of $1.35-1.85 \mu \mathrm{m}$ ) by the OPG/OPA process. This near IR beam was delivered to a third KTP crystal set where difference frequency generation occurs and mixed with a $1064 \mathrm{~nm}$ beam from the first beam splitter. The final wavelength generated from this last step was in between $2.3-5 \mu \mathrm{m}(2000-$ $4000 \mathrm{~cm}^{-1}$ ). Frequency scanning of the IR beam was achieved by rotating the second and third crystal sets in the OPG/OPA stages with a built-in servomotor control program provided by the OPG/OPA manufacture, Laser Vision. This mid-IR beam was also sent to the sample stage as the source of tunable IR light. Before the sample stage, the beam path and polarization of the visible and tunable IR beams were adjusted by a set of steering, polarization, and power optics. The intensity of the tunable IR radiation was $500 \mu \mathrm{J} /$ pulse near $3200 \mathrm{~cm}^{-1}$ and the power of a $532 \mathrm{~nm}$ beam employed was $1 \mathrm{~mJ} /$ pulse at the sample stage. The IR and $532 \mathrm{~nm}$ beams were combined at the sample interface with incident angles of 51 and 42 degrees with respect to the surface normal, respectively. Non-uniform intensity of the IR beam with respect to frequency was normalized by measuring the sum frequency spectrum from a quartz crystal. Calibration of each spectrum was achieved by dividing the sample spectrum by the spectrum from this normalization crystal. 


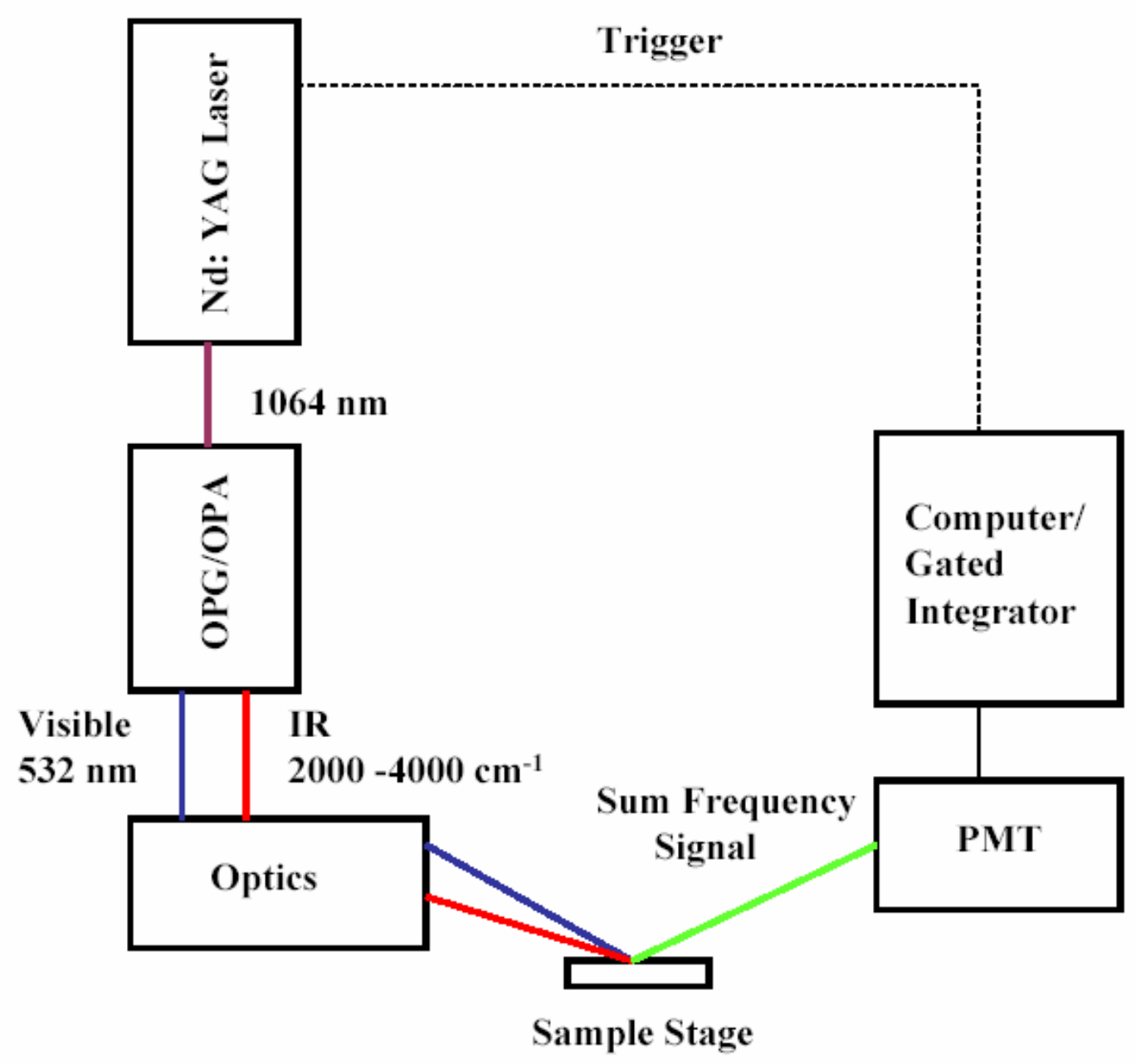

Figure 8. Schematic diagram of components of VSFG. 


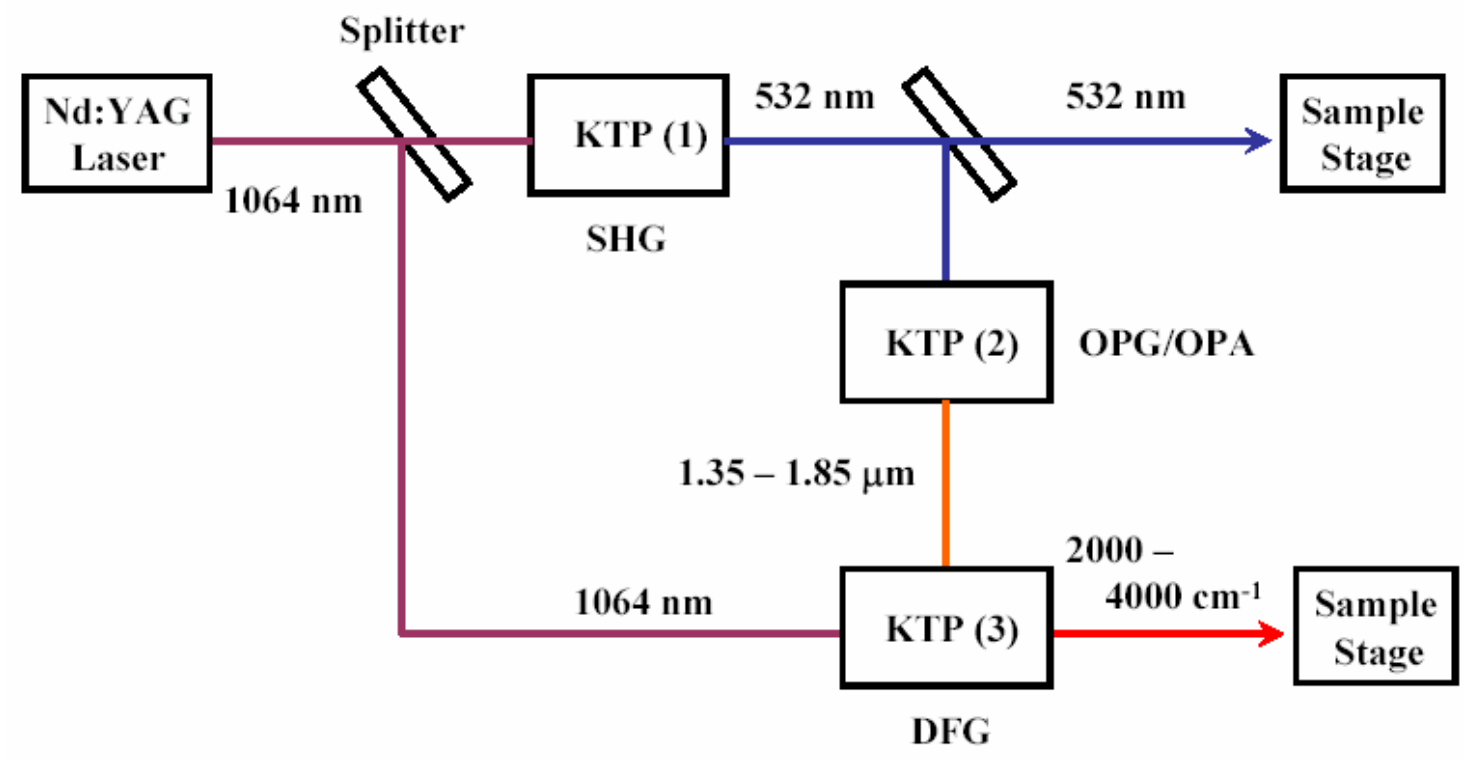

Figure 9. Schematic diagram of OPG/OPA. 
Selection of the sum frequency polarization was achieved by rotating a polarizer before a photo multiplier tube (PMT). The sum frequency signal was detected by the PMT (Type R647, Hamamatsu Corporation, Bridgewater, NJ). 1.2 KV of DC voltage was applied by a power supply unit (Model 362, Bertan High Voltage, Hicksville, NY). A main frame (SR280, Stanford Research Systems, Sunnyvale, CA) equipped with a PMT power supply and a gated integrator (SR250, Stanford Research System, Sunnyvale, CA) was used in integrating the sum frequency signal from the PMT. Data acquisition was performed with a program written with Labview 5.0 (National Instruments, Austin, TX). 


\section{CHAPTER III}

\section{MULTIVALENT LIGAND-RECEPTOR INTERACTIONS ON PLANAR SUPPORTED MEMBRANES}

\section{INTRODUCTION}

Since their initial fabrication two decades ago by McConnell and coworkers, fluid supported phospholipid bilayers (SLBs) have played a key role in the development of nanoscale assemblies of biological materials on artificial supports. ${ }^{51,52}$ The reason for this is quite straightforward. SLBs can serve as biomimetics for chemical and biological processes which occur in cell membranes. A thin aqueous layer (approximately $1 \mathrm{~nm}$ thick) is trapped between the bilayer and the underlying support (Figure 10). This water layer acts as a lubricant allowing both leaflets of the bilayer to remain fluid. ${ }^{53-59}$ Consequently, planar supported membranes retain many of the physical properties of free vesicles or even native cell surfaces when the appropriate recognition components are present. ${ }^{52,54}$ Specifically, SLBs are capable of undergoing lateral rearrangements to accommodate binding by aqueous proteins, viruses, toxins, and even cells. ${ }^{60}$ As substrate supported entities, they are convenient to study by a host of interface-sensitive techniques ${ }^{54}$ and are far less fragile than either unsupported membranes or full-blown cellular systems. SLBs can be formed by either Langmuir Blodgett methods or through the fusion of small unilamellar vesicles to a planar solid substrate. ${ }^{52,58}$ Either way it is 


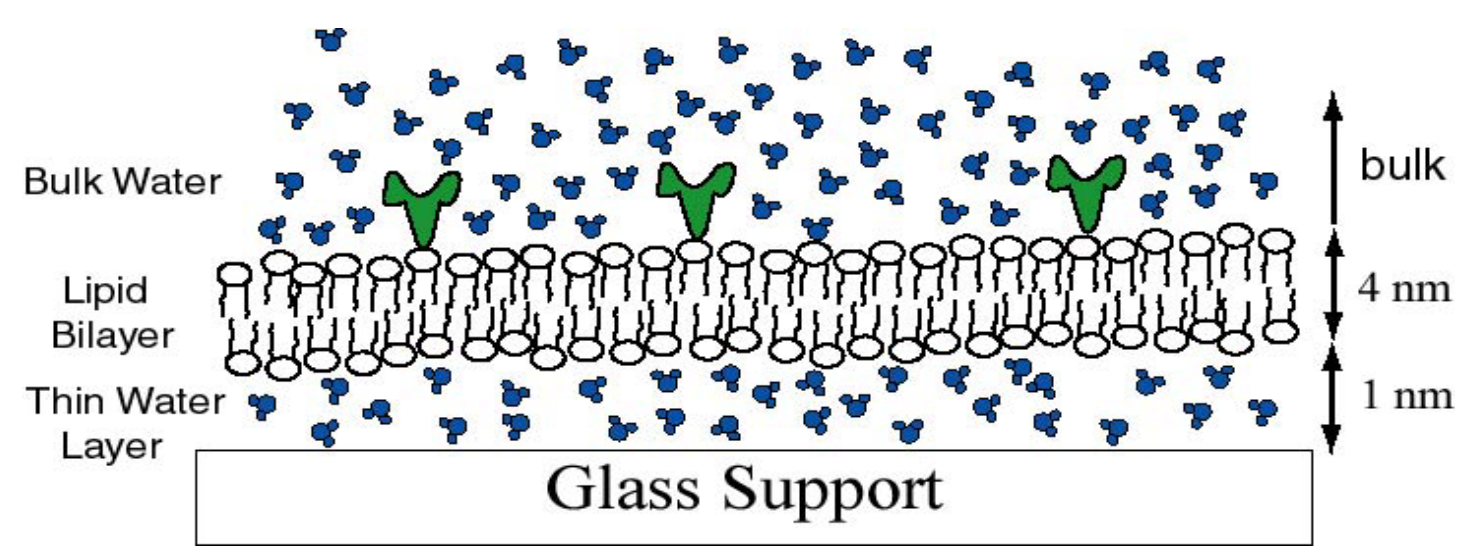

Figure 10. Schematic diagram of a supported phospholipid bilayer membrane containing a covalently attached ligand molecule (in green). 
relatively straightforward to incorporate ligands into these membrane models. Indeed, any numbers of species including peptides, peptide labeled lipids, biotinylated lipids, channel forming proteins, and antigenic ligands have been presented in supported bilayers. ${ }^{54}$ Herein the focus was on supported phospholipid bilayers on glass substrates. The work described below concerns the creation of two-dimensional membrane arrays and microfluidic devices for the investigation of multivalent ligand-receptor interactions. Probing these events at a fluid interface is fundamentally different than with ligands attached to polymer backbones or on the surface of other scaffolds ${ }^{61-65}$ because each ligand on the bilayer is free to rearrange its position on the surface to maximize its interactions with an incoming multivalent protein, virus, bacterium, or toxin. ${ }^{2,66,67}$ For example, in the case of anti-2,4 dinitrophenyl IgG antibodies interacting with a supported bilayer containing N-dinitrophenylaminocaproyl phosphatidylethanolamine (DNP-Cap PE), the overall interaction should be bivalent with both the bound IgG and ligands able to rearrange to accommodate proper binding (Figure 11). In this case, both binding sites are identical. The use of SLBs allows the ligand-receptor binding process to be facilely probed as a function of membrane chemistry. For example, the amount of cholesterol in the membrane, the charge on the membrane, the ligand density, the types of lipids present, as well as the presence of additional peptides or glycosylation can be varied on a single chip. Conducting such experiments is vital because cells carefully control the type of lipids and ligands present in each leaflet of each membrane. Establishing and maintaining such fine control is a significant metabolic burden to the cell. $^{68}$ 
(a)

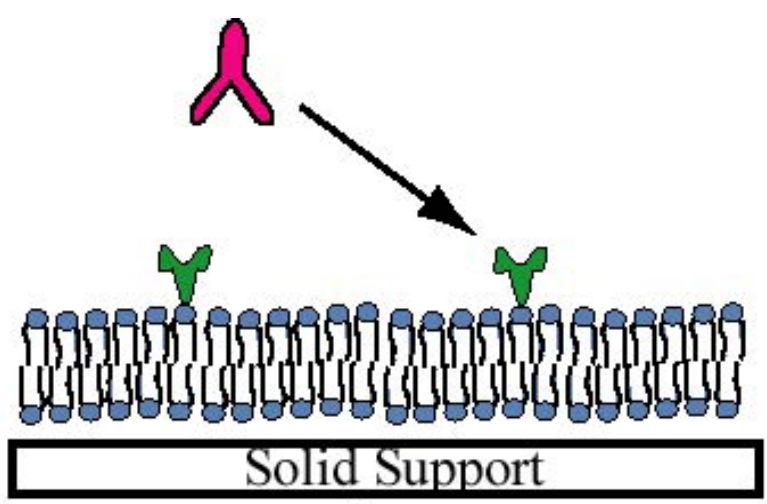

(b)

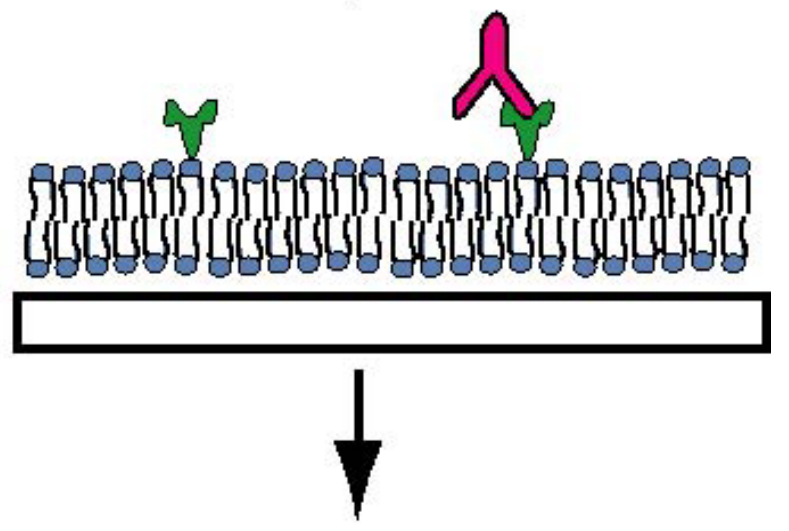

(c)

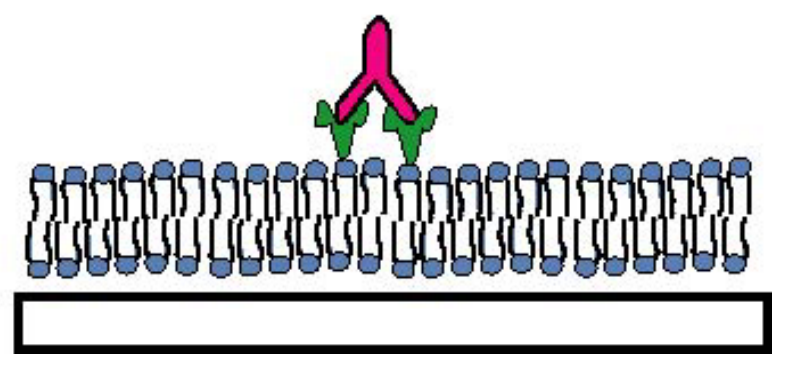

Figure 11 (a) An IgG antibody (in red) approaches a phospholipid membrane containing fluid ligands (in green). (b) The species first binds to one ligand and (c) then diffuses laterally to bind to a second ligand. 
Yet until now there has been only limited understanding as to the purpose of this lipid differentiation. Part of the reason for this paucity of understanding stems from the fact that testing ligand-receptor binding as a function of cell membrane chemistry is difficult due to the lack of high throughput platforms for probing multivalent interactions in a fluid membrane environment. This problem is overcome by combining SLBs with microfluidic and array based techniques. I will, therefore, first describe the formation of two-dimensional bilayer arrays and microfluidic platforms for making high throughput thermodynamic measurements. Then the use of these techniques will be demonstrated for probing the effects of ligand density on bivalent antibody binding.

\section{CREATION OF SPATIALLY ADDRESSED ARRAYS}

The use of planar supports for presenting large arrays of spatially addressed molecules is one of the most powerful and versatile methods for creating combinatorial libraries..$^{61,69,70}$ Extending this approach to supported phospholipid bilayer membranes is an especially valuable goal because of the ability of these systems to mimic many of the properties of native cell surfaces as suggested in Figure 12a. ${ }^{54}$ Addressing biomembrane mimics on planar supports, however, presents unique challenges, as the two-dimensional fluidity of the biomembrane must be preserved in many cases for it to function properly. ${ }^{71-73}$ The bilayer deposition process must take place in an aqueous environment and the entire system must continue to remain submerged under water to preserve the planar supported structure. Because of this physical constraint as well as the inherent complexities of biomembrane materials, traditional technologies such as light-directed 
synthesis for addressing peptide or DNA sequences onto solid supports are inherently difficult to apply. ${ }^{61}$ Therefore, an alternate approach $^{74}$ was employed based upon depositing mesoscopic quantities (10-100 pL) of aqueous solution onto lithographically patterned hydrophilic surface ${ }^{75}$ well plates, followed by the immersion of the entire substrate into buffer. This is a general and flexible method for directing chemically distinct phospholipid membranes into individually addressable surface sectors.

Previous investigators showed that patterned surfaces allow partitioning of one fluid lipid bilayer from the next. ${ }^{76,77}$ Molecules within an individual membrane are free to move within the confines of a single partition, but do not crossover to a neighboring region. In my laboratory, planar borosilicate substrates were partitioned into arrays of micrometer sized hydrophilic boxes using standard photolithography. Patterning was achieved by exposing the surface to ultraviolet light through a lithographic mask consisting of an array of square boxes. Developing the pattern and cleaning the substrate formed well plates of hydrophilic glass onto which picoliter-sized droplets of liposome solution were placed. The liposomes, which were small unilamellar vesicles (SUVs) of phospholipids, were present at $1 \mathrm{mg} / \mathrm{ml}$ concentration in a $\mathrm{pH} 7.0,100 \mathrm{mM}$ sodium phosphate buffer solution. Figure $12 \mathrm{~b}$ shows the epifluorescence image of nine $50 \mu \mathrm{m} x$ $50 \mu \mathrm{m}$ well plates that have been addressed with three chemically distinct types of supported phospholipid bilayers. The boxes appearing red in color contain $1 \mathrm{~mol} \%$ Texas Red DHPE fluorescent probes while those appearing green contain 3 mol\% NBDDHPE probes. The center box, which appears dark yellow, contains both kinds of fluorophores. 


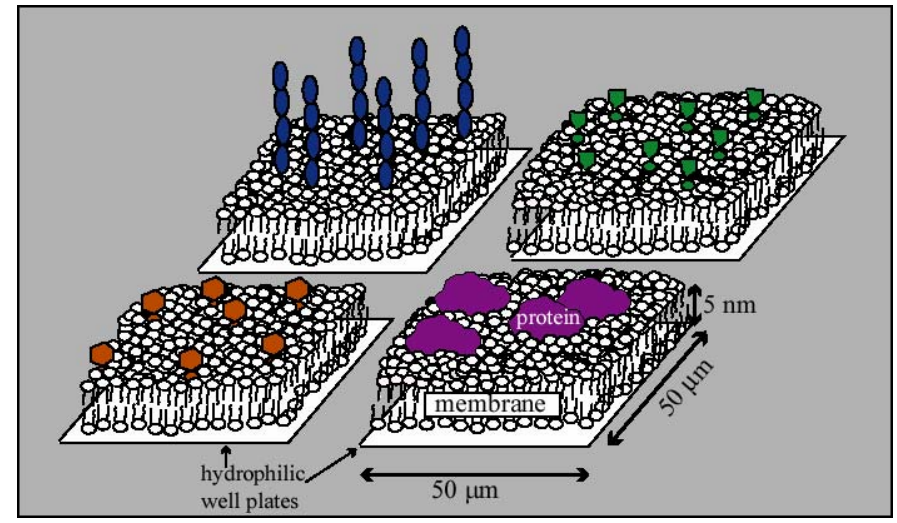

(a)

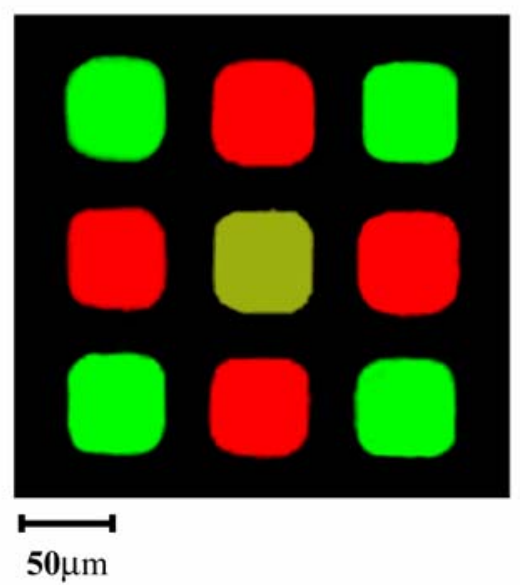

(b)

Figure 12. (a) A schematic representation of a $2 \times 2$ array of addressed supported fluid biomembranes with various components in each box. (b) An epifluorescence image of a $3 \times 3$ array of fluid biomembranes that have been addressed using the spatial addressing techniques described above. 
Fluorescence recovery after photobleaching (FRAP) ${ }^{78,79}$ demonstrated that the lipids were free to move throughout each two-dimensional box, but were otherwise completely confined.

The spatially addressed membrane arrays were used to investigate the effect of ligand density and cholesterol content on the binding of anti-2,4 dinitrophenyl $\operatorname{IgG}$ antibodies with DNP-Cap PE lipids in phosphatidylcholine membranes. The antibodies were labeled with Texas Red dye so that they could be visualized at the bilayer interface. Experiments were conducted on a $4 \times 4$ membrane array with cholesterol content varying from 0 to $20 \mathrm{~mol} \%$ and DNP-Cap PE concentrations ranging from 0 to $5 \mathrm{~mol} \%$ (Figure 13). The results indicated that binding was dependent on both ligand density and cholesterol content. It has been previously suggested by McConnell and coworkers that the addition of cholesterol to the phospholipid membranes increases the availability of the DNP ligand to antibodies in the bulk solution. ${ }^{80}$ Significantly, the effect is much larger at lower ligand concentrations then it is at high ligand concentrations.

\section{SUPPORTED BILAYER MICROFLUIDICS}

Exploiting fluid bilayer-based platforms for sensor design, biocompatibility studies, or fundamental investigations of lipid membranes could be made even more powerful by incorporating them into microfluidic networks for lab-on-a-chip assays. ${ }^{81-91}$ A schematic diagram of the concept is shown in Figure 14a, while $14 \mathrm{~b}$ shows the epifluorescence image of an array of eight microchannels coated with fluorescently labeled supported lipid bilayers. Each microchannel was addressed individually by 


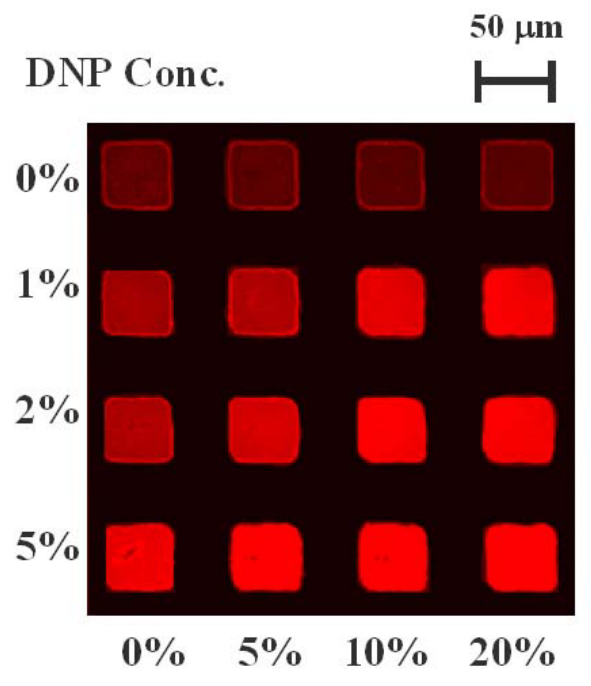

Cholesterol Conc.

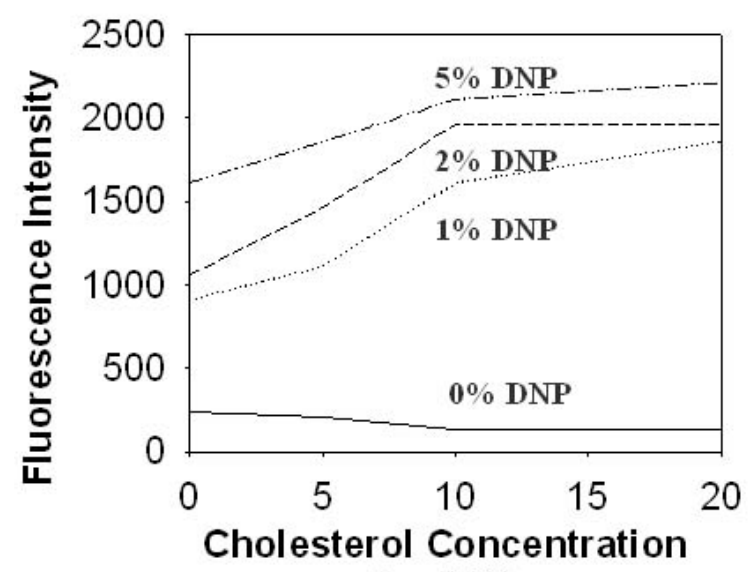

$(\mathrm{mol} \%)$

Figure 13. (a) An epifluorescence image of a 4 x 4 membrane array. (b) A quantitative plot of fluorescence intensity vs. cholesterol content at each DNP ligand concentration. 
(a)

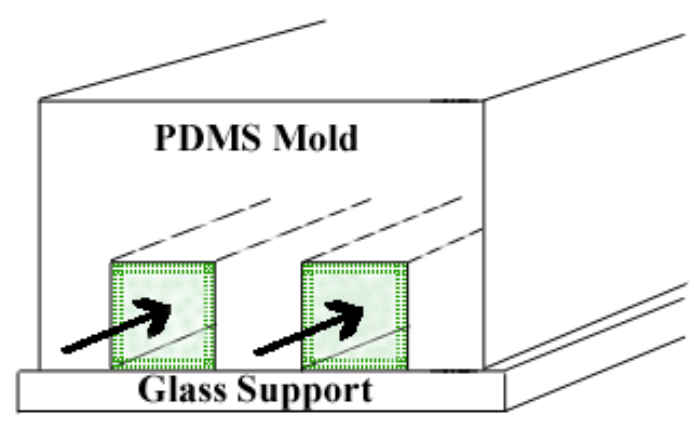

(b)

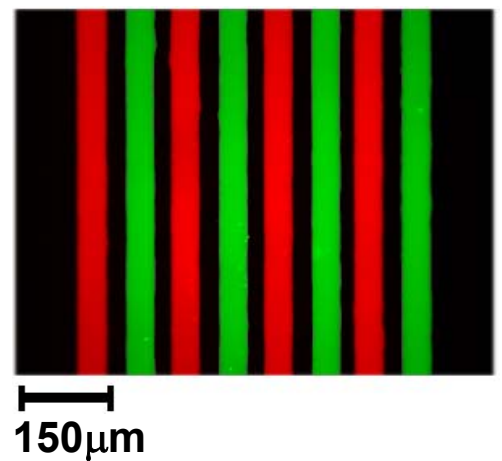

Figure 14. (a) Schematic diagram of bilayer coated PDMS microchannels on a planar glass substrate. The bilayer coats both the glass and polymer surfaces. Protein solutions can then be injected into the channels as indicated by the arrows. (b) Epifluorescence image of a spatially addressed array of eight egg PC bilayer coated microchannels. The channels are alternately coated with bilayers containing 1 mol\% Texas Red and 3 mol\% fluorescein labeled lipids. 
injecting SUVs in a $10 \mathrm{mM}$ PBS buffer at pH 7.2 into the channel inlet ports. The odd numbered microchannels contained 1 mol\% Texas Red DHPE probes in the lipid bilayers, while the even numbered channels were prepared with 3 mol\% fluorescein DHPE probes. Vesicle fusion occurred on both the PDMS channel walls ${ }^{92}$ as well as on the underlying borosilicate substrate. Fluorescence recovery after photobleaching experiments indicated that the supported membranes were mobile on both materials. It should be noted that vesicle injection was performed in all channels within 3-4 minutes after exposing the PDMS mold to the oxygen plasma. This not only ensured that the channels were sufficiently hydrophilic to induce flow by positive capillary action, but also led to the formation of high quality bilayers on the PDMS surface. The bilayers were stable on the microchannels for at least several weeks and probably longer.

\section{CREATION OF IMMUNOASSAYS}

One of the most important potential uses for bilayer microfluidics is the creation of quantitative on-chip immunoassays. Using parallel arrays of microchannels allows an entire binding curve to be obtained in one-shot simply by coating each channel with the same ligand-containing membrane and flowing different IgG concentrations over each. Such a methodology for performing heterogeneous immunoassays not only produces rapid results, but also requires much less protein than traditional procedures and eliminates some standard sources of experimental error. ${ }^{93}$

To discriminate between surface bound protein molecules and those in bulk solution, total internal reflection fluorescence microscopy (TIRFM) was employed. 
TIRFM creates an evanescence wave that decays as a function of distance from the surface as:

$$
I(z)=I_{0} e^{-z / d} \quad \text { and } d=\frac{\lambda_{0}}{4 \pi}\left[n_{1}^{2} \sin ^{2} \theta-n_{2}^{2}\right]^{-1 / 2}
$$

where $\mathrm{I}$ is the intensity of the incident light beam, $\mathrm{z}$ is the distance from the interface measured in the normal direction, $\mathrm{n}_{1}$ is the index of refraction of medium 1 (high index medium from which the light is incident) and $n_{2}$ is the index of refraction of medium 2 (low index medium into which the evanescent field is propagating), $\theta$ is the angle which the radiation makes with the surface normal and $\lambda_{0}$ is the wavelength. The substrate beneath the biochip on which the bilayers resided was made of borosilicate float glass, which has an index of refraction of about 1.52 (Figure 15). The aqueous solution above the surface has an index of refraction close to 1.33. Since the laser beam was incident on this surface at approximately $79^{\circ}$, the intensity of the evanescence field fell to $37 \%(1 / \mathrm{e})$ of its initial value at a distance of $70 \mathrm{~nm}$ above the liquid/solid interface for the $594 \mathrm{~nm}$ radiation employed.

The DNP/anti-DNP system was chosen as a test case for immunoassay fabrication. In order to obtain sufficient data for quantitative measurements of ligandreceptor binding as a function of antibody concentration, measurements were made over nearly two orders of magnitude in protein concentration. Twelve microchannels were arrayed on a single chip. Each channel was injected with a solution of small unilamellar vesicles composed of $92 \mathrm{~mol} \%$ egg PC, 5 mol\% DNP-PE and 3 mol\% fluorescein DHPE in a $10 \mathrm{mM}$ PBS buffer at $\mathrm{pH}$ 7.2. After flushing out excess vesicles, various 


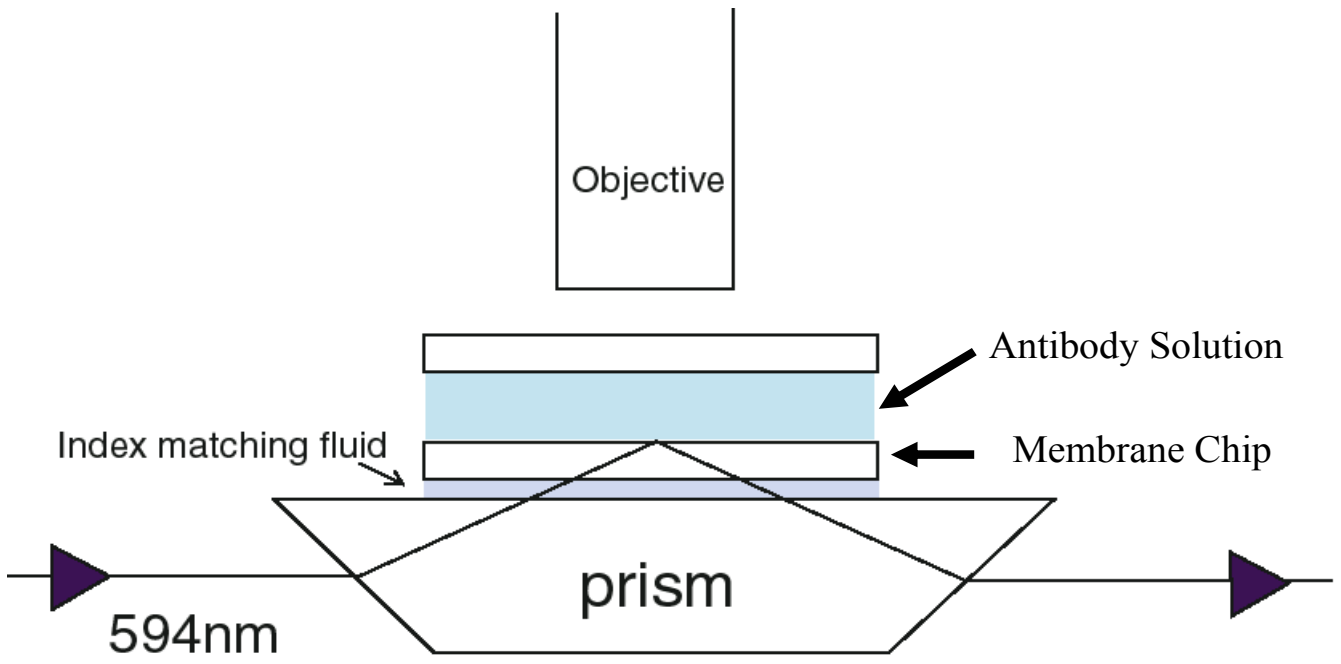

Figure 15. TIRFM setup for imaging antibody-antigen interactions on bilayer coated chips. 
concentrations of Alexa dye labeled anti-DNP were injected into the channels, with the highest protein concentration on the left side and the lowest on the right (Figure 16a).

Because surface binding causes bulk concentration depletion, protein solution was flowed continuously through the channels until the bulk concentration became stabile. This required an aliquot roughly equal to 4 or 5 times the channel volume in the microchannels with the lowest protein concentration, while the highest concentration channels required considerably less flow, as expected. A line profile generated from the epifluorescence image of these channels is shown in Fig. 16b. The majority of the signal emanated from the bulk.

Figure 17 a shows the same system as $10 \mathrm{a}$, but now imaged by TIRFM. As can be seen from the line profile (Figure 17b), the fluorescence intensity no longer showed a logarithmic decay with respect to bulk concentration. Instead, the signal represented a combination of specifically bound antibody, nonspecifically bound antibody, and near surface antibody in the bulk solution. To account for signal arising from the latter two effects, the experiment was repeated under the identical conditions, but in the absence of DNP-PE lipids in the SLBs. In this case, the fluorescence intensity from the total internal reflection experiments was dramatically reduced (data not shown). A binding curve for coverage vs. bulk protein concentration was obtained for the DNP/anti-DNP system by subtracting the background from the data in Fig. 17b. This is plotted in Figure 18. The half coverage point on the curve occurs at a concentration of $1.8 \mu \mathrm{M}$ and is in good agreement with data from previous experiments. ${ }^{9,94}$ 
(a)

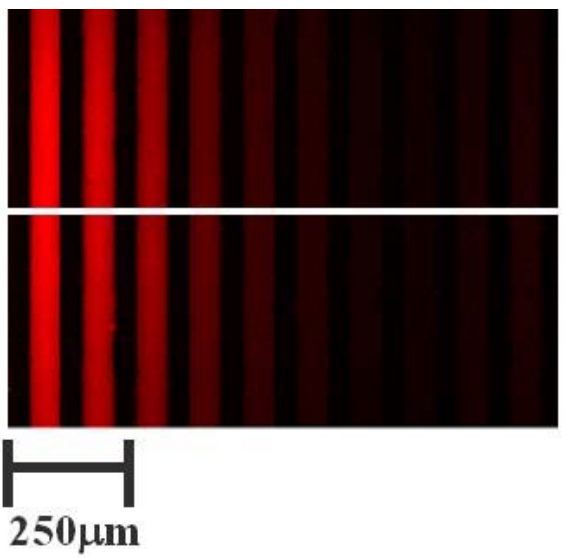

(b)

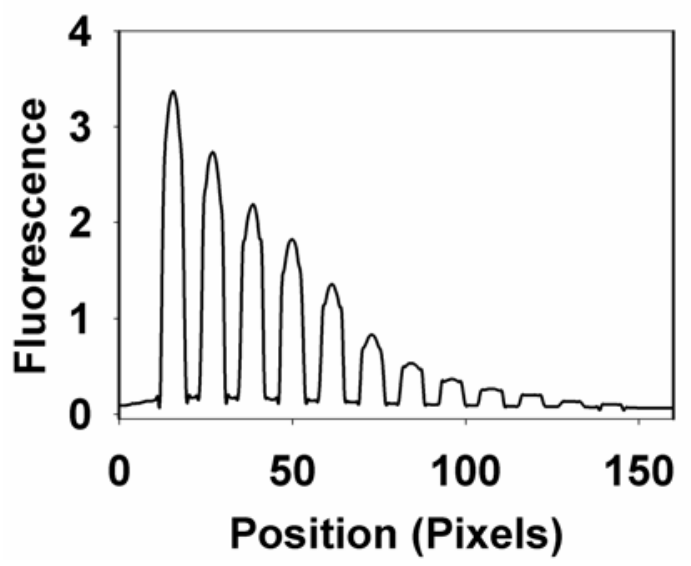

Figure 16. (a) Bulk phase epifluorescence image of Alexa 594 dye-labeled anti-DNP inside bilayer coated microchannels. Starting from the left-hand-side, the antibody concentrations are $13.2 \mu \mathrm{M}, 8.80 \mu \mathrm{M}, 5.87 \mu \mathrm{M}, 3.91 \mu \mathrm{M}, 2.61 \mu \mathrm{M}, 1.74 \mu \mathrm{M}, 1.16 \mu \mathrm{M}$, $0.77 \mu \mathrm{M}, 0.52 \mu \mathrm{M}, 0.34 \mu \mathrm{M}, 0.23 \mu \mathrm{M}$ and $0.15 \mu \mathrm{M}$, respectively. A line scan of fluorescence intensity (dotted line) across the microchannels is plotted in (b). 
(a)
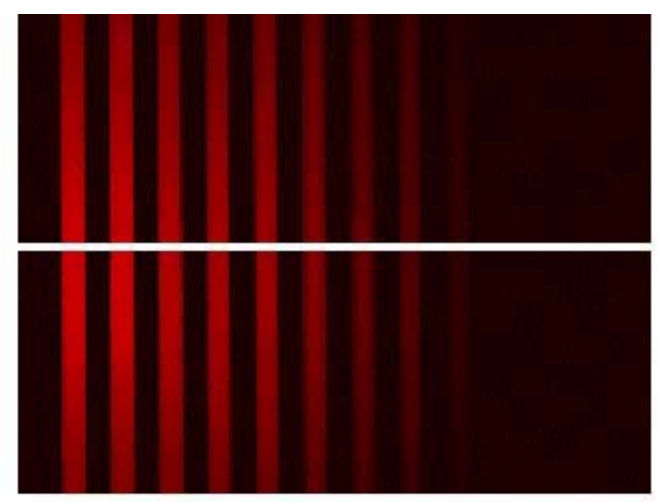

1

$250 \mu \mathrm{m}$ (b)

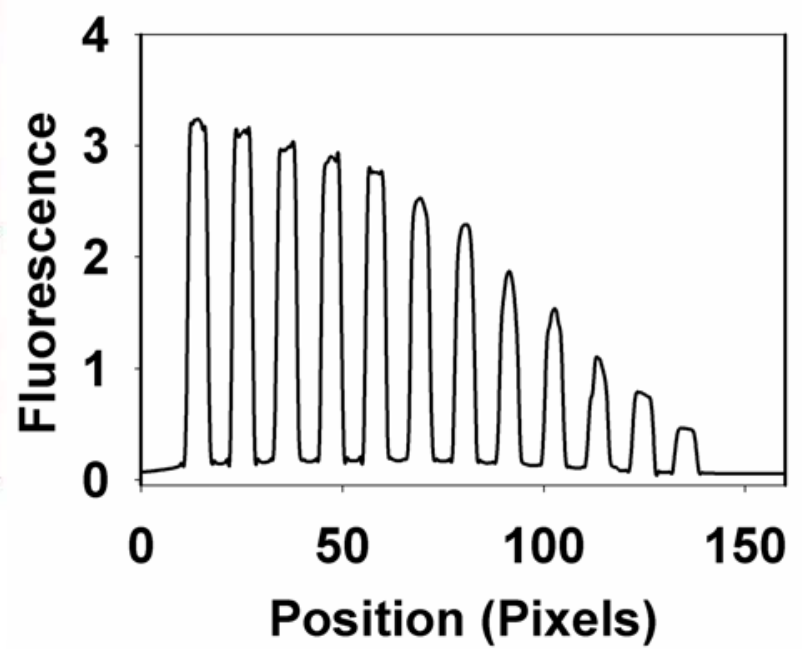

Figure 17. (a) A total internal reflection fluorescence image of the same conditions as shown in Figure 10a. (b) Line scan of fluorescence intensity (white line) across the microchannels. 


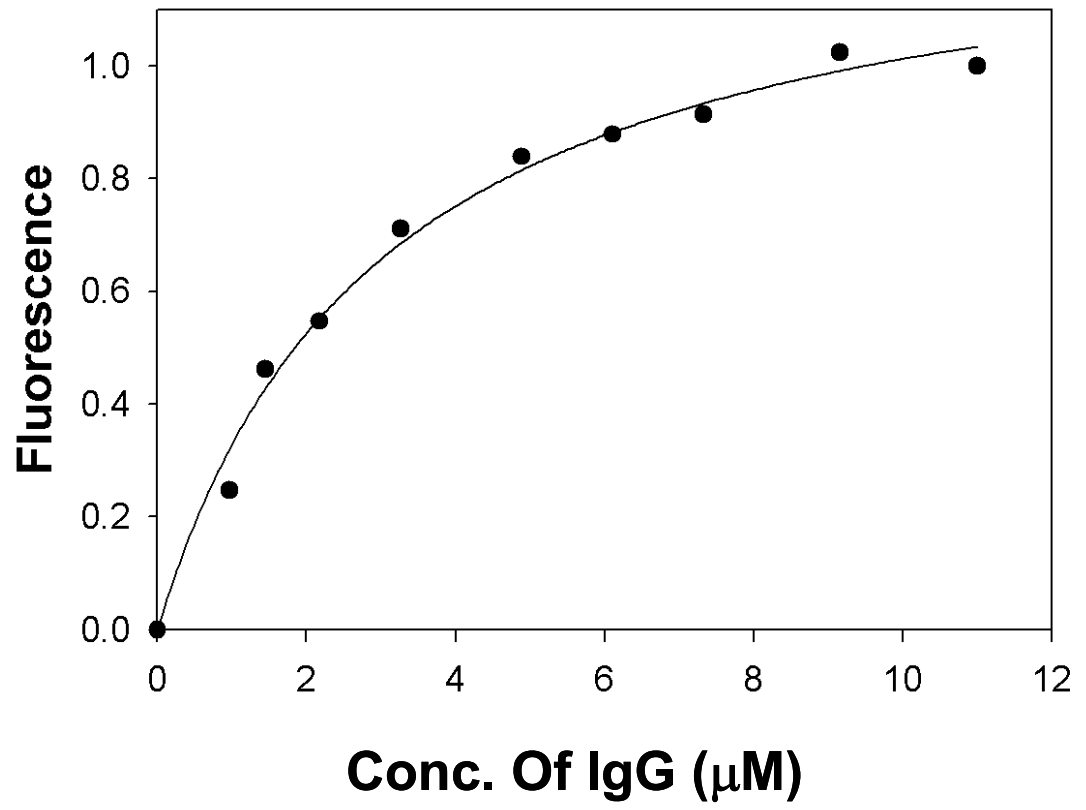

Figure 18. Binding curve for the DNP/anti-DNP system on a fluid phospholipid membrane. 


\section{CONCLUSION}

In the area of immunology, pharmacology and life science, researchers have looked forward to produce large amounts of data rapidly and reduce the amount of sample needed, but no traditional technique is sufficient to meet these objectives. One very effective system is the microfludics and micro arrays folded together with solid supported lipid bilayers developed by our lab. They combine the advantages of microchip technology with the mimetic celluar membrane surface. Under a very well controlled environment (ex. ionic strength, $\mathrm{pH}$, temperature), experiments can be performed with high accuracy and reproducibility. These advantages will enable us to investigate the fundamental processes of ligand receptor interactions at cell surfaces as well as to develop high throughput screening assays. The new drug development, material search, microscale separation and microreactor are the fields that require novel microfabrication methods and could be possible applications of our devices. 


\section{CHAPTER IV}

\section{THE VROMAN EFFECT: A MOLECULAR LEVEL DESCRIPTION OF FIBRINOGEN DISPLACEMENT}

\section{INTRODUCTION}

The formation of biofilms on man-made surfaces affects fields ranging from food processing to biosensor design. ${ }^{95,96}$ One particularly important topic is the adsorption of blood and related biofluids onto nascently implanted materials such as artificial hips. ${ }^{97}$ Leo Vroman and Ann Adams first demonstrated in the late 1960s that protein adsorption from blood plasma involves a complex series of adsorption and displacement steps. ${ }^{7}$ This phenomenon, now known as the Vroman effect, ${ }^{7,98-100}$ has subsequently been shown to involve the initial adsorption from the fluid phase of abundant but weakly surfaceactive proteins. These early adsorbers are subsequently displaced by more strongly binding species that are present in solution at lower concentration. Despite speculation of possible mechanisms for this phenomenon based on molecular structures, ${ }^{3}$ no definitive experimental evidence has been available to explain it. This is unfortunate because a mechanistic understanding of the Vroman effect could aid in the search for biocompatible materials. Indeed, proteins are usually the first species to arrive at a nascently formed biological/artificial interface and the nature and concentration of these adsorbates strongly influences subsequent cellular recruitment, platelet adhesion, and thrombosis. ${ }^{101,102}$ 
One of the classic Vroman effects involves the displacement of HPF from a silica substrate. $^{103-105}$ Over the past few decades it has been shown that fibrinogen displacement by other plasma proteins such as kininogen and clotting factor XII depends upon numerous factors including temperature, the extent of dilution of the plasma, and the specific surface chemistry. ${ }^{98,106}$ HPF consists of two peripheral D domains and one central E domain linked together by triple-stranded $\alpha$-helical coiled coils (Figure 19). ${ }^{3}$

Additionally, there are two $\alpha \mathrm{C}$ domains that interact with the central $\mathrm{E}$ domain in a $\mathrm{pH}$ specific manner. ${ }^{107}$ Namely, near neutral $\mathrm{pH}$ the $\alpha \mathrm{C}$ domains are strongly bound to E, but upon lowering the $\mathrm{pH}$ below 3.5 they become reversibly detached. ${ }^{3,102,107}$ HPF is net negatively charged at $\mathrm{pH} 7.4$ with the highest concentration of negatively charge residues residing on the $\mathrm{E}$ and $\mathrm{D}$ domains. On the other hand the $\alpha \mathrm{C}$ domains, which are rich in Arg and Lys residues, are actually positively charged. The hydropathic index for HPF indicates that the E and D domains are substantially more hydrophobic than the $\alpha \mathrm{C}$ domains. ${ }^{3}$

The work presented here employs a combination of techniques including atomic force microscopy, vibrational sum frequency spectroscopy (VSFS), immunochemical assays, and kinetic experiments to help elucidate the HPF displacement mechanism. The results demonstrate that the protein's $\alpha \mathrm{C}$ domains play the critical role. When the protein is adsorbed to a hydrophilic surface via these moieties, its displacement rate in the presence of human plasma is approximately $\sim 170$ times faster than when these domains are not in direct surface contact. Even more significantly, spectroscopic studies show evidence for highly aligned Arg and Lys residues interacting with the negatively 


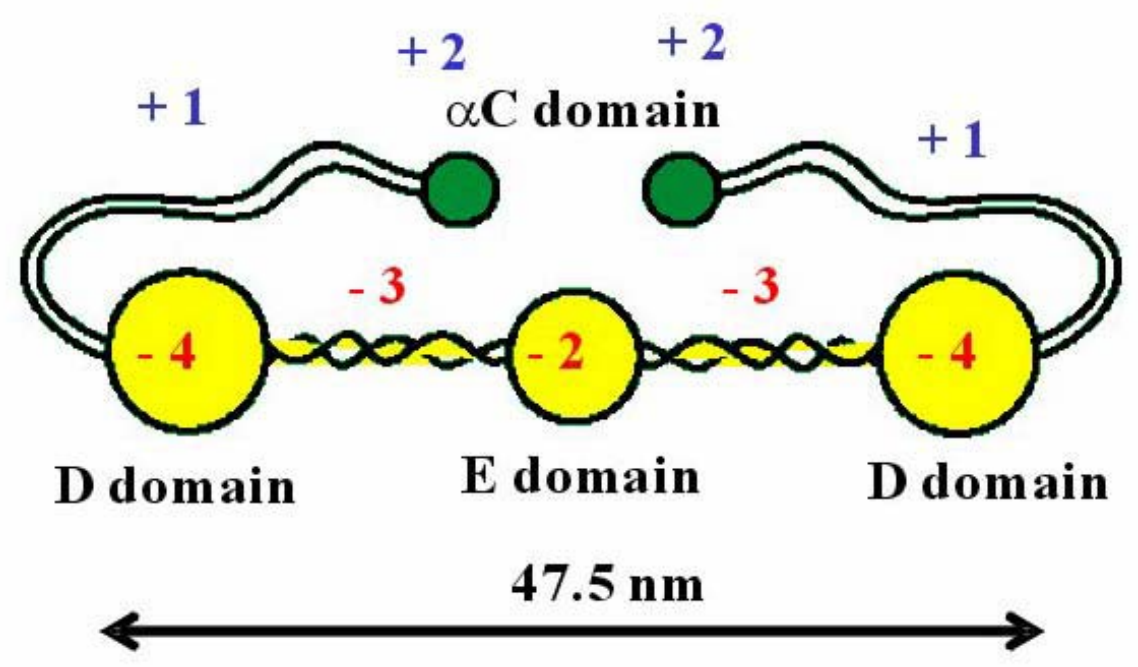

Figure 19. Molecular structure of human plasma fibrinogen (HPF). The D and E domains are formed from two sets of three polypeptide chains $(A \alpha, B \beta$ and $\lambda)$ connected by 29-disulfide bonds. The N-termini of these chains form the $\mathrm{E}$ domain while the $\mathrm{C}$ termini of the $\mathrm{B} \beta$ and $\lambda$ chains make up the two D domains. HPF is $90 \AA x 475 \AA \times 60$ $\AA$ with a molecular weight of $340 \mathrm{kD} .^{108}$ 
charged substrate only when the $\alpha \mathrm{C}$ domains make direct surface contact. The interfacial ordering of these residues appears to be the hallmark of a weak and labile electrostatic attraction between the substrate and the adsorbed macromolecule.

\section{MATERIALS AND METHODS}

\section{Materials}

Human plasma fibrinogen ( $>95 \%$ purity) was purchased from Sigma and its purity was verified in our laboratory using size exclusion chromatography with an Akta purifier (Amersham Bioscience). The results showed the protein to be at least $98 \%$ pure. Stock solutions of HPF were made by dissolving the macromolecule in a $\mathrm{NaHCO}_{3} /$ $\mathrm{Na}_{2} \mathrm{CO}_{3}$ buffer $(\mathrm{pH} 9.0,50 \mathrm{mM})$ at a concentration of $3.0 \mathrm{mg} / \mathrm{ml}$. These solutions were aliquoted and stored at $-80{ }^{\circ} \mathrm{C}$. Just before use, the protein solutions were thawed and diluted in appropriate phosphate buffers. Control experiments were performed with circular dichroism and on SDS PAGE gels (both with and without DTT). The results indicated that $\mathrm{pH}$ changes between 3.2 and 8.0 did not cleave the disulphide linkages. Human plasma was purchased from CBR Laboratories (Woburn, MA) and diluted to a 5\% solution in water (NANOpure Ultrapure Water System, Barnstead, Dubuque, IA) before use. The water employed had a minimum resistivity of $18 \mathrm{M} \Omega \cdot \mathrm{cm}$. Antifibrinogen A $\alpha$ chain (A $\alpha$ 529-539) antibody was purchased from Accurate Chemical \& Scientific Corp. (Westbury, NY) and labeled by Alexa Fluor-594 dye from Molecular Probes (Eugene, OR). IR grade fused silica discs, which were used in all experiments, were purchased from Quartz Plus Inc. (Brookline, NH). 
Atomic force microscopy

AFM images were taken with a Nanoscope IIIa Multimode SPM (Digital Instruments, Santa Barbara, CA) equipped with a type "J" scanner. The silica substrates were pretreated with an $\mathrm{H}_{2}-\mathrm{O}_{2}$ flame for 5 minutes. The pretreated substrates were then cleaned in a dichromate-sulfuric acid cleaning solution and annealed at $1050{ }^{\circ} \mathrm{C}$ for 12 hours in a kiln. Finally, the discs were $\mathrm{O}_{2}$ plasma treated immediately before use. To perform an experiment, a piece of silica was mounted onto a stainless steel disk for placement into a liquid cell. Protein solution at $0.5 \mu \mathrm{g} / \mathrm{ml}$ was introduced into the cell, which was equipped with an O-ring seal and allowed for exchange of the bulk solution. This concentration was chosen because higher concentrations made it difficult to keep track of the individual HPF molecules. The same concentration was therefore also used for all other experiments except VSFS. In that case, $5.0 \mu \mathrm{g} / \mathrm{ml}$ was employed to obtain sufficient signal. All AFM images were obtained with $100 \mathrm{~nm}$ long oxide-sharpened triangular probes (silicon nitride, spring constant: $0.58 \mathrm{~N} / \mathrm{m}$ ) in fluid tapping mode at a scan rate of $1-2.5 \mathrm{~Hz}$. The drive frequency was $8-9 \mathrm{kHz}$ and the drive amplitude was $0.25-0.7 \mathrm{~V}$. The set point was chosen at $85-90 \%$ of the free amplitude. The only treatment applied to the images was flattening.

Vibrational sum frequency spectroscopy

VSFS experiments were performed with a passive-active mode-locked Nd:YAG laser (Continuum, Santa Clara, CA) equipped with a negative feedback loop in the oscillator cavity to provide enhanced shot-to-shot stability. The $1064 \mathrm{~nm}$ beam had a pulse width of $21 \mathrm{ps}$ and operated at a repetition rate of $20 \mathrm{~Hz}$. It was used to pump an 
optical parametric generator/oscillator (OPG/OPA) stage (Laser Vision, Bellevue, WA) that produced the $532 \mathrm{~nm}$ and tunable infrared input beams $\left(2800 \mathrm{~cm}^{-1}\right.$ to $\left.3600 \mathrm{~cm}^{-1}\right)$ used in these experiments. All sum frequency spectra presented here have been taken with the SSP polarization combination, referring to the sum frequency, visible, and infrared beams, respectively. Each data set was normalized to spectra taken from a piece of Z-cut crystalline quartz.

\section{Total internal reflection florescence microscopy}

All protein solutions were prepared in phosphate buffered saline (PBS) $(0.05 \mathrm{M}$ $\mathrm{NaH}_{2} \mathrm{PO}_{4} ; 0.15 \mathrm{M} \mathrm{NaCl}$ ) at $\mathrm{pH}$ 8.0. Alexa Fluor-594 dye was used to label the fibrinogen for TIRFM. To minimize the effect of the dye on the adsorption properties, the labeling degree was kept to 0.7 dyes/protein. Alexa-594 HPF was employed at a concentration of $0.5 \mu \mathrm{g} / \mathrm{ml}$. Samples consisted of a silica substrate surrounded by simple polydimethylsiloxane walls to prevent solutions from spilling off the surface. A cover slip could be place over the top to prevent evaporation. To begin an experiment, Alexa594 HPF was allowed to adsorb onto the substrate from a protein solution for $20 \mathrm{~min}$. The bulk solution was then rinsed away with PBS at $\mathrm{pH}$ 8.0. This process and subsequent displacement experiments were monitored via total internal reflection fluorescence microscopy using a Nikon E800 fluorescence microscope equipped with a Micromax 1024 CCD camera (Princeton Instruments). All images were acquired under a 10X objective. TIRFM was performed by reflecting a $1 \mathrm{~mW} 594 \mathrm{~nm}$ Helium-Neon laser beam (Uniphase Manteca, CA) off the sample/solution interface using a dove prism setup which was optically coupled to the back side of the planar silica substrate through 
immersion oil. Displacement studies were performed by replacing the buffer with diluted human plasma, which was incubated over the surface for the duration of the experiment.

\section{RESULTS}

\section{Protein displacement kinetics}

To investigate fibrinogen displacement kinetics, silica samples were coated with fluorescently labeled HPF by introducing a $0.5 \mu \mathrm{g} / \mathrm{ml}$ protein solution in PBS at $\mathrm{pH} 8.0$ over the substrate. The solution was allowed to incubate for 20 minutes and then replaced with pure buffer. Next, 5\% human plasma was incubated over the surface and the displacement rate of the labeled HPF was monitored as a function of time using TIRFM. As can be seen from the data, the fibrinogen was displaced from the interface as a function of time in an exponentially decaying manner (Figure 20, •). ${ }^{109}$ Roughly $80 \%$ was removed after 90 minutes. On the other hand, hardly any protein was displaced from the surface if only buffer was introduced instead of the $5 \%$ plasma solution (Figure 20, $\mathbf{\nabla}$ ). Finally, the displacement rate was probed under conditions that should allow the $\alpha \mathrm{C}$ domains to be detached from the $\mathrm{E}$ domains and then subsequently reattached. ${ }^{107}$ This was accomplished by replacing the $\mathrm{pH} 8.0$ buffer with a similar PBS solution at $\mathrm{pH} 3.2$ and then rinsing again with $\mathrm{pH} 8.0$ buffer before attempting to displace the surface adsorbed HPF with 5\% human plasma (Figure 20, o). The results from this final kinetics experiment showed a severe attenuation in the amount of protein 


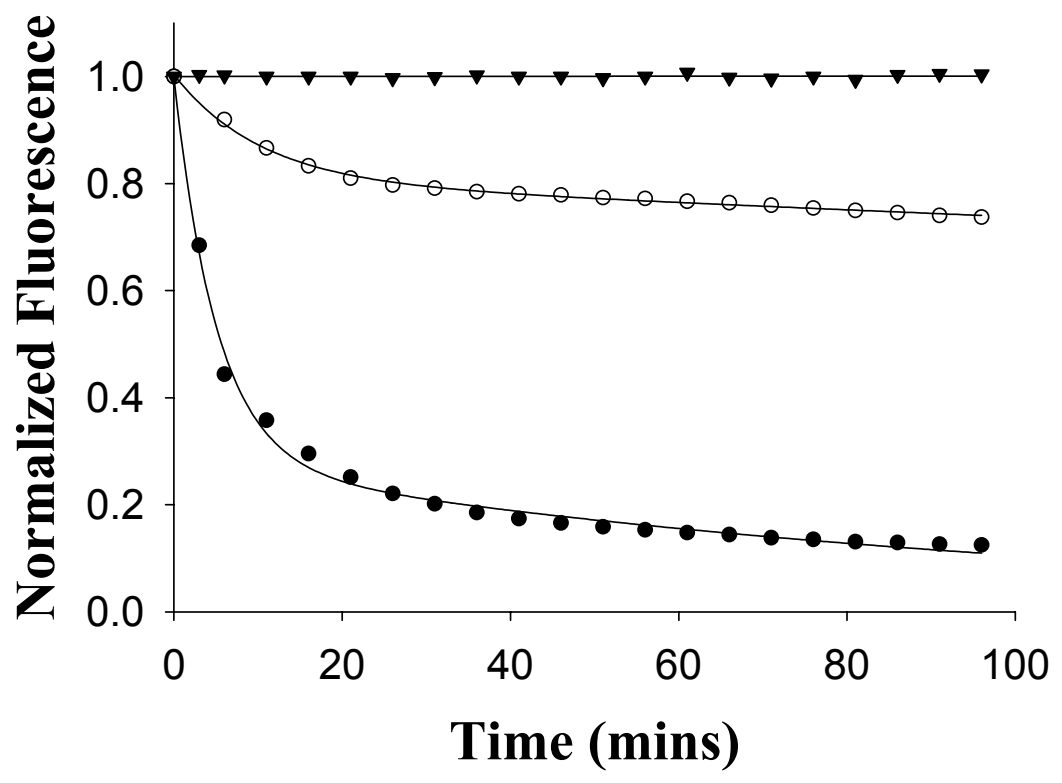

Figure 20. Displacement of Alexa 594-labeled fibrinogen from a silica surface by a 5\% human plasma solution. The closed circles $(\bullet)$ indicate experiments with $5 \%$ human plasma after only exposing the sample to PBS at pH 8.0. The open circles (o) show displacement kinetics with 5\% human plasma after $\mathrm{pH}$ cycling through 3.2 and back to 8.0. The inverted triangles $(\boldsymbol{\nabla})$ represent a control experiment where only buffer was introduced over the HPF coated surface. 
that could be displaced from the surface. The data sets taken with $5 \%$ plasma could be fit to double exponential decay curves:

$$
y=a_{1} e^{-t / \tau_{1}}+a_{2} e^{-t / \tau_{2}}
$$

where $\mathrm{t}$ is time, $\mathrm{y}$ is the fluorescence intensity, $\mathrm{a}_{1}$ and $\mathrm{a}_{2}$ are coefficients between 0 and 1 such that $\mathrm{a}_{1}+\mathrm{a}_{2}=1$, and $\tau_{1}$ and $\tau_{2}$ are the time constants. All data sets were repeated 5 times. Fitting the data and averaging gave the time constants and surface fractions of the fast and slow exchange components (table 1).

Table 1. The time constant and surface fraction of the fast and slow exchange components

\begin{tabular}{|l|l|l|}
\hline & $\begin{array}{l}\text { First time constant }\left(\tau_{1}\right) \text { and } \\
\text { coefficient }\left(\mathrm{a}_{1}\right)\end{array}$ & $\begin{array}{l}\text { Second time constant }\left(\tau_{2}\right) \text { and } \\
\text { coefficient }\left(\mathrm{a}_{2}\right)\end{array}$ \\
\hline pH 8.0 sample & $5.3 \pm 2.3 \mathrm{~min} .(0.72 \pm .01)$ & $196 \pm 98 \mathrm{~min} .(0.28 \pm .01)$ \\
\hline pH cycled sample & $6.7 \pm 3.5 \mathrm{~min} .(0.20 \pm .02)$ & $909 \pm 372 \mathrm{~min} .(0.80 \pm .02)$ \\
\hline
\end{tabular}

As indicated, $72 \%$ of the protein from the standard $\mathrm{pH} 8.0$ sample can be displaced with a time constant, $\tau_{1}$, of just over 5 minutes. Furthermore, the $\mathrm{pH}$ cycled sample shows nearly the identical $\tau_{1}$ value, but the surface concentration of this fraction was reduced to just $20 \%$. There is a reasonable fraction of protein that is more difficult to remove, even on the sample that wasn't exposed to acidic conditions (28\%). Substrate defects, trace surface impurities, differences in the orientation of the protein at the interface, as well as other factors may all potentially contribute to this slow component, $\tau_{2}$. Significantly, $\tau_{2}$ is substantially affected by $\mathrm{pH}$ cycling. Indeed, the 909 min time constant seems to reflect a restructuring of the adsorbed protein and the majority of HPF molecules $(80 \%)$ 
now fell under the slow classification. To elucidate the origin of the $\mathrm{pH}$ cycling effect, atomic force microscopy, immunochemistry, and vibrational sum frequency experiments were performed.

Atomic force microscopy and immunochemistry

HPF was imaged by atomic force microscopy at the silica/buffer interface. Various concentrations of protein solution in PBS at $\mathrm{pH} 8.0$ was flowed over a planar silica substrate, incubated for 20 minutes and replaced with pure buffer before an image was obtained. Figure 21 shows HPF images with different bulk concentrations. Surface coverage of protein was linearly dependent on the bulk concentration of protein. While the coverage of the protein film on the surface was about $32 \%$ at $5 \mu \mathrm{g} / \mathrm{ml}$ of protein concentration as shown in Figure 21a, $1.5 \mu \mathrm{g} / \mathrm{ml}$ of bulk protein gives $7.5 \%$ of surface coverage. (Figure 21b) When $0.5 \%$ of protein solution was introduced (Figure 21c), approximately $2.5 \%$ of the substrate was found to be covered with protein. A close-up picture of a typical fibrinogen molecule is shown in Figure 22a. Wider field AFM images as a function of protein concentration are provided in the supplementary section of this paper. The average length of the adsorbed molecules was $59.8 \mathrm{~nm} \pm 3.4 \mathrm{~nm}$. This number is approximately 30\% larger than the value obtained from electron microscope ${ }^{110}$ mostly because of convolution with the finite-sized AFM tip and perhaps also because of a small amount of surface spreading by the protein.

The three main domains of HPF (one central E domain and two D domains) were clearly identifiable. The height of the D domains averaged $2.7 \pm 0.2 \mathrm{~nm}$, while the $\mathrm{E}$ 
(a)

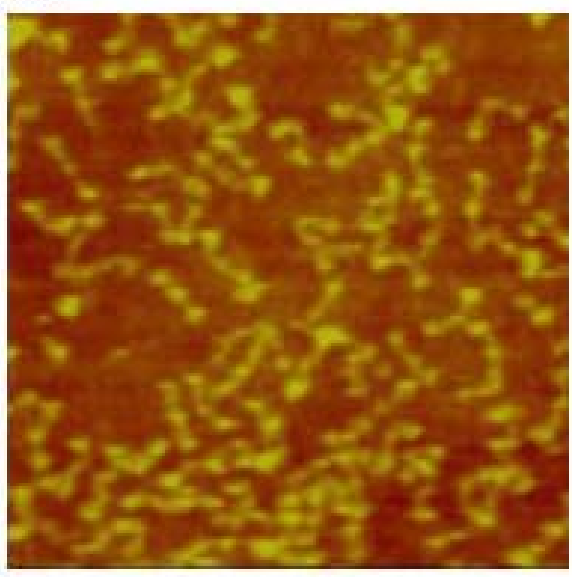

(c)

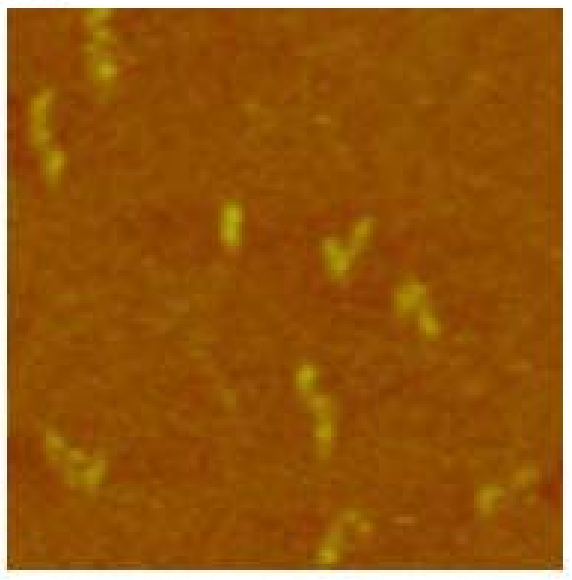

(b)

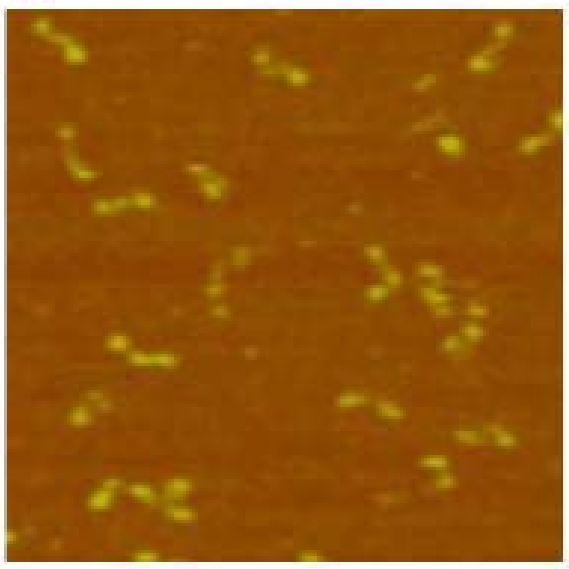

Figure 21. AFM images of HPF on silica surface at $5 \mu \mathrm{g} / \mathrm{ml}$ (a), $1.5 \mu \mathrm{g} / \mathrm{ml}$ (b) and 0.5 $\mu \mathrm{g} / \mathrm{ml}$ (c). Images were obtained after washing out protein solution with pure PBS. Each image is $500 \mathrm{~nm} \times 500 \mathrm{~nm}$ on a side. 


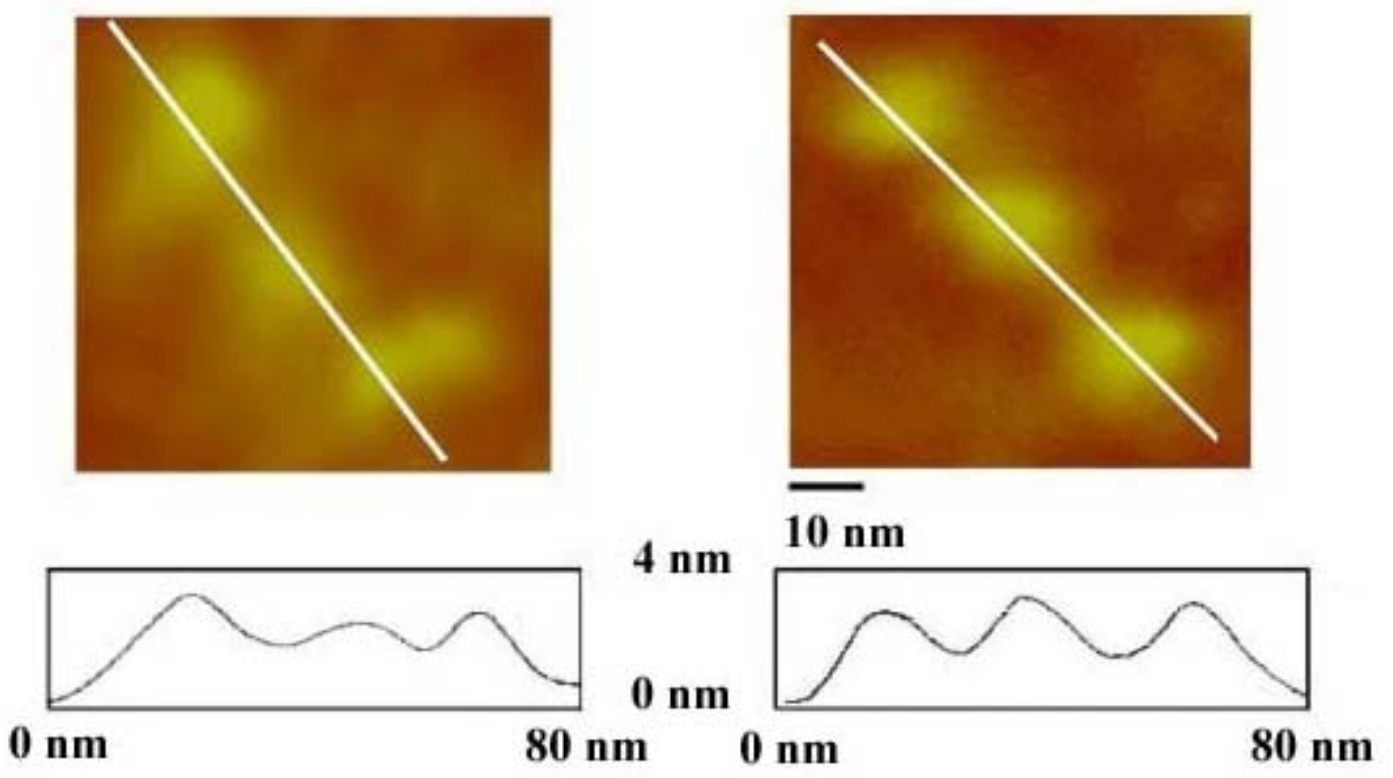

Figure 22. AFM images of a single HPF molecule adsorbed at the silica/buffer interface (a) at $\mathrm{pH} 8.0$ and (b) at $\mathrm{pH} 8.0$ after cycling to $\mathrm{pH} 3.2$. The line profiles for height vs. position (from the white lines) are shown below each image. 
domain was $2.3 \pm 0.4 \mathrm{~nm}$. These numbers are in good agreement with previous data from hydrophilic mica surfaces. ${ }^{111}$ At this point, the $\mathrm{pH}$ of the solution was lowered to $\mathrm{pH}$ 3.2. Images of adsorbed HPF under these conditions showed little change from the initial conditions at 8.0; however, substantial changes were noted when the $\mathrm{pH}$ was cycled back to 8.0 (Figure 22b). As can be seen, the central E domain was raised significantly, while the D domains showed only minor changes. Specifically, the heights of the D domains were still the same $(2.6 \pm 0.3 \mathrm{~nm})$ within experimental error, whereas the E domains increased to $3.4 \pm 0.4 \mathrm{~nm}$. (Appendix I) The single molecule experiment was repeated dozens of times and the $\sim 1 \mathrm{~nm}$ height increase of the E domain with little change in the D domains occurred roughly $80 \%$ of the time. The other $20 \%$ of the time, little or no changes were observed in either the D or E domains. The presence of the minority component is in good agreement with the kinetic experiments, which also showed the presence of two populations.

The AFM studies suggested that for the majority of the HPF, the $\alpha \mathrm{C}$ domains migrated from the silica interface to the top of the $\mathrm{E}$ domain after $\mathrm{pH}$ cycling. To verify this conclusion, immunochemical assays were performed. $5 \mu \mathrm{g} / \mathrm{ml}$ of HPF was deposited onto the surface of three silica samples under the same conditions used above. In the first, the $\mathrm{pH}$ was cycled to 3.2 and back to 8.0. To prevent the nonspecific binding, the exposed area was protected by adsorption of $100 \mu \mathrm{g} / \mathrm{ml}$ of Rabbit IgG for 20 minutes. A $150 \mu \mathrm{g} / \mathrm{ml}$ solution of dye labeled anti fibrinogen IgG raised against the $\alpha \mathrm{C}$ domains (peptide sequence A $\alpha$ 529-539) of HPF was introduced above the substrate for 20 minutes and washed away. The results showed a significant amount of binding of the 


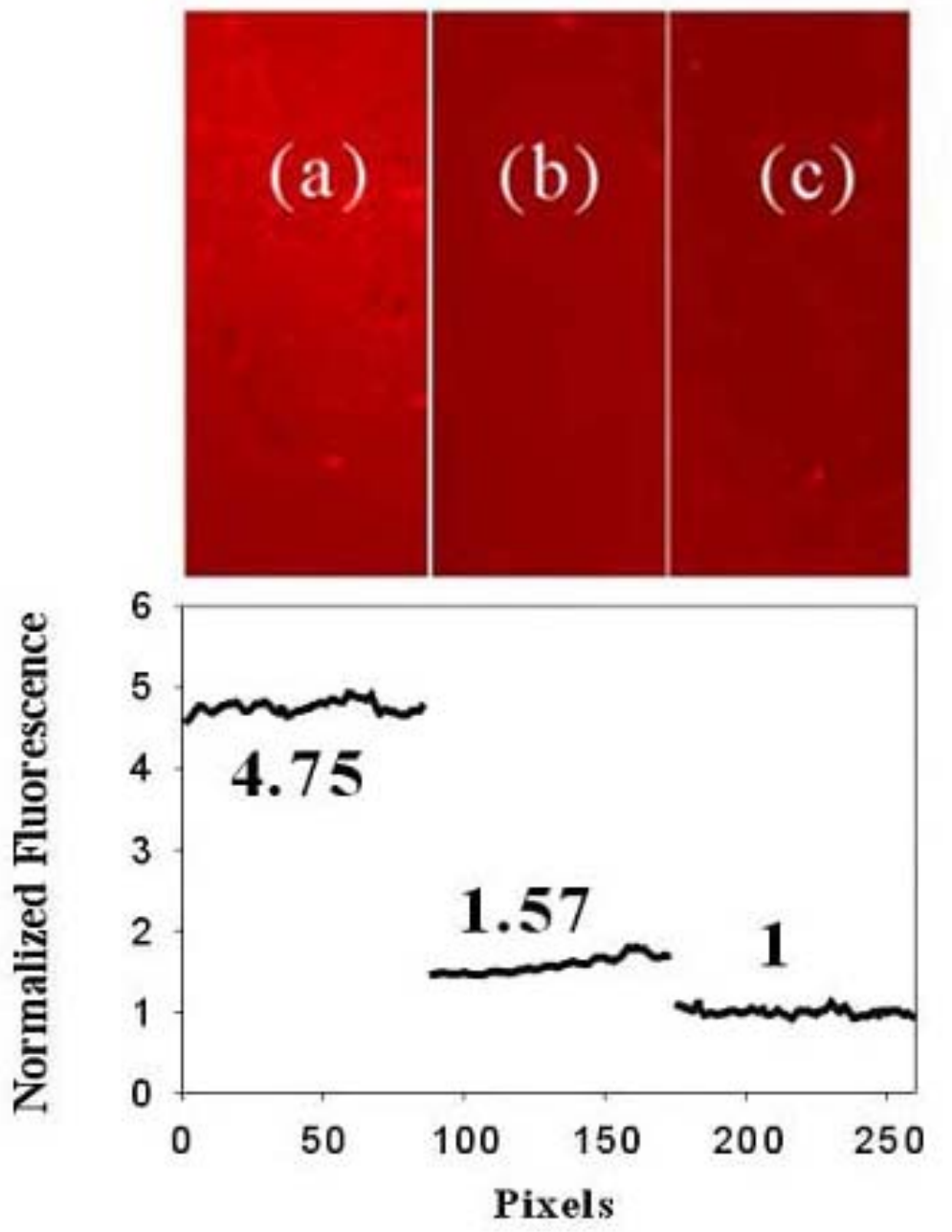

Figure 23. Fluorescence images of Alexa 594-labeled anti-fibrinogen (anti- $\alpha \mathrm{C}$ domain) antibody applied to (a) an HPF coated surface after pH cycling, (b) an HPF coated surface at $\mathrm{pH} 8.0$ without $\mathrm{pH}$ cycling and (c) a silica surface without HPF. 
$\operatorname{IgG}$ at the interface as indicated by the high fluorescence signal (Figure 23a). The binding experiment was repeated with the second sample without $\mathrm{pH}$ cycling (Figure 23b). In this case, the binding was substantially reduced. Finally, a control experiment was performed by adding the IgG over a substrate surface that was not coated with protein (Figure 23c). Subtracting the non-specific background found in this third experiment from the data in the first two and taking the ratio of these revealed that 6.6 times as much $\operatorname{IgG}$ was specifically adsorbed after $\mathrm{pH}$ cycling than before cycling. Quantitative fluorescence measurement was performed and showed that $\sim 75$ antibodies non-specifically adsorbed per square micron. (Data and calculation are shown in Appendix II) In other words, the accessibility of the $\alpha \mathrm{C}$ domains to the $\operatorname{IgG}$ was substantially increased upon cycling. In fact, the $\alpha \mathrm{C}$ domains are almost certainly at least somewhat beneath the rest of the protein upon initial HPF adsorption, since they are inaccessible to the IgG. They should also be directly bound to the E domain. ${ }^{107}$ Once the $\mathrm{pH}$ was lowered to 3.2, however, these moieties became unbound from the $\mathrm{E}$ domain, which allowed the rest of the protein to come into direct contact with the silica surface. When the $\mathrm{pH}$ was subsequently raised to 8.0 , these species were forced to rebind to the $\mathrm{E}$ domain from the top side of the molecule as the bottom was no longer accessible (Figure 24). 

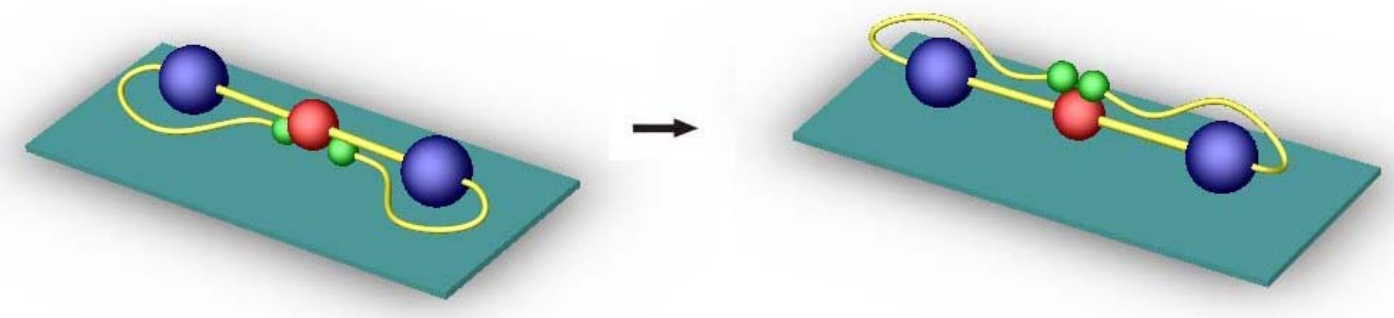

Figure 24. The proposed mechanism for interfacial HPF rearrangement upon $\mathrm{pH}$ cycling. 
Vibrational sum frequency spectroscopy

VSFS is a surface specific vibrational spectroscopy that can be employed to probe interfacial protein alignment and water structure even in the presence of an overwhelming contribution from bulk aqueous solution. ${ }^{31,12-115}$ Experiments were carried out by first introducing protein free $\mathrm{pH}$ 8.0 PBS into a flow cell. An SFS spectrum of the silica/water interface in the $\mathrm{OH}$ stretch region of the vibrational spectrum $\left(2800-3600 \mathrm{~cm}^{-1}\right)$ is shown in Figure 25a. The two peaks visible near 3200 $\mathrm{cm}^{-1}$ and $3400 \mathrm{~cm}^{-1}$ correspond to water molecules with tetrahedrally coordinated structure and water with less ordered bonding, respectively. ${ }^{35,116,117}$ The interfacial water is ordered by the charged hydrophilic silica surface. At this point $5.0 \mu \mathrm{g} / \mathrm{ml} \mathrm{HPF}$ was flowed into the cell, allowed to incubate for 20 minutes, and washed out with pure buffer. The surface coverage of fibrinogen was approximately $32 \%$ as judged by additional AFM measurements as already shown. The VSFS spectrum showed dramatic changes under these conditions (Figure 25b). Specifically, the $3200 \mathrm{~cm}^{-1}$ feature increased in intensity and shifted upward in frequency to near $3270 \mathrm{~cm}^{-1}$. Such a result is very atypical for $\mathrm{OH}$ stretch peaks from water at a hydrophilic interface upon the adsorption of a net negatively charged protein. ${ }^{29}$ In fact, the charged macromolecules and their counter ions should cause a suppression of the water features under these circumstances due to charge screening. This is strong evidence that an additional feature is convoluted with the water peaks. 

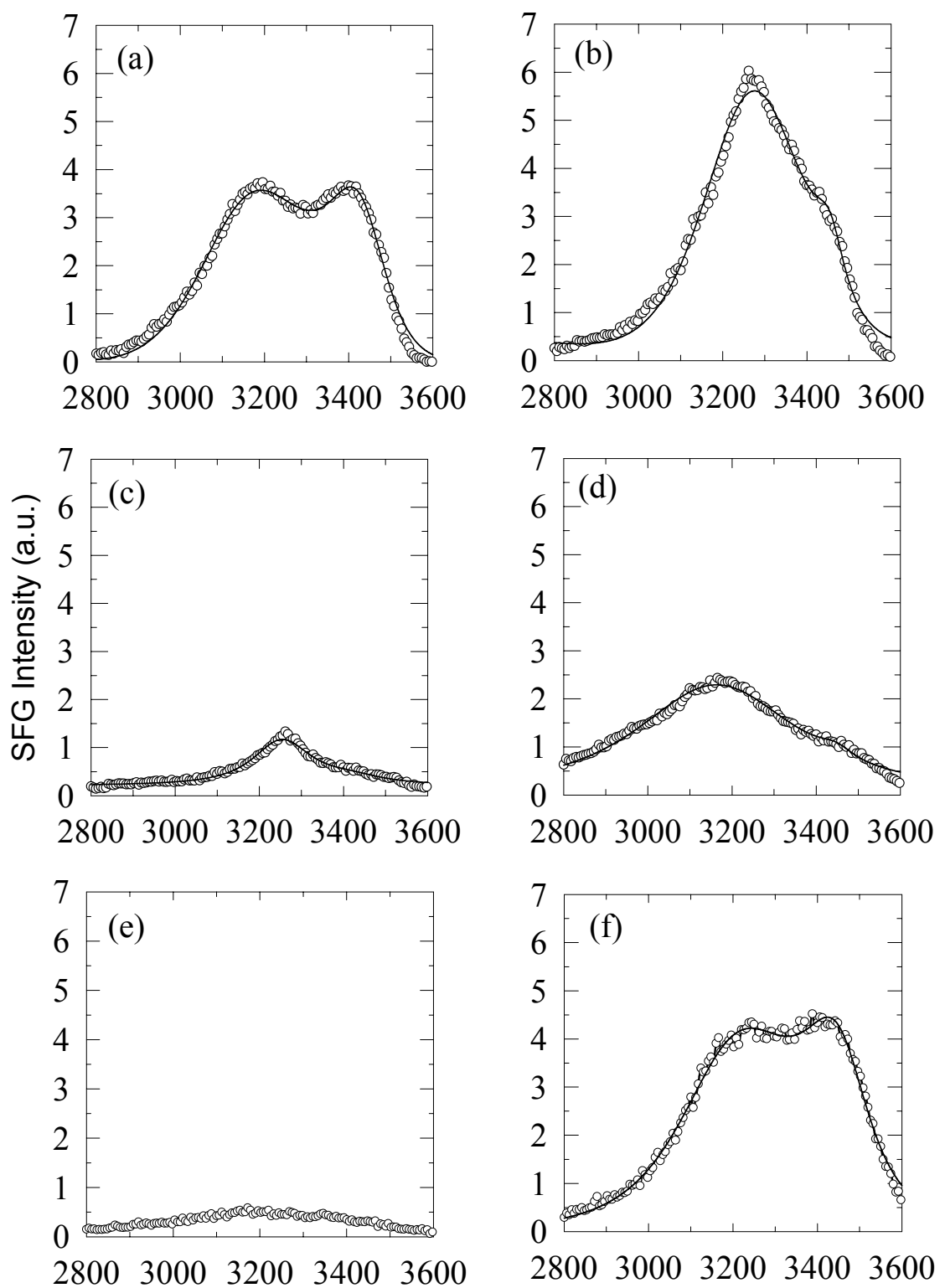

\section{Wavenumber $\left(\mathrm{cm}^{-1}\right)$}

Figure 25. Sum frequency spectra of (a) a bare silica/water interface at $\mathrm{pH} 8.0$, (b) an HPF coated surface at $\mathrm{pH}$ 8.0, (c) an HPF coated surface at $\mathrm{pH} 5.5$, (d) an HPF coated surface at $\mathrm{pH} 3.2$, (e) an HPF coated surface at $\mathrm{pH} 5.5$ after cycling to $\mathrm{pH} 3.2$, and (f) an HPF coated surface at $\mathrm{pH} 8.0$ after cycling to $\mathrm{pH} 3.2$. 
The additional peak could be revealed by lowering the system's $\mathrm{pH}$ to the isoelectric point near $\mathrm{pH} 5.5,{ }^{108}$ which almost completely eliminated the signal from organized water molecules (Figure 25c). In this case a small sharp feature near 3270 $\mathrm{cm}^{-1}$ was revealed, which can be assigned to the $\mathrm{NH}$ stretch of aligned primary amine moieties on Lys residues and the related NH stretches on Arg. ${ }^{118}$ Confirmation that this was not an $\mathrm{OH}$ stretch peak was obtained by repeating all the experiments in $\mathrm{H}_{2}{ }^{18} \mathrm{O}$ and noting that the $3270 \mathrm{~cm}^{-1}$ feature hardly moved while the $\mathrm{OH}$ peaks red shifted by $\sim 12$ $\mathrm{cm}^{-1}$, as expected. The spectra at $\mathrm{pH} 5.5$ and 8.0 were shown to be completely reversible by $\mathrm{pH}$ cycling between them; however, when the $\mathrm{pH}$ was subsequently cycled through 3.2 (Figure 25d), both the $\mathrm{pH} 5.5$ and 8.0 spectra were changed irreversibly (Figures 25e\&f) and the NH stretch peak disappeared. The presence of an NH stretch upon initial protein adsorption is direct molecular level evidence that Lys and Arg residues become highly oriented at the negatively charged silica interface. Indeed, such orientation is also in excellent agreement with the idea that adsorption via the $\alpha \mathrm{C}$ domains is largely electrostatic in nature. It should be noted that when the VSFS experiments were repeated at lower concentration of $\mathrm{HPF}$, that the NH stretch signal became substantially weaker. Since most of the fibrinogen molecules still remained distinct from each other at $32 \%$ surface coverage, there is little reason to suspect that the $\mathrm{NH}$ stretch peak is the result of protein-protein interactions. Indeed, no major changes in the peak intensity were observed when very high concentrations $(50 \mu \mathrm{g} / \mathrm{ml})$ of HPF were employed. Under these last conditions all protein molecules are in contact with their neighbors at the interface. Finally, it should be mentioned that no $\mathrm{CH}$ stretch peaks were observed in 
these spectra, which probably indicated that a high degree of alignment was not achieved for residues other than Arg and Lys. In fact, $\mathrm{CH}$ alignment from proteins ${ }^{31}$ and polymers $^{32}$ at the silica/buffer interface has typically been found only at high $\mathrm{pH}$ (e.g. 912) where the electric field emanating from the surface was quite large. Even then, $\mathrm{CH}$ stretch observation was limited to cases where the macromolecules possessed a net positive charge.

\section{DISCUSSION}

The facile displacement of HPF from a silica interface is remarkable given the protein's large size. This property is clearly related to the $\alpha \mathrm{C}$ domain's ability to prevent other portions of the protein from making stronger contacts than those afforded by simple electrostatic binding between Arg/Lys residues and deprotonated surface silanols. In the somewhat analogous problem of analyte retention on chromatography columns, ${ }^{119-}$

121 the literature indicates that very long retention times on silica can be related to isolated surface silanol groups which afford strong hydrogen bonds. On the other hand, interactions with deprotonated silanols seem to be associated only with shorter retention times. In the case of proteins, strongly adsorbing species almost certainly interact with the substrate through hydrogen bonding, van der Waals, and related hydrophobic interactions. ${ }^{122}$ The key point for fibrinogen is that these types of interfacial contact can be substantially attenuated near physiological $\mathrm{pH}$ by the intervention of the positively charged $\alpha \mathrm{C}$ domains. 
The final issue to be addressed here is the role $\alpha \mathrm{C}$ domains play in HPF's function in vivo. It is well established that the cleavage of small peptides from the Cterminus of fibrinogen's $\alpha$ and $\beta$ polypeptides by thrombin forms the active protein, fibrin. $^{123}$ Fibrin readily cross-links to form a blood clot in a process known as thrombosis. It is believed that the $\alpha \mathrm{C}$ domains can perform a supporting role in maintaining a cross-linked fiber's integrity by interacting with other $\alpha \mathrm{C}$ domains on neighboring molecules. ${ }^{107,124}$ Since several of the steps in the blood clotting cascade can be accelerated by the presence of a phospholipid membrane, it is reasonable to consider whether the $\alpha \mathrm{C}$ domains may also play a role in keeping fibrinogen soluble in the bloodstream until it is needed. Indeed, many cell membranes are negatively charged and might be expected to interact with the positively charged portion of HPF. Such labile interactions might help prevent fibrinogen from strongly adsorbing to cell surfaces before conversion to fibrin has commenced. It would be curious if the Vroman effect for this molecule were a consequence of such a role for the $\alpha \mathrm{C}$ domains. Further experiments will be needed to test this hypothesis. 


\section{CHAPTER V}

\section{SPECTROSCOPIC EVIDENCE FOR THE NH STRETCHING: A FIBRINOGEN ADSORPTION ONTO FUSED SILICA}

\section{INTRODUCTION}

Adsorption of proteins at the solid/liquid interface involves the diffusion of the biopolymer from the bulk solution to the interface, surface denaturation and rearrangement of the adsorbed layer. ${ }^{125}$ It is important to understand these phenomena for modern technologies, such as immunology, ${ }^{126}$ pharmaceutical development, ${ }^{127}$ artificial implants ${ }^{5,127}$ and chemical/biological sensor design ${ }^{128,129}$. One of the most important proteins in regard to biocompatibility is human plasma fibrinogen (HPF), an abundant species in the blood stream with a concentration $\sim 3 \mathrm{mg} / \mathrm{ml}$. The X-ray crystal structure of fibrinogen is currently known to a resolution of $5.5 \AA .^{130}$ Fibrinogen is a fibrous macromolecule with dimensions of $90 \AA \times 450 \AA$ x $60 \AA$ and a molecular weight of $340 \mathrm{kD}$. It consists of two lateral $\mathrm{D}$ domains and one central $\mathrm{E}$ domain linked together by $\alpha$-helical coils and has an isoelectric point of $\sim 5.5$ (Figure 26a). Fibrinogen plays a major role in blood clotting by linking platelets together through its polymerization. $^{3}$ Several adsorption studies have been preformed with fibrinogen on various solid substrates, such as polymers, ${ }^{6}$ self assembled monolayers, ${ }^{131-133}$ and polyelectrolytes. $^{105}$ It has been shown that adsorption of HPF onto cell and man-made surfaces may lead to problems ranging from heart disease and inflammation to rejection of artificial implants. ${ }^{134}$ One interesting characteristic of fibrinogen is its unusual 
(a)

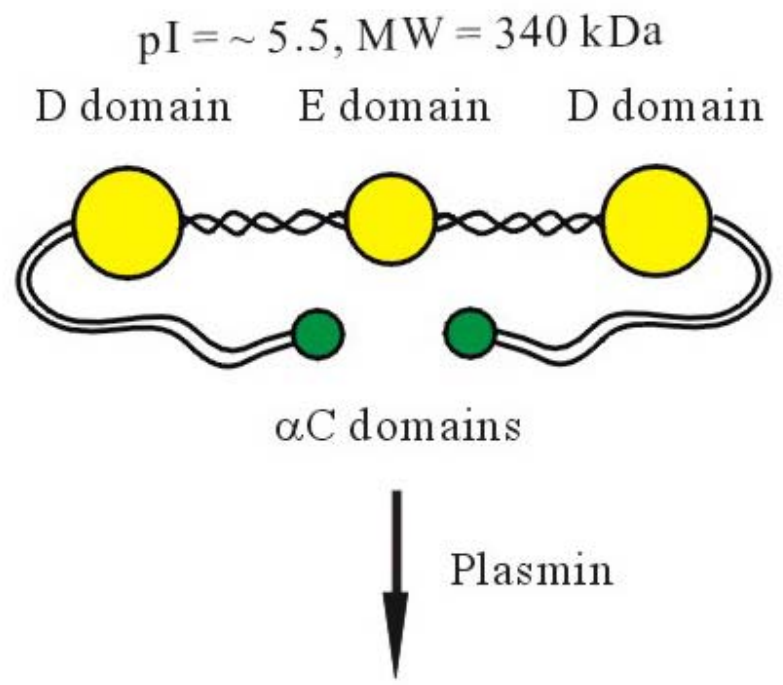

(b)
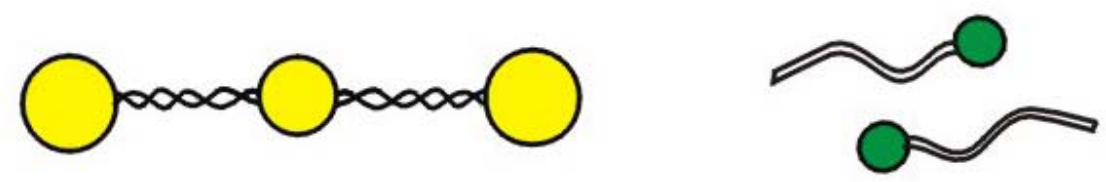

Fragment $\mathrm{X}, \mathrm{MW}=240 \mathrm{kDa} \quad \alpha \mathrm{C}$ domains, $\mathrm{MW}=50 \mathrm{kDa}$

Figure 26. Structure of fibrinogen (a) and fragment products cleaved by plasmin (b). 
behavior on implantable substrates during adsorption. In coexistence with other plasma proteins, such as kininogen, HPF is known to adsorb early in the processes. Later, however, it is displaced by other proteins, a phenomenon known as the Vroman effect. $^{7,99,100,126,135}$ Fibrinogen adsorbs less well and is more easily displaced from hydrophilic substrates than from hydrophobic substrates. ${ }^{136}$ Attempts have been made to follow conformational changes during the adsorption process. ${ }^{134,137,138}$ For example, ATR-FTIR experiments have been performed, but no definitive information was obtained about the vibrational modes of the various functional groups. ${ }^{137,139}$

Very recently, our laboratory employed a combination of surface specific techniques to probe the conformational changes of adsorbed HPF as a function of $\mathrm{pH} .{ }^{140}$ A combination of vibrational sum frequency spectroscopy (VSFS), atomic force microscopy (AFM), and immunochemical assays revealed that fibrinogen undergoes a dramatic change in conformation at the silica/aqueous interface upon cycling the $\mathrm{pH}$ from 8.0 down to 3.2 and then back to 8.0. Specifically, it was found that the $\alpha \mathrm{C}$ domains of this protein were initially adsorbed toward the surface, protecting the rest of the molecule from intimate surface contact. However, when the bulk $\mathrm{pH}$ is cycled to 3.2, the $\alpha \mathrm{C}$ domains of this molecule became detached from the central $\mathrm{E}$ domain allowing the rest of the protein to make direct surface contact. Raising the $\mathrm{pH}$ back to 8.0 forced rebinding to occur between the $\alpha \mathrm{C}$ domains and $\mathrm{E}$ domain on the side of the macromolecule facing away from the substrate. This change in binding location was directly related to the rate at which the protein could be displaced from the interface by 
other proteins in human plasma. Namely, the displacement was rapid before $\mathrm{pH}$ cycling and became slow afterwards.

Based on the above work, we wished to extend our studies of the fibrinogen adsorption process. We elected to enzymatically cleave HPF into its fragment $\mathrm{X}$ and $\alpha \mathrm{C}$ domain components (Figure 26b). Studies with these fragments revealed that the $\alpha \mathrm{C}$ domains were largely responsible for observed changes in the $\mathrm{NH}$ and $\mathrm{OH}$ stretch region of VSFS spectra. In fact, it could be demonstrated though isotropic shift studies with $\mathrm{H}_{2}{ }^{18} \mathrm{O}$, that an additional feature was present at the interface only in the presence of the $\alpha \mathrm{C}$ domains, but not from fragment $\mathrm{X}$. This resonance, an NH stretch, appeared around $3270 \mathrm{~cm}^{-1}$

\section{EXPERIMENTAL SECTION}

Instrumentation

VSFS experiments were performed with a passive-active mode-locked Nd:YAG laser (PY61c, Continuum, Santa Clara) equipped with a negative feedback loop in the oscillator cavity to provide enhanced shot-to-shot stability. The $1064 \mathrm{~nm}$ beam had a pulse width of $21 \mathrm{ps}$ and operated at a repetition rate of $20 \mathrm{~Hz}$. It was used to pump an optical parametric generator/oscillator (OPG/OPA) stage (Laser Vision, Bellevue, WA) that generated the $532 \mathrm{~nm}$ and tunable infrared input radiation $\left(2800 \mathrm{~cm}^{-1}\right.$ to $\left.3600 \mathrm{~cm}^{-1}\right)$ used in these experiments. The IR and the visible beams were concentrically overlapped at the sample interface with incident angles of $51^{\circ}$ and $42^{\circ}$, respectively, with respect to the surface normal. All sum frequency spectra presented in herein were taken with the 
SSP polarization combination, referring to the sum frequency, visible, and infrared beams, respectively. Each data set was normalized to spectra taken from a piece of Zcut crystalline quartz.

Both the experimental and theoretical details of vibrational sum frequency spectroscopy have been described elsewhere. ${ }^{36,49,50}$ Briefly, a sum frequency response is elicited, in the dipole approximation, only in media that lack inversion symmetry. In systems where the bulk is isotropic, the overwhelming majority of the signal is obtained at interfacial boundaries where inversion symmetry is necessarily broken. Vibrational spectra are produced in VSFS experiments through resonance enhancements that occur as the infrared beam is tuned over vibrational modes of the surface species. As shown in equation (1), the sum frequency signal, $I_{S F S}$, is proportional to the square of the second order nonlinear susceptibility, $\chi^{(2)}$. $\chi^{(2)}$ can be broken into two parts, a frequency dependent resonant term, $\chi_{R}^{(2)}$, and a nonresonant term, $\chi_{N R}^{(2)}$ :

$$
I_{S F S} \propto\left|\chi^{(2)}\right|^{2} I_{v i s} I_{I R}=\left|\chi_{R}^{(2)}+\chi_{N R}^{(2)}\right|^{2} I_{v i s} I_{I R}
$$

where, $I_{v i s}$ and $I_{I R}$ denote the visible and IR beam intensities, respectively. The resonant term can be expressed as follows:

$$
\chi_{R_{n}}^{(2)}=\sum_{n} \frac{A_{n}}{\omega_{I R}-\omega_{n}+i \Gamma_{n}}
$$

where $A_{n}, \omega_{n}, \omega_{I R}$, and $\Gamma_{n}$ are the oscillator strength, resonant frequency, frequency of the IR beam, and damping constant of the $n^{\text {th }}$ vibrational resonant mode, respectively. $A_{n}$ is the product of the infrared and Raman transition dipole moments, their orientational vector average, as well as their number density at the interface. The vast 
majority of the signal is derived from an ordering of dipoles, which occurs readily at interfaces.

Materials

Human plasma fibrinogen was purchased from Sigma. The concentrations of HPF solutions were determined by absorption measurements at $280 \mathrm{~nm}$ in a UV/visible spectrometer. To prepare $\alpha \mathrm{C}$ domains $(40 \mathrm{kD})$ and the fragment of fibrinogen without $\alpha \mathrm{C}$ domains (fragment $\mathrm{X}$ ), fibrinogen $(20 \mathrm{mg} / \mathrm{ml})$ in a $10 \mathrm{mM}, \mathrm{pH} 7.2$ phosphate buffered saline (PBS) solution was digested with plasmin (0.02 caseinolytic unit/ml, United States Biological, Swampscott, MA) at $25^{\circ} \mathrm{C}$ for 6 hours. ${ }^{107}$ After cleavage, $1 \mathrm{mM}$ of 4-(2Aminoethyl) benzenesulfonylfluoride, $\mathrm{HCl}$ (AEBSF, Calbiochem, San Diego, CA) was used as a protease inhibitor to stop the reaction. The fragments were purified and separated by an AKTA FPLC (Amersham Biosciences, Piscataway, NJ) with a Superdex 200 HR 10/30 size exclusion column. Ultrapure water from a NANOpure Ultrapure Water System (Barnstead, Dubuque, IA) with minimum resistivity of $18 \mathrm{M} \Omega \cdot \mathrm{cm}$ was used to prepare samples and clean all apparatus during these experiments.

Buffers at $\mathrm{pH} 3.2,5.5$ and 8.0 were made by dissolving appropriate amounts of sodium phosphate into solution. The $\mathrm{pH}$ was adjusted to within $0.1 \mathrm{pH}$ units of the desired value by adding $\mathrm{HCl}$ or $\mathrm{NaOH}$. Sufficient $\mathrm{NaCl}$ was added to all buffers to raise the total ionic strength to $0.030 \mathrm{M}$. For isotopic labeling studies, $95 \%$ enriched $\mathrm{H}_{2}{ }^{18} \mathrm{O}$ was used. This was purchased from Medical Isotopes (Pelham, NH). A flow cell was designed by sandwiching a glass cover slip and a quartz disc on either side of a $2 \mathrm{~mm}$ thick poly(dimethylsiloxane) (PDMS) slap with an $11 \mathrm{~mm}$ diameter hole. (Figure 27) 
The volume of the flow cell was $200 \mu \mathrm{l}$ and experiments were carried out by first introducing all HPF solutions at $\mathrm{pH}$ 8.0. After 20 minutes of incubation, excess fibrinogen was carefully rinsed away with a $\mathrm{pH} 8.0$ buffer. Sum frequency spectra were obtained both before and after rinsing out excess fibrinogen. Very little difference was noted between these two sets of spectra and, therefore, only spectra after rinsing are presented here. Ellipsometry measurement confirmed that little change in protein layer thickness occurred upon rinsing. ${ }^{141}$

Data acquisition

A data acquisition program written in Labview 5.0 (National Instruments, Austin, TX) was used to acquire spectra for each experiment. The fitting of each VSFS spectrum was performed with a Voigt profile by a program written in MatLab version 5.3 with the optimization toolbox version 2.0 (Mathworks Inc, Natick, MA). After collection, the data were transferred to SigmaPlot 2001 for further treatment.

\section{RESULTS AND DISCUSSION}

\section{Time dependence of fibrinogen adsorption}

To determine the timescale for fibrinogen adsorption/rearrangement at the silica/water interface, time dependent adsorption experiments were performed. First, PBS was flowed into the cell at $\mathrm{pH} 8.0$. Next, $0.01 \mathrm{mg} / \mathrm{ml}$ fibrinogen at $\mathrm{pH} 8.0$ was introduced and the intensity $3270 \mathrm{~cm}^{-1}$ was continuously monitored (Figure 28). This frequency was chosen because it shows the most 


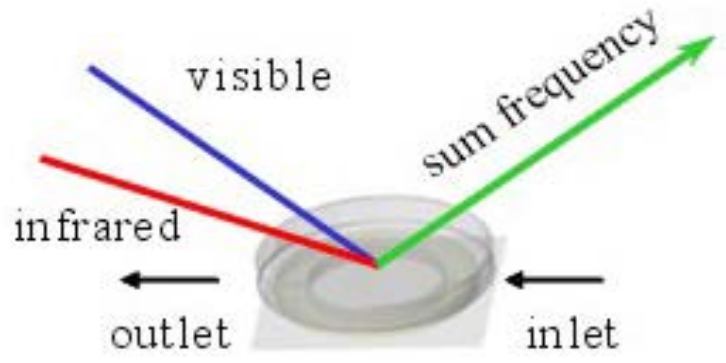

Figure 27. Diagram of a flow cell used for adsorption studies of fibrinogen at the silica/water interface. The laser beams used in the VSFS experiments are shown with their approximate geometry. 
dramatically change upon fibrinogen adsorption. ${ }^{140}$ After approximately 12 minutes, the intensity reached a plateau which indicated that the fibrinogen adsorption/rearrangement process had finished. Therefore, in all subsequent experiments we waited at least 20 minutes after the initial adsorption to ensure that steady state had been reached.

\section{Fibrinogen adsorption}

Figure 29 shows sum frequency spectra in the $\mathrm{OH}$ stretch region at the quartz/water interface both before and after HPF adsorption at various $\mathrm{pH}$ values. Figures 29a, 29c, and 29e are from the bare silica/water interface and are shown for reference. On the other hand Figure 29b, 29d, and 29f represent data taken after fibrinogen adsorption. It should be noted that all fibrinogen adsorption experiments were performed at $\mathrm{pH}$ 8.0. The bulk $\mathrm{pH}$ was adjusted to the desired value only after rinsing away excess protein. The peaks in the spectra from bare quartz were identified in previous studies. $35,116,117,142$ Two features are seen in each spectrum before adsorption. The first near $3200 \mathrm{~cm}^{-1}$ is associated with the $\mathrm{OH}$ stretch of interfacial water tetrahedrally coordinated to neighboring molecules. The feature near $3450 \mathrm{~cm}^{-1}$ is from water molecules that lack a full complement of hydrogen bonds, and is, hence, somewhat disordered with respect to the first species. Recently, our laboratory has been able to demonstrate that this higher frequency peak is associated with water species directly adjacent to the silica/water interface. ${ }^{143}$ It is the juxtaposition of these waters with the underlying silanol terminated surface which prevents them from forming a full complement of hydrogen bonds. On the other hand, the next layer of water molecules is capable of tetrahedral coordination, which gives rise to the $3200 \mathrm{~cm}^{-1}$. The intensity of 


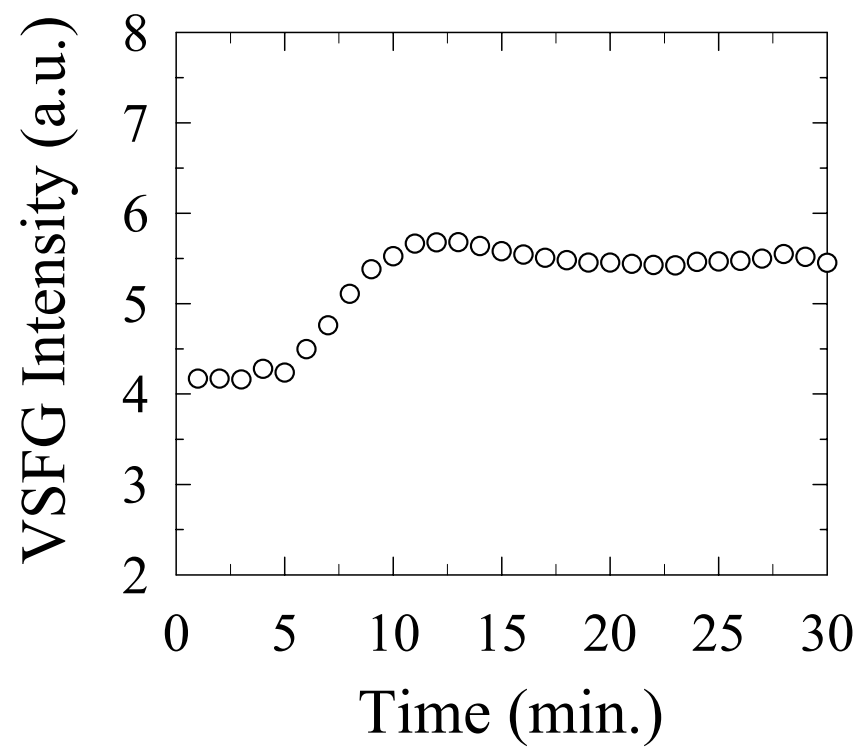

Figure 28. Sum frequency intensity at $3270 \mathrm{~cm}^{-1}$ monitored during the adsorption of fibrinogen at $\mathrm{pH} 8.0$ from a $0.01 \mathrm{mg} / \mathrm{ml}$ protein solution. The fibrinogen solution was introduced at $\mathrm{t}=5 \mathrm{~min}$. 


\section{Before adsorption}
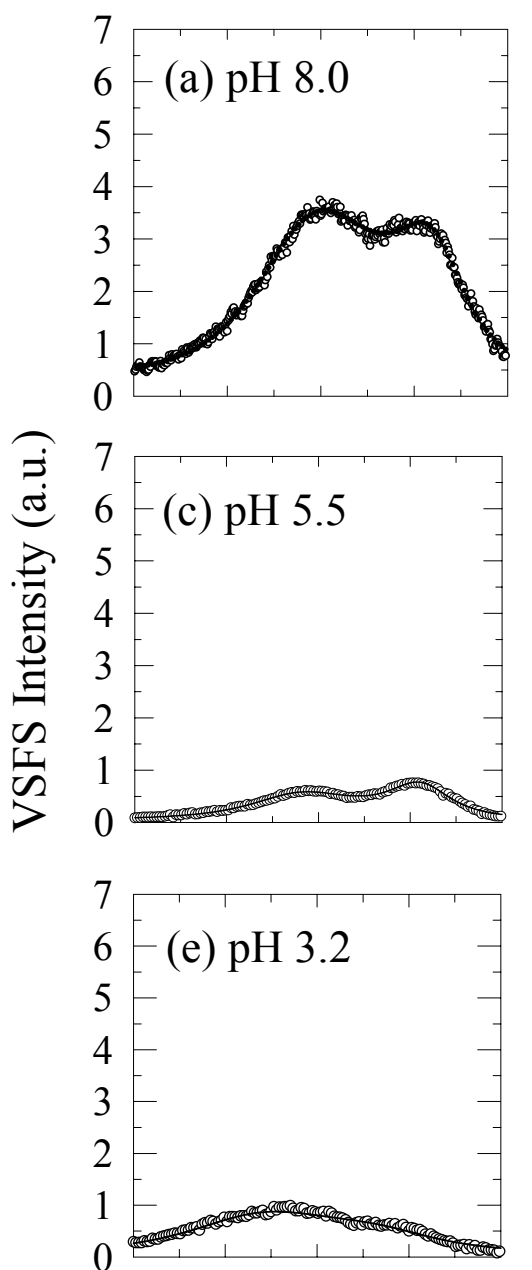

28003000320034003600
After adsorption
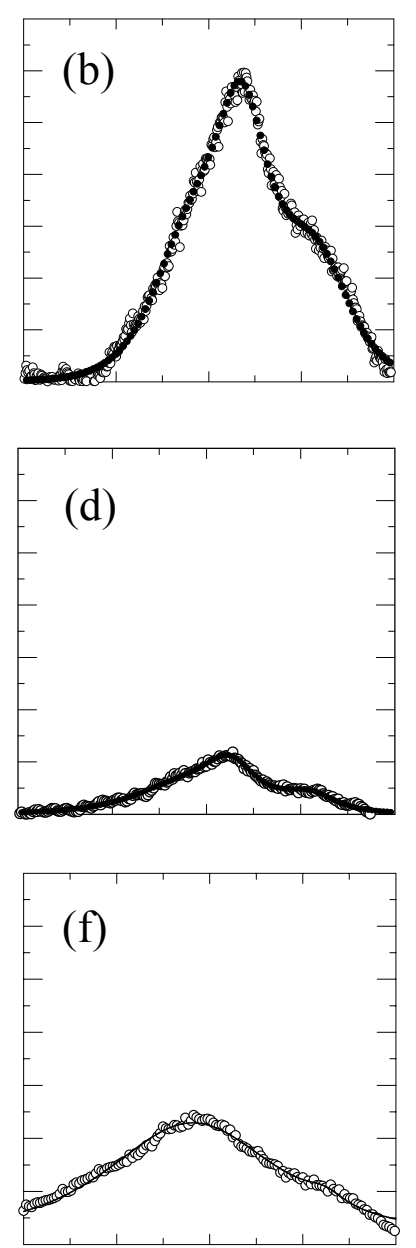

28003000320034003600

Wavenumber $\left(\mathrm{cm}^{-1}\right)$

Figure 29. Sum frequency spectra of a bare silica/water interface at (a) $\mathrm{pH} 8.0$, (c) $\mathrm{pH}$ 5.5, and (e) $\mathrm{pH}$ 3.2. Sum frequency spectra of HPF coated silica surface at (b) $\mathrm{pH} 8.0$, (d) $\mathrm{pH} 5.5$ and (f) $\mathrm{pH} 3.2$. 
this red-shifted feature is related to the strength of the electric field emanating from the interface. Namely, when the surface potential increases, the $3200 \mathrm{~cm}^{-1}$ peak becomes stronger.

The sum frequency spectrum upon adsorption of fibrinogen at $\mathrm{pH} 8.0$ is shown in Figure 29b. Significantly, an intense and narrow peak appeared around $3270 \mathrm{~cm}^{-1}$. Both the frequency and narrow line width of this peak are strong indications that it is not from water, but rather from another source. The whole spectrum could be well fit with three peaks and the feature at $3270 \mathrm{~cm}^{-1}$ can be tentatively assigned to the $\mathrm{NH}$ stretch of Lys/Arg residues in the protein's $\alpha-\mathrm{C}$ domain. This assignment is in line with the known vibrational modes these amino acids. ${ }^{144,145}$ Another example of an NH stretch in the VSFS literature comes from Shultz and her coworkers, who reported the NH stretch from ammonia near $3312 \mathrm{~cm}^{-1}$ at the air/water interface. ${ }^{35}$ Experiments to rule out an $\mathrm{OH}$ stretch as the source for the $3270 \mathrm{~cm}^{-1}$ will be described in the next section of the paper.

The sum frequency spectrum of the water/fibrinogen/silica system at $\mathrm{pH} 5.5$ is shown in Figure 29d. The existence of the relatively weak but narrow peak around 3270 $\mathrm{cm}^{-1}$ was also found at this $\mathrm{pH}$; however, the water peaks at $3200 \mathrm{~cm}^{-1}$ and $3450 \mathrm{~cm}^{-1}$ were greatly attenuated. This can be explained by the fact that the $\zeta$-potential of the fibrinogen coated silica surface is close to zero under these conditions. ${ }^{108}$ The lack of surface charge almost completely suppresses the $3200 \mathrm{~cm}^{-1}$ as expected. Also, the water molecules directly adjacent to the surface, which would give rise to the $3450 \mathrm{~cm}^{-1}$, have presumably been displaced. Apparently, water molecules at the protein/water interface 
are not well enough aligned to substantially contribute to signal at this frequency. This leaves the $3270 \mathrm{~cm}^{-1}$ as almost the sole source of signal under these $\mathrm{pH}$ conditions.

Further lower the system's $\mathrm{pH}$ to 3.2 causes the system to take on a net positive charge $^{29,30,146}$ and the VSFS spectrum is shown in Figure 29f. As can be seen, the 3200 $\mathrm{cm}^{-1}$ peak is approximately twice as strong as the one under the identical $\mathrm{pH}$ conditions but without fibrinogen. The reason for this is that the charge density in the presence of fibrinogen is actually higher than for the mostly protonated bare silica/water interface, although it is of opposite sign.

$\mathrm{H}_{2} \mathrm{O}^{16}$ and $\mathrm{H}_{2} \mathrm{O}^{18}$ spectra

In order to ensure that the $3270 \mathrm{~cm}^{-1}$ peak is not from an $\mathrm{OH}$ stretch, experiments were performed with $\mathrm{H}_{2}{ }^{18} \mathrm{O}$ labeled water. It would be expected that both the frequency and intensity of $\mathrm{OH}$ stretches should be changed through such isotopic labeling, but $\mathrm{NH}$ stretch features would be left virtually unaltered. Experiments were performed with $95 \%$ pure $\mathrm{H}_{2}{ }^{18} \mathrm{O}$ with less than 0.2 mol\% sodium hydroxide $\left(\mathrm{Na}^{16} \mathrm{OH}\right)$ added to prepare the appropriate PBS buffers. The peak shift caused by isotopic substitution is expected to be on the order of $\sim 10 \mathrm{~cm}^{-1}$ by simple reduced mass arguments. Shifts of 7 and 11 wavenumbers have been measured for the 3252 and $3405 \mathrm{~cm}^{-1}$ peaks of water via raman and FTIR spectroscopy. ${ }^{147-149}$

Figure 30a shows the silica/water interface at $\mathrm{pH} 8.0$ in standard $\mathrm{H}_{2}{ }^{16} \mathrm{O}$ PBS buffer. The VSFS spectrum was repeated at the same interface with $\mathrm{H}_{2}{ }^{18} \mathrm{O}$ and is also shown in Figure 30a. As can be clearly seen from the data, the intensity in the second spectrum was attenuated. Indeed, a similar $20-40 \%$ decrease has typically been noted in 


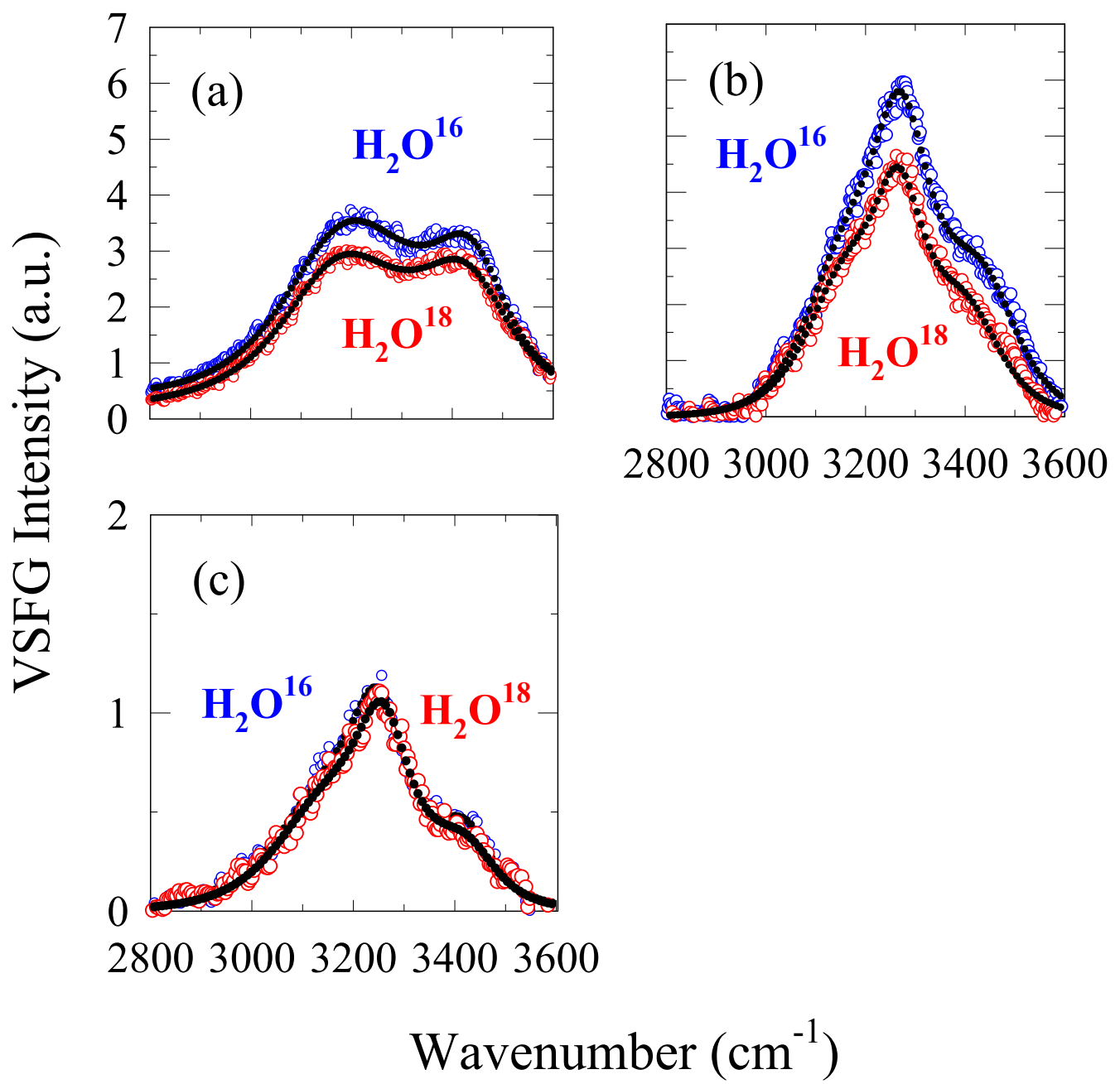

Figure 30. Sum frequency spectra of (a) a bare silica/water interface at $\mathrm{pH} 8.0$, (b) an HPF coated surface at $\mathrm{pH} 8.0$, (c) an HPF coated surface at $\mathrm{pH}$ 5.5. In these spectra $\mathrm{H}_{2} \mathrm{O}^{16}$ data are plotted with blue dots and $\mathrm{H}_{2} \mathrm{O}^{18}$ with red dots. 
$\mathrm{OH}$ stretch intensity for water in infrared spectra when switching from ${ }^{16} \mathrm{O}$ to ${ }^{18} \mathrm{O} \cdot{ }^{150,151}$ The frequency of the $\mathrm{OH}$ stretches also red-shifted, although this is less obvious due to the very broad linewidths of the peaks. Fitting the spectra, however, revealed that the oscillator frequency for the lower peak shifted from 3185 to $3172 \mathrm{~cm}^{-1}$ while the higher frequency stretch moved from roughly 3444 to $3434 \mathrm{~cm}^{-1}$. This is in good agreement with previous IR data. ${ }^{149}$

Figure 30b shows VSFS spectra of the silica/water interface in the presence of an adsorbed fibrinogen layer at $\mathrm{pH} 8.0$ in $\mathrm{PBS}$ with $\mathrm{H}_{2}{ }^{16} \mathrm{O}$ and $\mathrm{H}_{2}{ }^{18} \mathrm{O}$. The fibrinogen was deposited from a $0.015 \mathrm{mg} / \mathrm{ml}$ protein solution and the excess was washed away after 20 minutes of incubation. Again, the intensity from the ${ }^{18} \mathrm{O}$ spectrum is weaker than that from ${ }^{16} \mathrm{O}$. The data were curve fit for 3 peaks and showed a greater than $10 \mathrm{~cm}^{-1}$ wavenumber shift for the water, but a much smaller shift for the third feature from 3279 to $3273 \mathrm{~cm}^{-1}$. The actual extent of this small shift is suspect since the value is based on fitting measurements. Indeed, this feature overlaps strongly with the $\mathrm{OH}$ peaks and is difficult to deconvolve. Therefore, the data were repeated at $\mathrm{pH} 5.5$ where the intensity of the water peaks could be greatly diminished. In this case, almost no difference is seen in the VSFS intensity between the ${ }^{16} \mathrm{O}$ and ${ }^{18} \mathrm{O}$ labeled systems. Peak fitting in this case showed only a $2 \mathrm{~cm}^{-1}$ shift from 3266 to $3264 \mathrm{~cm}^{-1}$. This isotopic labeling data represents strong evidence that the feature in question is not from an $\mathrm{OH}$ stretch, but rather from $\mathrm{NH}$. 
Fragment $\mathrm{X}$ and $\alpha \mathrm{C}$ domain adsorbed at $\mathrm{pH} 8.0$ in $\mathrm{H}_{2} \mathrm{O}$

Human plasma fibrinogen was cleaved into fragment $\mathrm{X}$ and $\alpha \mathrm{C}$ domains as described in the experimental section. Adsorption experiments were attempted with fragment $\mathrm{X}(\mathrm{MW} \sim 240 \mathrm{kD})$ at $\mathrm{pH} 8.0$ from a protein solution in PBS (Figure 31a). The VSFS spectrum looks almost identical to that for the bare silica/water interface. This is not surprising as fragment $\mathrm{X}$ has a net negative charge of -16 at $7.4^{3}$ and seems to be electrostatically repelled from the surface. On the other hand, adsorption experiments with the positively charged $\alpha \mathrm{C}$ domains $(\mathrm{MW} \sim 50 \mathrm{kD})$ under the same condition led to large spectral changes (Figure 31b). The same NH stretch peak observed from the entire fibrinogen molecule again appears around $3270 \mathrm{~cm}^{-1}$. In fact, the spectrum looks almost identical to the one from adsorbed fibrinogen under these conditions (Figure 29b). The results appear to be in agreement with the idea that fibrinogen adsorption occurs via the $\alpha \mathrm{C}$ domains and that this portion of the molecule is responsible for the highly aligned NH peak seen around $3270 \mathrm{~cm}^{-1}$.

As noted above, we have proposed a mechanism to explain the Vroman effect for fibrinogen on silica substrates in the presence of human blood plasma. This work demonstrated that fibrinogen can be displaced from the interface two to three orders of magnitude more rapidly when the $\alpha \mathrm{C}$ domains face the substrate as opposed to other portions of the protein. Herein, we clearly demonstrated by using ${ }^{18} \mathrm{O}$ labeled water, that the $3270 \mathrm{~cm}^{-1}$ feature observed in the VSFS spectrum is not from an $\mathrm{OH}$ stretch, but rather an NH stretch. This is consistent with the notion that Arg and Lys residues are aligned at the interface giving rise to strong signal at this frequency. 


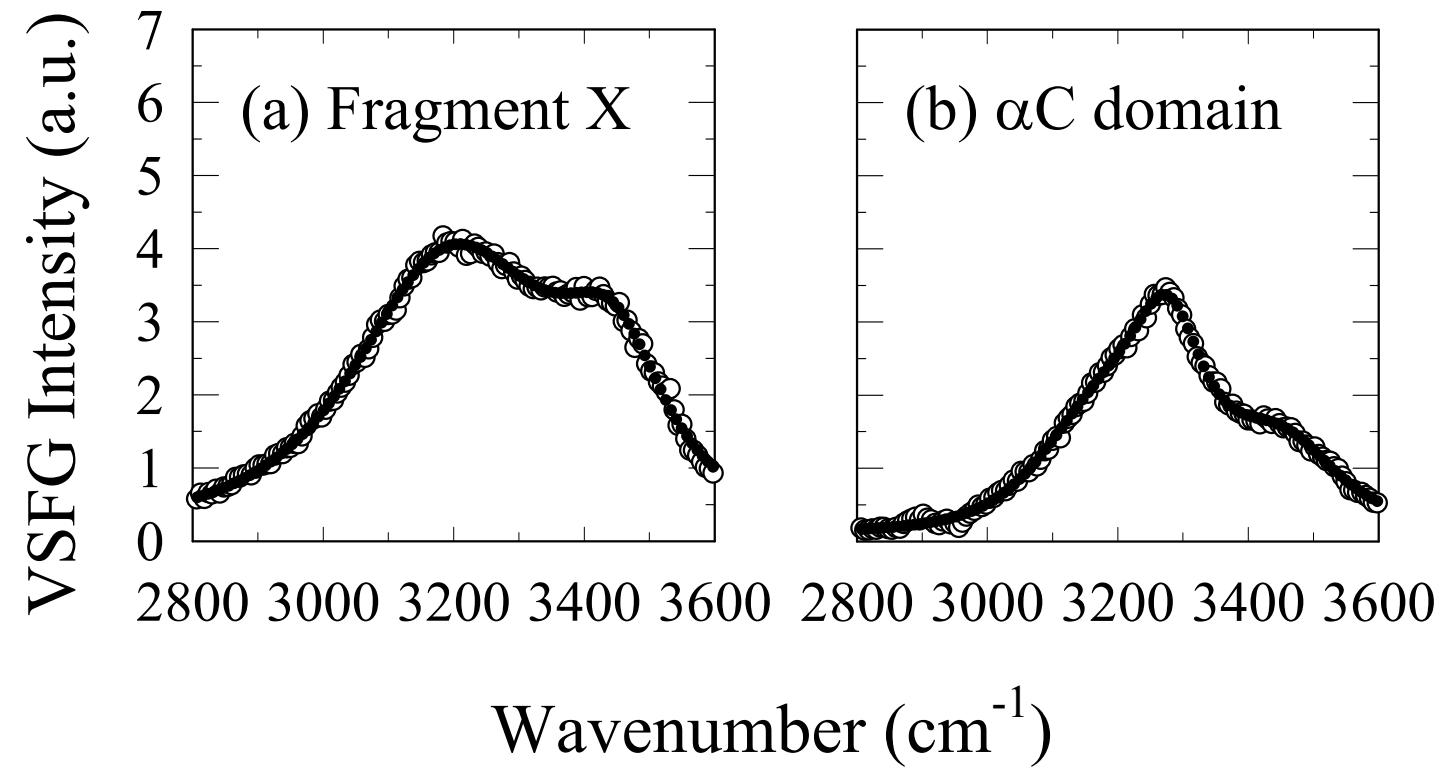

Figure 31. Sum frequency spectra of the silica/water interface at $\mathrm{pH} 8.0$ after the adsorption of (a) fragment $\mathrm{X}$ from fibrinogen and (b) the $\alpha \mathrm{C}$ domains. 
Furthermore, VSFS experiments with fragment $\mathrm{X}$ and $\alpha \mathrm{C}$ domains demonstrated that the only Arg and Lys residues on the later portion of the molecule were responsible for this signal. 


\section{CHAPTER VI}

\section{SUMMARY}

Microfabrication and total internal reflection fluorescence microscopy have been applied to study anti-DNP antibodies and phospholipids membranes containing DNP conjugated lipids as a model for specific ligand-receptor binding. Twelve independent data points of surface coverage versus bulk protein concentration could be made simultaneously by forming a linear array of channels and flowing fluorescently labeled antibodies into them. This enabled an entire binding curve to be obtained in a single experiment. The measured apparent binding constant for the DNP/anti-DNP system was $1.8 \mu \mathrm{M}$.

Non-specific protein adsorption from blood plasma involves a complex series of adsorption and displacement steps. This phenomenon, called the Vroman effect, has been shown to involve the initial adsorption from the fluid phase of abundant but weakly surface-active proteins. These early adsorbers are subsequently displaced by more strongly binding species that are present in solution at lower concentration. We employed a combination of techniques including atomic force microscopy, vibrational sum frequency spectroscopy, immunochemical assays, and kinetic experiments to elucidate the Vroman mechanism for the blood component, fibrinogen. The critical role of the protein's $\alpha \mathrm{C}$ domains was revealed by our demonstrations. The interactions between fibrinogen and hydrophilic surfaces increase significantly when fibrinogen is forced to interact with the surface directly by $\mathrm{pH}$ cycling. Also, the presence of an $\mathrm{NH}$ 
stretch around $3270 \mathrm{~cm}^{-1}$ was confirmed by isotopic labeling experiments. This unusual peak was observed only when the $\alpha \mathrm{C}$ domains made direct contact with the surface. The $\mathrm{NH}$ peak indicates that positive charge groups on the $\alpha \mathrm{C}$ domains are highly aligned by their interaction with the negatively charged substrate, and it might be a common motif for weak interactions between proteins and substrates. 


\section{REFERENCES}

(1) Baszkin, A.; Norde, W. Physical chemistry of biological interfaces; Marcel Dekker: New York, 2000.

(2) Mammen, M.; Choi, S.-K.; Whitesides, G. M. Angew. Chem. Int. Ed. 1998, 37, 2754-2794.

(3) Horbett, T. A.; Brash, J. L. Proteins at interfaces II : fundamentals and applications; American Chemical Society: Washington, DC, 1995.

(4) Sood, A.; Panchagnula, R. Chem. Rev. 2001, 101, 3275-3303.

(5) Kenausis, G. L.; Voros, J.; Elbert, D. L.; Huang, N.; Hofer, R.; Ruiz-Taylor, L.; Textor, M.; Hubbell, J. A.; Spencer, N. D. J. Phys. Chem. B. 2000, 104, 3298-3309.

(6) Shen, M. C.; Wagner, M. S.; Castner, D. G.; Ratner, B. D.; Horbett, T. A. Langmuir 2003, 19, 1692-1699.

(7) Vroman, L.; Adams, A. L. Surf. Sci. 1969, 16, 438-446.

(8) Vroman, L.; Adams, A. L.; Klings, M. Fed. Proc. 1971, 30, 1494-1502.

(9) Pisarchick, M. L.; Thompson, N. L. Biophys. J. 1990, 58, 1235-1249.

(10) Timbs, M. M.; Poglitsch, C. L.; Pisarchick, M. L.; Sumner, M. T.; Thompson, N. L. Biochimica et Biophysica Acta 1991, 1064, 219-228.

(11) Thompson, N. L.; Lagerholm, B. C. Curr. Opin. Biotech. 1997, 8, 58-64.

(12) Starr, T. E.; Thompson, N. L. Biophys. J. 2001, 80, 1575-1584.

(13) Mann, D. A.; Kanai, M.; Maly, J.; Kiessling, L. L. J. Am. Chem. Soc. 1998, 120, $10575-10582$. 
(14) Margulies, D. H.; Plaksin, D.; Khilko, S. N.; Jelonek, M. T. Curr. Opin. Immun. 1996, 8, 262-270.

(15) Muller, K. M.; Arndt, K. M.; Pluckthun, A. Anal. Biochem. 1998, 261, 149-158.

(16) Nelson, R. W.; Krone, J. R.; Jansson, O. Anal. Chem. 1997, 69, 4363-4368.

(17) Wahlgren, M.; Arnebrant, T.; Lundstrom, I. J. Colloid Interface Sci. 1995, 175, 506-514.

(18) Lu, J. R.; Su, T. J.; Thirtle, P. N.; Thomas, R. K.; Rennie, A. R.; Cubitt, R. J. Colloid Interface Sci. 1998, 206, 212-223.

(19) Su, T. J.; Lu, J. R.; Thomas, R. K.; Cui, Z. F.; Penfold, J. J. Colloid Interface Sci. 1998, 203, 419-429.

(20) Choi, K. H.; Friedt, J. M.; Frederix, F.; Campitelli, A.; Borghs, G. Appl. Phys. Lett. 2002, 81, 1335-1337.

(21) Murray, B. S.; Deshaires, C. J. Colloid Interface Sci. 2000, 227, 32-41.

(22) Billsten, P.; Wahlgren, M.; Arnebrant, T.; McGuire, J.; Elwing, H. J. Colloid Interace Sci. 1995, 175, 77-82.

(23) Chen, L.; Pielak, G. J.; Thompson, N. L. Biochemistry 1999, 38, 2102-2109.

(24) Vermeer, A. W. P.; Norde, W. J. Colloid Interface Sci. 2000, 225, 394-397.

(25) Giacomelli, C. E.; Bremer, M. G. E. G.; Norde, W. J. Colloid Interface Sci. 1999, $220,13-23$.

(26) Zhu, X. D.; Suhr, H.; Shen, Y. R. Physical Review B 1987, 35, 3047-3050.

(27) Su, X. C.; Cremer, P. S.; Shen, Y. R.; Somorjai, G. A. J. Am. Chem. Soc. 1997, 119, 3994-4000. 
(28) Kim, J.; Cremer, P. S. J. Am. Chem. Soc. 2000, 122, 12371-12372.

(29) Kim, J.; Cremer, P. S. ChemPhysChem 2001, 2, 543-546.

(30) Kim, J.; Kim, G.; Cremer, P. S. Langmuir 2001, 17, 7255-7260.

(31) Kim, G.; Gurau, M.; Kim, J.; Cremer, P. S. Langmuir 2002, 18, 2807-2811.

(32) Kim, J.; Kim, G.; Cremer, P. S. J. Am. Chem. Soc. 2002, 124, 8751-8756.

(33) Walker, R. A.; Gruetzmacher, J. A.; Richmond, G. L. J. Am. Chem. Soc. 1998, 120, 6991-7003.

(34) Watry, M. R.; Richmond, G. L. J. Phys. Chem. B 2002, 106, 12517-12523.

(35) Shultz, M. J.; Baldelli, S.; Schnitzer, C.; Simonelli, D. J. Phys. Chem. B 2002, $106,5313-5324$.

(36) Miranda, P. B.; Shen, Y. R. J. Phys. Chem. B 1999, 103, 3292-3307.

(37) Binnig, G.; Quate, C. F.; Gerber, C. Phys. Rev. Lett. 1986, 56, 930-933.

(38) Birdi, K. S. Scanning probe microscopes: applications in science and technology; CRC Press: Boca Raton, FL, 2003.

(39) Jandt, K. D. Surf. Sci. 2001, 491, 303-332.

(40) Czarnik, A. W. Anal. Chem. 1998, 70, 378 A-386 A.

(41) Xia, Y. N.; Whitesides, G. M. Angew Chem Int Edit 1998, 37, 551-575.

(42) Campbell, D. J.; Beckman, K. J.; Calderon, C. E.; Doolan, P. W.; Ottosen, R. M.; Ellis, A. B.; Lisensky, G. C. J. Chem. Educ. 1999, 76, 537-541.

(43) Duffy, D. C.; McDonald, J. C.; Schueller, O. J. A.; Whitesides, G. M. Anal. Chem. 1998, 70, 4974-4984.

(44) Muller, D. J.; Engel, A. Biophys. J. 1997, 73, 1633-1644. 
(45) Muller, D. J.; Amrein, M.; Engel, A. J. Struct. Biol. 1997, 119, 172-188.

(46) Siedlecki, C. A.; Marchant, R. E. Biomaterials 1998, 19, 441-454.

(47) Allen, M. J.; Hud, N. V.; Balooch, M.; Tench, R. J.; Siekhaus, W. J.; Balhorn, R. Ultramicroscopy 1992, 42, 1095-1100.

(48) Velegol, S. B.; Pardi, S.; Li, X.; Velegol, D.; Logan, B. E. Langmuir 2003, 19, 851-857.

(49) Richmond, G. L. Analytical Chemistry News \& Features 1997, 17, 536A-543A.

(50) Bain, C. D. J. Chem. Soc. Faraday Trans. 1995, 91, 1281.

(51) Brian, A. A.; McConnell, H. M. Proc. Natl. Acad. Sci. USA 1984, 81, 6159-6163.

(52) Tamm, L. K.; McConnell, H. M. Biophys. J. 1985, 47, 105-113.

(53) Johnson, S. J.; Bayerl, T. M.; McDermott, D. C.; Adam, G. W.; Rennie, A. R.;

Thomas, R. K.; Sackmann, E. Biophys. J. 1991, 59, 289-294.

(54) Sackmann, E. Science 1996, 271, 43-48.

(55) Williams, L. M.; Evans, S. D.; Flynn, T. M.; Marsh, A.; Knowles, P. F.; Bushby, R. J.; Boden, N. Langmuir 1997, 13, 751-757.

(56) Stelzle, M.; Miehlich, R.; Sackmann, E. Biophys. J. 1992, 63, 1346-1354.

(57) Cheng, Y.; Boden, N.; Bushby, R. J.; Clarkson, S.; Evans, S. D.; Knowles, P. F.; Marsh, A.; Miles, R. E. Langmuir 1998, 14, 893-844.

(58) Kalb, E.; Frey, S.; Tamm, L. K. Biochim Biophys Acta 1992, 1103, 307-316.

(59) Cremer, P. S.; Boxer, S. G. J. Phys. Chem. B 1999, 103, 2554-2559.

(60) Heldin, C. Cell 1995, 80, 213-223. 
(61) Fodor, S. P. A.; Read, J. L.; Pirrung, M. C.; Stryer, L.; Lu, A. T.; Solas, D. Science 1991, 251, 767-773.

(62) Brockman, J. M.; Frutos, A. G.; Corn, R. M. J. Am. Chem. Soc. 1999, 121, 80448051.

(63) MacBeath, G.; Koehler, A. N.; Schreiber, S. L. J. Am. Chem. Soc. 1999, 121, 7967-7968.

(64) Mrksich, M.; Whitesides, G. M. Trends Biotechnol. 1995, 13, 228-235.

(65) Mrksich, M.; Whitesides, G. M. Ann. Rev. Biomol. Struct. 1996, 25, 55-78.

(66) Jans, D. A. The mobile receptor hypothesis: The role of membrane receptor lateral movement in signal transduction; Chapman \& Hall: Austin, TX, 1997.

(67) Kiessling, L. L.; Pohl, N. L. Chem. Biol. 1996, 3, 71-77.

(68) Finegold, L. Cholesterol in model membranes; CRC Press: Boca Raton, FL, 1993.

(69) Xiang, X. D.; Sun, X. D.; Briceno, G.; Lou, Y. L.; Wang, K. A.; Chang, H. Y.; Wallacefreedman, W. G.; Chen, S. W.; Schultz, P. G. Science 1995, 268, 1738-1740.

(70) Reddington, E.; Sapienza, A.; Gurau, B.; Viswanathan, R.; Sarangapani, S.; Smotkin, E. S.; Mallouk, T. E. Science 1998, 280, 1735-1737.

(71) McConnell, H. M.; Watts, T. H.; Weis, R. M.; Brian, A. A. Biochim Biophys Acta 1986, 864, 95-106.

(72) Watts, T. H.; Gaub, H.; McConnell, H. M. Nature 1986, 320, 179-181.

(73) Tozeren, A.; Sung, P. K.-L.; Sung, L. A.; Dustin, M. L.; Chan, P. Y.; Springer, T. A.; Chien, S. J. Cell. Biol. 1992, 116, 997-1066.

(74) Cremer, P. S.; Yang, T. J. Am. Chem. Soc. 1999, 121, 8130-8131. 
(75) Kumar, A.; Whitesides, G. M. Science 1994, 263, 60-62.

(76) Groves, J. T.; Ulman, N.; Boxer, S. G. Science 1997, 275, 651-653.

(77) Groves, J. T.; Ulman, N.; Cremer, P. S.; Boxer, S. G. Langmuir 1998, 14, 33473350.

(78) Axelrod, D.; Koppel, D. E.; Schlessinger, J.; Elson, E.; Webb, W. W. Biophys. J. 1976, 16, 1055-1069.

(79) Soumpasis, D. M. Biophys. J. 1983, 41, 95-97.

(80) Balakrishnan, K.; Mehdi, S. Q.; McConnell, H. M. J. Biol. Chem. 1982, 257, 6434-6439.

(81) Figeys, D.; Pinto, D. Anal. Chem. 2000, 72, 330A-335A.

(82) Harrison, D. J.; van der Berg, A. Micro total analysis systems 98; Kluwer Academic Publishers: Dordrecht, The Netherlands,1998.

(83) van der Berg, A.; Bergveld, P. Micro total analysis systems; Kluwer Academic Publishers: Dordrecht, The Netherlands, 1995.

(84) Jacobson, S. C.; McKnight, T. E.; Ramsey, J. M. Anal. Chem. 1999, 71, 44554459.

(85) Hosokawa, K.; Fujii, T.; Endo, I. Anal. Chem. 1999, 71, 4781-4785.

(86) Kenis, P. J. A.; Ismagilov, R. F.; Whitesides, G. M. Science 1999, 285, 83-85.

(87) Colyer, C. L.; Tang, T.; Chiem, N.; Harrison, D. J. Electrophoresis 1997, 18, $1733-1741$.

(88) Chiem, N. H.; Harrison, D. J. Electrophoresis 1998, 19, 3040-3044. 
(89) Duffy, D. C.; Gillis, H. L.; Lin, J.; Sheppard, N. F. J.; Kellogg, G. J. Anal. Chem. 1999, 71, 4669-4678.

(90) Delamarche, E.; Bernard, A.; Schmid, H.; Michel, B.; Biebuyck, H. Science 1997, 276, 779-781.

(91) Schasfoort, R. B. M.; Schlautmann, S.; Hendrikse, J.; van den Berg, A. Science 1999, 286, 942-945.

(92) Hovis, J. S.; Boxer, S. G. Langmuir 2000, 16, 894-897.

(93) Yang, T. L.; Jung, S. Y.; Mao, H. B.; Cremer, P. S. Anal. Chem. 2001, 73, $165-$ 169.

(94) Mammem, M.; Gomez, F. A.; Whitesides, G. M. Anal. Chem. 1995, 67, 35263535.

(95) Hanker, J. S.; Giammara, B. L. Science 1988, 242, 885-892.

(96) Davies, D. Nature Reviews Drug Discovery 2003, 2, 114-122.

(97) Holland, N. B.; Qiu, Y.; Ruegsegger, M.; Marchant, R. E. Nature 1998, 392, 799-801.

(98) Wojciechowski, P.; ten Hove, P.; Brash, J. L. J. Coll. Inter. Sci. 1986, 111, 455465.

(99) Slack, S. M.; Horbett, T. A. J. Biomater. Sci. Polym. Ed. 1991, 2, 227-237.

(100) Bamford, C. H.; Cooper, S. L.; Tsuruta, T. The Vroman Effect: Festschrift in honour of the 75th birthday of Dr. Leo Vroman; VSP: Zeist, Netherlands, 1992.

(101) Doolittle, R. F. Ann. Rev. Biochem. 1984, 53, 195-229. 
(102) Nieuwenhuizen, W.; Mosesson, M. W.; De Maat, M. P. M. Fibrinogen; New York Academy of Sciences: New York, 2001.

(103) Cacciafesta, P.; Humphris, A. D. L.; Jandt, K. D.; Miles, M. J. Langmuir 2000, $16,8167-8175$.

(104) Ta, T. C.; Sykes, M. T.; McDermott, M. T. Langmuir 1998, 14, 2435-2443.

(105) Huang, N.-P.; Michel, R.; Voros, J.; Textor, M.; Hofer, R.; Rossi, A.; Elbert, D. L.; Hubbell, J. A.; Spencer, N. D. Langmuir 2001, 17, 489-498.

(106) Slack, S. M.; Horbett, T. A. J. Colloid Interface Sci. 1989, 133, 148-165.

(107) Veklich, Y. I.; Gorkun, O. V.; Medved, L. V.; Nieuwenhuizen, W.; Weisel, J. W. J. Biol. Chem. 1993, 268, 13577-13585.

(108) Zembala, M.; Dejardin, P. Colloid. Surf. B-Biointerfaces 1994, 3, 119-129.

(109) Control experiments with just fibrinogen in the buffer solution demonstrated that exchange of adsorbed fibrinogen by species from the bulk was far slower and much less extensive than displacement by other proteins in human plasma.

(110) Weisel, J. W.; Stauffacher, C. V.; Bullitt, E.; Cohen, C. Science 1985, 230, 13881391.

(111) Sit, P. S.; Marchant, R. E. Thrombosis and Haemostasis 1999, 82, 1053-1060.

(112) Shen, Y. R. Nature 1989, 337, 519-525.

(113) Wang, J.; Buck, S. M.; Even, M. A.; Chen, Z. J. Am. Chem. Soc. 2002, 124, $13302-13305$.

(114) Wang, J.; Buck, S. M.; Chen, Z. J. Phys. Chem. B 2002, 106, 11666-11672.

(115) Kim, J.; Somorjai, G. A. J. Am. Chem. Soc. 2003, 125, 3150-3158. 
(116) Du, Q.; Freysz, E.; Shen, Y. R. Phys. Rev. Lett. 1994, 72, 238-241.

(117) Richmond, G. L. Chem. Rev. 2002, 102, 2693-2724.

(118) This assignment was verified by repeating the experiments in $\mathrm{H}_{2}{ }^{18} \mathrm{O}$, whereby the water peaks shifted downward in frequency as expected while the amine peak frequency remained unchanged. It should also be noted that the NH stretch frequency from the Lys and Arg strongly overlap in the IR and Raman spectra.

(119) Nawrocki, J. J. Chromatogr. A 1997, 779, 29-71.

(120) Wirth, M. J.; Swinton, D. J. J. Phys. Chem. B 2001, 105, 1472-1477.

(121) Wirth, M. J.; Swinton, D. J.; Ludes, M. D. J. Phys. Chem. B 2003, 107, 62586268.

(122) Norde, W.; Lyklema, J. J. Biomater. Sci. Polym. Ed. 1991, 2, 183-202.

(123) Voet, D.; Voet, J. G. Biochemistry; 2nd ed.; John Wiley and Sons, Inc.: New York, 1995.

(124) Weisel, J. W.; Medved, L. Ann N Y Acad Sci 2001, 936, 312-327.

(125) Baszkin, A.; Norde, W. Physical chemistry of biological interfaces; Marcel Dekker: New York, 2000.

(126) Vroman, L. In Interfacial phenomena in biological systems; Bender, M., Ed; Marcel Dekker, Inc.: New York, 1991; Vol. 39, p 137.

(127) Malmsten, M. Colloids Surf., A 1999, 159, 77.

(128) Jones, V. W.; Kenseth, J. R.; Porter, M. D.; Mosher, C. L.; Henderson, E. Anal. Chem. 1998, 70, 1233.

(129) Seigel, R. R.; Harder, P.; Dahint, R.; Grunze, M. Anal. Chem. 1997, 69, 3321. 
(130) Yang, Z.; Mochalkin, I.; Veerapandian, L.; Riley, M.; Doolittle, R. F. Proc. Natl. Acad. Sci. U. S. A. 2000, 97, 3907-3912.

(131) Holmlin, R. E.; Chen, X. X.; Chapman, R. G.; Takayama, S.; Whitesides, G. M. Langmuir 2001, 17, 2841-2850.

(132) Wertz, C. F.; Santore, M. M. Langmuir 2002, 18, 706-715.

(133) Ostuni, E.; Chen, C. S.; Ingber, D. E.; Whitesides, G. M. Langmuir 2001, 17, 2828-2834.

(134) Yongli, C.; Xiufang, Z.; Nanning, Z.; Tingying, Z.; Xingi, S. J. Colloid Interface Sci. 1999, 214, 38.

(135) Wojciechowski, P.; Ten Hove, P.; Brash, J. L. J. Colloid Interface Sci. 1986, 111, $455-465$.

(136) Ostuni, E.; Chapmen, R. G.; Liang, M. N.; Melueni, G.; Pier, G.; Ingber, D. E.; Whitesides, G. M. Langmuir 2001, 17, 5605.

(137) Morrissey, B. W.; Stromberg, R. R. J. Colloid Interface Sci. 1974, 46, 152.

(138) Malmsten, M. J. Colloid Interface Sci. 1994, 166, 333.

(139) Ball, A.; Jones, R. A. L. Langmuir 1995, 11, 3542-3548.

(140) Jung, S.; Lim, S.; Albertorio, F.; Kim, G.; Gurau, M. C.; Yang, D.; Holden, M. A.; Cremer, P. S. J. Am. Chem. Soc. 2003, 125, 12782-12786.

(141) Nygren, H.; Stenberg, M.; Karlsson, C. J. Biomed. Mater. Res. 1992, 26, 77.

(142) Gragson, D. E.; McCarty, B. M.; Richmond, G. L. J. Am. Chem. Society 1997, $119,6144-6152$. 
(143) Gurau, M.; Kim, G.; Lim, S.; Albertorio, F.; Fleisher, H. C.; Cremer, P. S. ChemPhysChem 2003, in press.

(144) The Sadtler handbook of infrared spectra; Sadtler Research Laboratories:

Philadelphia, 1978.

(145) J. Popp, P. R., E. Vogel, W. Kiefer In Progress in surface Raman spectroscopy theory, techniques and application; Z. Q. Tian, B. R., Ed.; Xiamen University Press:

Xiamen, China, 2000, pp 163-166.

(146) Zembala, M.; Dejardin, P. Colloids Surf. B 1994, 3, 119.

(147) Brooker, M. H.; Hancock, G.; Rice, B. C.; Shapter, J. J. Raman Spectrosc. 1989, 20, 683-694.

(148) Fraley, P. E.; Rao, K. N. J. Mol. Spectrosc. 1969, 29, 312-\&.

(149) Qinglian, Z.; Shifu, W. Kexue Tongbao 1985, 30, 1475.

(150) Pinchas, S.; Laulicht, I. Infrared spectra of labeled compounds; Academic Press: London, 1971.

(151) Person, W. B. Studies in physical and theoretical chemistry, Vol. 20: vibrational intensities in infrared and Raman spectroscopy; Elsevier Scientific Pub.: New York, 1982. 


\section{APPENDIX I}

Before pH cycling

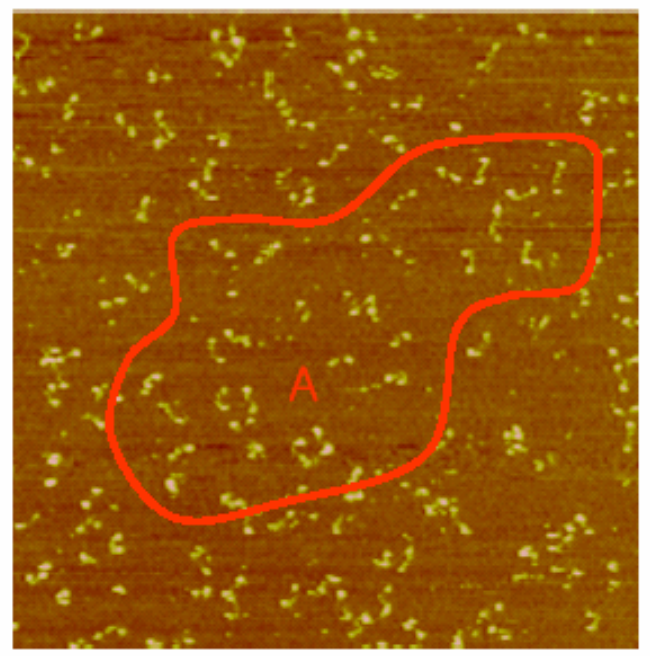

After pH cycling

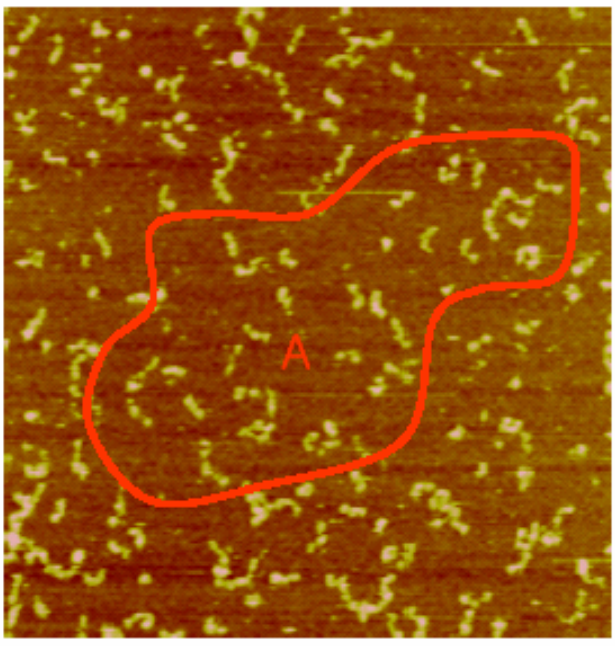

\section{$1.25 \mu \mathrm{m}$}

These AFM images were taken over the same area before and after $\mathrm{pH}$ cycling. By comparing the images, it was clear that the central $\mathrm{E}$ domains were identified much more readily in the picture after $\mathrm{pH}$ cycling than before because of the height increase. To get quantitative information about height changes of domains, molecules which did not move very much upon buffer exchange were selected. For example, the HPF molecules in area A (red lines) did not changes their positions significantly by $\mathrm{pH}$ cycling in these pictures. Data from more than 70 of molecules were collected from 5 different experimental sets with different surface densities of HPF. It was found that approximately $55-70 \%$ of the molecules could be used by employing this criterion. 


\begin{abstract}
APPENDIX II
Experiment conditions: To calculate absolute density of anti-fibrinogen adsorbed on surface, 3 microfluidic channels were created by PDMS. First channel (left) contained 1\% of Texas Red DHPE/ 99\% Egg PC bilayer. Second channel (middle) was coated by $0.5 \%$ of Texas Red DHPE / 99\% Egg PC bilayer. The last channel was treated by 100 $\mu \mathrm{g} / \mathrm{ml}$ of Rabbit IgG for 20 minutes to prevent the nonspecific binding. After that, 150 $\mu \mathrm{g} / \mathrm{ml}$ of anti fibrinogen labeled with Texas Red was introduced and bulk solution was rinsed away after 20 minutes as described above. TIR was used to measure the intensity difference of these three channels as shown below.
\end{abstract}

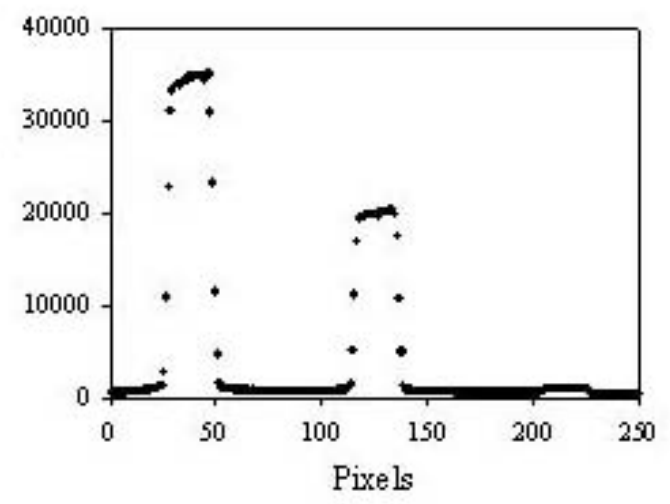


Calculations

From the average head group area of phospholipids, the density of these species could be calculated and as well as the density of Texas Red which gives the intensity of first and second channels. Head group area of 1 lipid molecule is $\sim 70 \AA^{2}$, therefore, in 1 $\mu \mathrm{m}^{2}$, there are 1428571 lipids. $1 \%$ of these lipids are Texas Red labeled DHPE and the lipids form a bilayer, so 28570 Texas Red labeled DHPE will produce the fluorescence intensity of the first channel. From the ratio of fluorescence intensities between the first channel and the third channel (36130/363), the density of Texas Red dyes in the third channel could be calculated $\left(285.7\right.$ dyes $\left./ \mu \mathrm{m}^{2}\right)$. After considering the labeling degree of anti-fibrinogen (3.8 dyes/protein), it was estimated that 75 anti-fibrinogens were nonspecifically adsorbed per $\mu \mathrm{m}^{2}$. The number of fibrinogens $(317 \pm 19$ molecules $)$ adsorbed in $1 \mu \mathrm{m}^{2}$ with $5 \mu \mathrm{g} / \mathrm{ml}$ of bulk concentration was counted by AFM. From the experiment described above, 43 molecules of anti-fibrinogen (57\% of nonspecifically adsorbed fibrinogen) were bound to the surface adsorbed fibrinogen before $\mathrm{pH}$ cycling. This is the $13.5 \%$ of total adsorbed fibrinogen. After $\mathrm{pH}$ cycling, this number rose to $89.1 \%$ (6.6 times greater than before $\mathrm{pH}$ cycling). It is, however, difficult to obtain an exact count of fibrinogen molecules containing a bound $\mathrm{IgG}$ from fluorescence. This is because each fibrinogen contains two binding sites as each has two $\alpha \mathrm{C}$ domains. Therefore, if two anti-fibrinogens bind with one fibrinogen, $6.8 \%$ of all fibrinogen will be labeled before cycling and $44.5 \%$ of fibrinogen after cycling. 
VITA

Name

Permanent Address
Seung-Yong Jung

Chungkok-3 dong, 177/23

Kwangjin-ku,

Seoul, Korea

\title{
Education
}

\author{
1998 - $2003 \quad$ Ph.D. in Chemistry, \\ Texas A\&M University, College Station, Texas \\ Major Field: Biointerface and biophysical chemistry \\ 1995 - $1997 \quad$ M.S. in Chemistry \\ Korea University, Seoul, Korea \\ Major Field: Analytical Chemistry \\ $1989-1995 \quad$ B.S. in Chemistry \\ Korea University, Seoul, Korea
}

